UNIVERSIDADE DE SÃO PAULO

FACULDADE DE CIÊNCIAS FARMACÊUTICAS

Curso de Pós-Graduação em Farmácia

Área de Análises Toxicológicas

\title{
DETERMINAÇÃO ESPECTROFOTOMÉTRICA DA CARBOXIEMOGLOBINEMIA EM \\ INDIVÍDUOS EXPOSTOS OCUPACIONALMENTE AO MONÓXIDO DE CARBONO
}

ANA CRISTINA C.G.C. MALHEIRO

Dissertação para obtenção do grau de MESTRE

Orientador:

Prof. Dr. MARIA ELISA P.B. SIQUEIRA

SÃO PAULO

1991 


\title{
FICHA CATALOGRÁFICA
}

\author{
Elaborada pelo serviço de Biblioteca \\ e documentação do Conjunto das Químicas
}

615.907 Malheiro, Ana Cristina C. Gabriel da Costa

M249d Determinaçāo espectrofotométrica da carboxiemo-

globinemia em indivíduos expostos ocupacionalmente

ao monóxido de carbono / Ana C.C.G.C.Malheiro. Sāo

Paulo, 1991.

$125 p$

Dissertação (mestrado) - Faculdade de Ciências Farmacêuticas da Universidade de São Paulo. Departamento de Análises Clínicas e Toxicológicas.

Orientador: Siqueira, Maria Elisa P. Bastos

1.Carboxiemoglobinemia. 2.Monóxido de carbono. 3.Monitorizaçāo biológica. I.T. II.Siqueira,M.E.P.

B., orientador. 
Este trabalho é dedicado,

a todos que tiveram valiosa participação na sua execuçāo e

àqueles que, por ventura, venham a se interessar pelo seu conteúdo.

Em especial, à minha $M \bar{A} E$. 


\section{À MARIA ELISA,}

a minha admiração e gratidão.

" AS PESSOAS QUE VENCEM NESTE MUNDO SÃO AS QUE PROCURAM AS CIRCUNSTÂNCIAS DE QUE PRECISAM E QUANDO NÃO AS ENCONTRAM, AS CRIAM."

(Bernard Shaw - Filosofo) 


\section{AGRADECIMENTOS}

Aos PROFESSORES DO CURSO DE PÓS-GRADUAÇÃO, por terem-me mostrado parte do mundo da Toxicologia;

ao DR. KOITI TSUSHIDA, pelo incentivo e valiosas sugestões apresentadas e pelo meu constante aprendizado;

ao DR. FELIX VAN DEURSEN, pela breve, mas muito importante, participação na minha formaçāo profissional;

ao PROF. DR. GUNTER HOXTER, pelo auxílio na análise estatística e pelo interesse que demonstrou em ensiná-la;

aos $A M I G O S$ da disciplina de Toxicologia da Faculdade de Ciências Farmacêuticas da USP, pelo companheirismo e amizade sempre presentes;

à MOEMA RODRIGUES DOS SANTOS, pela normalização das referências bibliográficas;

Ao LEONARDO VAN HALSEMA pela inestimável colaboração e compreensão;

à $L E I L A, K A T L A E A U R I L U C E$ pela ajuda, paciência e qualidade nos trabalhos de datilografia e computação;

ao ROBSON RICCO, pelas sugestões e auxílio na arte gráfica;

à PROF ${ }^{a}$. FELISMINA DA SILVA e à CHRISTLANNE, pelo trabalho de revisão gramatical e ortográfica do texto;

ao $F A B I O$ que acompanhou e me apoiou em todas as fases da realização deste trabalho; 


\section{RESUMO}

O monóxido de carbono ( $\mathrm{CO}$ ) constitui sério risco à saúde de indivíduos expostos a este gás. Os efeitos nocivos aparecem como conseqüência de sua combinação com a hemoglobina formando a carboxiemoglobina $(\mathrm{COHb})$. A avaliação da exposição ao $\mathrm{CO}$ pela monitorizaçāo biológica é realizada, preferencialmente, pela determinaçāo da carboxiemoglobinemia. O método espectrofotométrico proposto, para a determinação de $\mathrm{COHb}$, utiliza a leitura na regiāo Soret (420 e $432 \mathrm{~nm}$ ) e fatores de calibraçāo do espectrofotômetro. É realizado estudo comparativo entre o uso do $\mathrm{CO}$ obtido por reação química e o de cilindro de gás nă preparo de solução $100 \%$ de COHb. O método apresenta boa precisão (coeficiente de variação de 2 e $6 \%$ para 4,98 e 1,01 \% de COHb, respectivamente) e sensibilidade $(0,50 \% \mathrm{de} \mathrm{COHb})$ adequadas à avaliação da exposição ao monóxido de carbono. A quantificação da $\mathrm{COHb}$ não é comprometida pelo teor hemoglobínico nem pela opalescência (lipemia) da amostra colhida no período pós-prandial. É apresentada a carboxiemoglobinemia em fumantes $(n=119)$ e não-fumantes $(n=189)$ que constituem 4 grupos de indivíduos expostos ocupacionalmente ao $\mathrm{CO}(\mathrm{n}=209)$ e um grupo controle $(n=99)$; e a análise estatística dos resultados (teste não-paramétrico). 


\section{ABSTRACT}

Carbon monoxide (CO) is recognized as a high risk hazard to the health of exposed workers. Combining with hemoglobin it reduces the oxigen carrying capacity of the blood. The individual overall exposure may be assessed through the carboxyhemoglobin ( $\mathrm{COHb}$ ) content of blood samples, as a biological exposure index. A spectrophotometric method is proposed using measurements in the region Soret $(420-432 \mathrm{~nm})$ together with calibration factors of the instrument. A comparative study is made between the use of $\mathrm{CO}$ from compressed gas cilinders and the $\mathrm{CO}$ delivered by a chemical reaction in preparing the saturated $\mathrm{COHb}$ solution. The method presents precision (coefficient of variation is 2 and $6 \%$ to 4,98 and $1,01 \%$ of $\mathrm{COHb}$, respectively) and sensitivity $(0,5 \%$ of $\mathrm{COHb})$, which are adequate to the purpose. Hemoglobin and lipidic content of samples showed no effect in the $\mathrm{COHb}$ measurement. Carboxyhiemoglobin level of four groups of exposed workers $(n=209)$ and a control group $(n=99)$ among smokers $(n=115)$ and non-smokers $(n=189)$ were determinated using the method. The statistical analysis of the results are presented (non-parametric test). 


\section{ASPECTOS TOXICOLÓGICOS DA EXPOSIÇÃO AO MONÓXIDO DE}

CARBONO

2.1. Propriedades físicas e químicas ............................................................................ 3

2.2. Fontes naturais e antropogênicas ........................................................................... 4

2.3. Mecanismo de ação .......................................................................................... 8

2.4. Absorção, distribuição, biotransformação e eliminação .......................................... 20

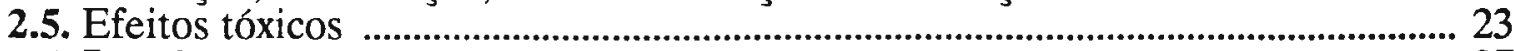

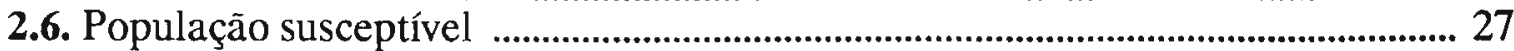

2.7. Monitorização biológica ................................................................................ 29

2.7.1. Indicadores biológicos e seus limites ........................................................... 29

2.7.2. Metodologia analítica ...................................................................................... 31

3. OBJETIVO E PLANO DE TRABALHO ……………................................................... 43

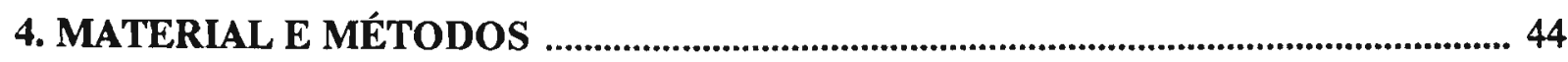

4.1. Otimização da determinação espectrofotométrica da carboxiemoglobinemia 44

4.1.1. Material ............................................................................................................. 44

4.1.1.1. Amostras ......................................................................................................... 44

4.1.1.2. Aparelhos e acessórios ............................................................................ 44

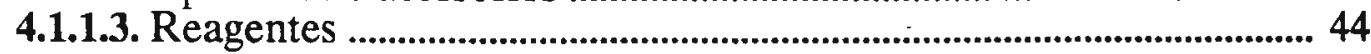

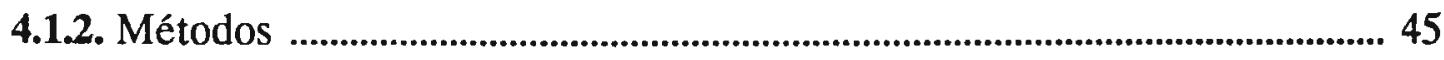

4.1.2.1. Procedimento analítico ................................................................................. 45

4.1.2.2. Determinação dos fatores de calibração do espectrofotômetro 47

4.1.2.3. Linearidade da técnica de quantificação ......................................... 50

4.1.2.4. Precisão do método ...................................................................................... 51 
4.1.2.5. Estabilidade das leituras de absorvância 52

4.1.2.6. Estabilidade da carboxiemoglobina nas amostras 52

4.1.3. Influência da matriz biológica 52

4.1.3.1. Conteúdo hemoglobínico 52

4.1.3.2. Lipemia 53

4.2. Determinação da carboxiemoglobinemia em indivíduos expostos ocupacionalmente ao monóxido de carbono 54

4.2.1. Material 54

4.2.1.1. População estudada 54

4.2.1.2. Aparelhos e acessórios 55

4.2.1.3. Reagentes 55

4.2.2. Métodos 55

5.1. Otimização da determinação espectrofotométrica da carboxiemoglobinemia 56

5.1.1. Preparação das soluções de carboxiemoglobina e de hemoglobina reduzida 56

5.1.2. Uso do monóxido de carbono obtido por reação química na preparação de solução de carboxiemoglobina 50

5.1.3. Deslocamento do monóxido de carbono dissolvido na solução ................ 60

5.1.4. Fatores de calibração do espectrofotômetro ............................................. 61

5.1.5. Linearidade da técnica de identificação ..................................................... 63

5.1.6. Precisão do método ....................................................................................... 65

5.1.7. Estabilidade das leituras de absorvância ...................................................... 67

5.1.8. Estabilidade da carboxiemoglobina nas amostras ..................................... 68

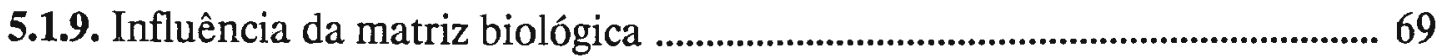


5.1.9.1. Conteúdo hemoglobínico

5.2. Carboxiemoglobinemia em indivíduos expostos ocupacionalmente ao monóxido de carbono

6. DISCUSSÃO 83

7. CONCLUSÕES 103

8. REFERÊNCIAS BIBLIOGRÁFICAS 105

ANEXOS

Anexo I - Equivalência entre as unidades de concentraçāo de monóxido de carbono e as de pressão

Anexo II - Relações matemáticas entre a concentração atmosférica demonóxido de carbono e a carboxiemoglobinemia 122

Anexo III - Limites máximos permissíveis de monóxido de carbono no ar 124

Anexo IV - Limites biológicos de exposição 125 


\section{INTRODUÇÃo}

A combustão da matéria carbonada é a principal fonte de energia usada pelo homem há milênios, o que lhe permitiu obter qualidade de vida adequada e alcançar grande desenvolvimento tecnológico. Entretanto, dessa queima resulta também gás de conhecida periculosidade, o monóxido de carbono (CO). Atribuem-se ao filósofo grego Aristóteles (384-322 a.C.) as primeiras observaçōes sobre os efeitos nocivos do $\mathrm{CO}$. A fumaça da queima do carvão foi usada por gregos e romanos na execução de criminosos e em suicídios (106-43 a.C. $)^{127}$.

$\mathrm{O}$ uso doméstico da queima do carvão, difundido no século $\mathrm{XV}$, intensificou a ocorrência de intoxicações pelo $\mathrm{CO}$; nas condições primitivas de cozimento dos alimentos, a ventilação insuficiente durante a combustão originava altas concentraçōes deste gás. Com o desenvolvimento da mineração, no século XVI, surgiu a exposição ocupacional aos gases venenosos, freqüentemente encontrados em minas e ricos em $\mathrm{CO}^{127}$.

No decorrer do século XIX, o risco da exposição doméstica e industrial aumentou consideravelmente, atribuído à produçāo do gás de iluminação (4 a $15 \%$ de $\mathrm{CO}$ ), do gás pobre ( 30 a $35 \%$ de $\mathrm{CO}$ ) e do gás de água ( 35 a $45 \%$ de $\mathrm{CO})$. A gravidade da exposição a altas concentrações de $\mathrm{CO}$ foi relatada em muitos escritos médicos. Com o advento dos veículos movidos a gás, após a $2^{2}$ Guerra Mundial, foi despertado o interesse sobre os possíveis efeitos do $\mathrm{CO}$ em exposiçōes a baixos níveis ${ }^{127,136}$.

O monóxido de carbono é considerado a causa mais freqüente de intoxicaçāo tanto no meio industrial como no doméstico. Milhares de pessoas morrem, anualmente, intoxicadas e estima-se a ocorrência de número ainda maior de casos não fatais, que podem deixar seqüelas permanentes no sistema nervoso central $^{104,191}$.

Os efeitos nocivos do $\mathrm{CO}$ aparecem, principalmente, como conseqüência de sua combinaçāo com a hemoglobina. Em 1895, Haldane demonstrou a importante relação entre $\mathrm{CO}$ e a hemoglobina, a formação da carboxiemoglobina $(\mathrm{COHb})$ e o comprometimento do fornecimento de oxigênio às células $^{82,83,127}$.

Devido à diversidade e à amplitude dos processos industriais, que produzem ou usam monóxido de carbono, um grande número de trabalhadores se 
expõe diariamente ao CO. Entre eles, podem ser citados, a fundiçāo de metais, o craqueamento catalítico do petróleo em refinarias, os fornos de calcinação e os de recuperação de papel, a produção sintética do metanol e de outros compostos a partir do $\mathrm{CO}$, além da produção de carbonetos e de formaldeído ${ }^{30,104}$. Existem ainda, outras numerosas atividades que podem expor repetidamente os trabalhadores - bombeiros, guardas de trânsito, motoristas de táxi, operadores de empilhadeiras, mecânicos e soldadores em operações dentro de tanques - a concentrações consideravelmente altas de CO, suficientes para formar de 5 a $10 \%$ de $\mathrm{COHb}$, mesmo em não-fumantes. O hábito de fumar constitui outra importante fonte de exposição humana ao $\mathrm{CO}$, afetando não só o fumante como as pessoas que aspiram passivamente a fumaça do cigarro ${ }^{15,36,62,96,131,149.195}$.

O monóxido de carbono proveniente da combustão interna nos veículos automotores tem contribuído significativamente para a poluição dos centros urbanos. Visando ao atendimento dos padrōes de qualidade de ar, o Conselho Nacional do Meio Ambiente, em 1986, instituiu em caráter nacional o PROGRAMA DE CONTROLE DA POLUIÇÃO DO AR POR VEÍCULOS AUTOMOTORES (PROCONVE) que estabelece os limites máximos de emissão de CO para motores e veículos automotores em 24,0,12,0 e 2,0 g/ km rodado para 1990, 1992 e 1997, respectivamente ${ }^{25}$.

O reconhecimento e a avaliação do risco ocupacional da exposição ao CO tornam obrigatória a adoção de medidas de proteçāo à saúde dos trabalhadores, entre as quais a implementação de programa de Higiene e Medicina do Trabalho nas indústrias. A monitorização biológica ocupa lugar de destaque, neste programa, permitindo averiguar a magnitude da exposiçāo humana. A carboxiemoglobina é um indicador biológico (IB), que avalia a absorção (IB de dose interna) assim como reflete a intensidade do efeito nocivo do monóxido de carbono no organismo (IB de efeito).

A determinação de baixos teores de $\mathrm{COHb}$, de ocorrência comum entre os indivíduos expostos ocupacionalmente e entre os fumantes, por um método simples, sensível e preciso, aplicável rotineiramente, apresenta dificuldades em nosso país, o que nos motivou a realizar este trabalho. 


\section{ASPECTOS TOXICOLÓgICOS DA EXPOSIÇÃO AO MONÓXIDO DE CARBONO}

O monóxido de carbono é um dos agentes químicos mais perigosos para o homem e para outros animais. Esta periculosidade está ligada diretamente às condições de exposição ao xenobiótico. Apesar de ser o mais abundante poluente gasoso das atmosferas urbanas, nāo é o de maior risco para a populaçāo em geral. Por outro lado, a exposição no ambiente de trabalho tem sido responsável por número significativo de intoxicações ${ }^{47}$.

O grau da exposição ocupacional ao CO é intensificado pelo tipo de atividade física exercida no local de trabalho e pela susceptibilidade individual. A quantidade do xenobiótico absorvida pelo organismo depende também das características físicas e químicas da substância, da intensidade e freqüência da exposição e de hábitos pessoais como o de fumar.

O conhecimento dos parâmetros que regem a absorção, distribuição e eliminação do xenobiótico no organismo é importante para estimar-se a biodisponibilidade do agente ${ }^{2,4,42,109,110}$. Por outro lado, a elucidaçāo do mecanismo de ação tóxica permite escolher o melhor indicador biológico (IB) para avaliação da exposição. $\mathrm{Na}$ monitorização biológica da exposição ao $\mathrm{CO}$, dispõe-se de três IB: o $\mathrm{CO}$ no sangue, o $\mathrm{CO}$ no ar exalado e a carboxiemoglobinemia ${ }^{112}$.

\subsection{Propriedades físicas e químicas}

O monóxido de carbono [CAS 630-08-0] é um gás incolor, inodoro e insípido, pouco solúvel na água e com densidade menor que a do ar, ao qual se mistura sem estratificação. É inflamável e sua queima produz $\mathrm{CO}_{2}$ com chama de coloração azul brilhante ${ }^{190}$.

As principais propriedades físicas são $0^{5,80.104 .132 .137 .189}$ :

- peso molecular :

- ponto de fusão :

- ponto de ebulição :

- densidade :

a $0^{\circ} \mathrm{C}, 1 \mathrm{~atm}$

a $25^{\circ} \mathrm{C}, 1 \mathrm{~atm}$
28,01

$-205,1{ }^{\circ} \mathrm{C}$

$-191,5{ }^{\circ} \mathrm{C}$

$1,250 \mathrm{~g} / \mathrm{l}$

$1,145 \mathrm{~g} / \mathrm{L}$ 
- peso específico relativo ao ar:

- solubilidade em água, a $1 \mathrm{~atm}$ :
a $0^{\circ} \mathrm{C}$
a $10^{\circ} \mathrm{C}$
a $25^{\circ} \mathrm{C}$
a $37^{\circ} \mathrm{C}$
$3,54 \mathrm{~mL} / 100 \mathrm{~mL}$
$2,82 \mathrm{~mL} / 100 \mathrm{~mL}$
$2,14 \mathrm{~mL} / 100 \mathrm{~mL}$
$1,84 \mathrm{~mL} / 100 \mathrm{~mL}$

- limite de inflamabilidade no ar :

inferior

superior

- temperatura de ignição :
$12,5 \%(\mathrm{v} / \mathrm{v})$

$74,2 \%(\mathrm{v} / \mathrm{v})$

$608,9^{\circ} \mathrm{C}$

- absorve radiação eletromagnética na região de infravermelho e a principal banda de absorção é a $4670 \mathrm{~nm}$.

Em condiçōes normais de temperatura e pressão (CNTP), o CO é gás quimicamente inerte, mas torna-se reativo em temperaturas mais elevadas, podendo atuar como agente redutor enérgico. A oxidação do $\mathrm{CO}$ a $\mathrm{CO}_{2}$ é catalisada por paládio e por mistura de óxidos de cobre e magnésio. A concentração de $\mathrm{CO}$ no ar pode ser expressa em partes por milhão (ppm), porcentagem em volume (\%) ou em $\mathrm{mg} / \mathrm{m}^{3}$. Os fatores de conversão destas unidades são válidos para determinadas condiçōes $^{137}$. A quantidade de $\mathrm{CO}$ e de $\mathrm{O}_{2}$ dissolvida num líquido é freqüentemente representada pela pressão parcial, $\mathrm{pCO}$ e $\mathrm{pO}_{2}$, e expressa em milímetros de mercúrio (mmHg), torricelli (Torr), pascal (Pa) ou milibar (milibar).

As equivalências entre as unidades de concentração de $\mathrm{CO}$ no ar e entre as de pressão constam no (anexo I).

\subsection{Fontes naturais e antropogênicas}

Entre as fontes naturais produtoras de $\mathrm{CO}$, citam-se, como mais importantes, a oxidaçāo do metano, a atividade vulcânica e a dos pântanos e as minas de carvão. Pequenas quantidades de $\mathrm{CO}$ são produzidas por vegetais, durante a germinaçāo da semente e no crescimento da planta, e por certas algas marinhas ${ }^{127,137,160}$.

O CO produzido na superfície da terra difunde-se da troposfera à estratosfera, onde é oxidado a $\mathrm{CO}_{2}{ }^{104}$. A permanência do $\mathrm{CO}$ na atmosfera é de, 
aproximadamente, 2 meses e meio e os principais mecanismos de transformaçāo ambiental são a oxidação a $\mathrm{CO}_{2}$ no ar , a absorção pelo solo e pela vegetação e a dissolução em águas de rios, lagos e oceanos. Esta solubilidade depende, principalmente, da pressão parcial do gás na atmosfera e da temperatura da água.

A oxidação também ocorre por reações com contaminantes do ar e por microorganismos presentes no solo. A oxidaçāo por bactérias anaeróbias a $\mathrm{CO}_{2}$, na ausência de $\mathrm{H}_{2}$, e a redução a metano, em presença de $\mathrm{H}_{2}$, também contribuem para a remoçāo do $\mathrm{CO}$ atmosférico ${ }^{101,127}$.

O monóxido de carbono é produzido também pela atividade humana, através da queima de matéria orgânica - carvão, madeira, papel, óleo, gasolina, ou qualquer outro material que contenha carbono-quando há insuficiência de oxigênio. Portanto, as fontes de exposição ao $\mathrm{CO}$ podem ser consideradas onipresentes.

Se o processo de combustão ocorrer com excesso de oxigênio, não há formação significativa de CO. Contudo, se a chama da queima do material carbonado entrar em contato com superfície de temperatura inferior à de ignição, haverá formação de CO.

As fontes que resultam da atividade humana podem ser divididas em móveis e estacionárias.

As fontes móveis são representadas, principalmente, por veículos com motores a explosāo, responsáveis por cerca de 55\% a $66 \%$ das emissōes artificiais de $\mathrm{CO}^{44}$. Nos motores a gasolina, com igniçāo por faísca, o volume de $\mathrm{CO}$ na fumaça liberada para o ar atmosférico pode variar de 1 a $10 \%$ e, nos motores a diesel, com detonação por compressão, emite-se cerca de $0,1 \%$ de CO. Dependendo do ajuste do motor, sobrecarga ou falta de manutençāo, as quantidades podem aumentar consideravelmente ${ }^{104}$.

A infiltraçāo e o acúmulo dos gases emitidos pelos veículos no seu interior podem ocorrer, acidentalmente, por deficiência no sistema de eliminação, expondo assim o homem a concentraçōes elevadas de $\mathrm{CO}^{9,101,136}$.

A CETESB (Companhia de Tecnologia de Saneamento Ambiental), no Relatório de Qualidade do Ar na Regiāo Metropolitana de São Paulo e Cubatão, estima a contribuição relativa dos veículos a gasolina, álcool e diesel na 
emissão de 1,391 milhōes de toneladas de CO (1988) em 60, 12 e 16\%, respectivamente. Os processos industriais e a queima ao ar livre representam apenas $6 \%{ }^{44}$.

Durante o inverno, as condiçōes meteorológicas são desfavoráveis à dispersāo dos poluentes atmosféricos ${ }^{3,47}$. O fenômeno de inversão térmica e a precipitação pluviométrica pouco freqüente aumentam os problemas relacionados à poluição do ar. Motivada por estes fatores a CETESB implantou a OPERAÇÃo INVERNO de 1 de maio a 31 de agosto. Neste período, aumenta a vigilância no controle da qualidade do $\operatorname{ar}^{44}$.

As fontes estacionárias incluem os processos industriais de produçāo e os de uso. O CO é produzido, em escala industrial, por oxidação parcial de hidrocarbonetos gasosos presentes no gás natural ou pela gaseificaçāo do coque ou da hulha ${ }^{104}$. Na indústria metalúrgica, o $\mathrm{CO}$ é usado como agente redutor, principalmente no processo de recuperação de níquel e nas fundiçōes de ferro ${ }^{30}$.

A redução do minério de ferro é realizada em alto forno, de funcionamento contínuo, carregado periodicamente com minério de ferro, calcário $\left(\mathrm{CaCO}_{3}\right)$ e coque (carbono). Na decomposição térmica do calcário, produz-se o óxido de cálcio que reage com as impurezas de sílica e silicato formando-se a escória de silicato. $O$ ferro fundido e a escória pouco densa saem por aberturas de separação, localizadas na parte inferior do forno. $O$ ar quente injetado queima $o$ carbono, formando $\mathrm{CO}$, o principal agente redutor. $\mathrm{O}$ gás do alto forno contém, cerca de $24 \%$ de CO, que participa das reações de redução do ferro ${ }^{166}$ :

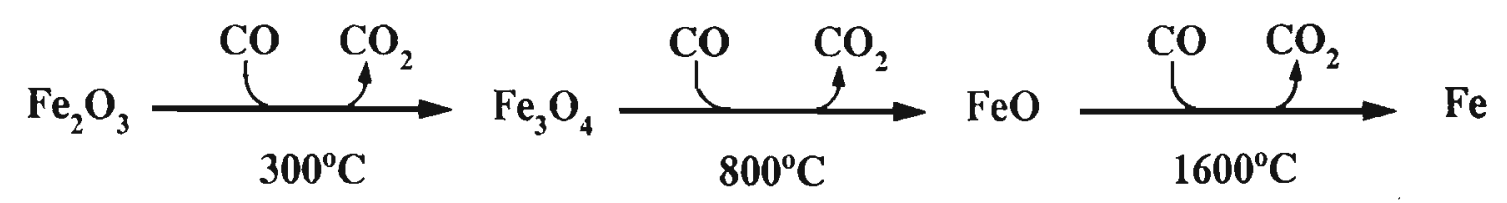

Obtém-se assim o ferro gusa que contém, em média, 5\% de impurezas em Si, P, Mn e S. Os diferentes processos de purificação do ferro gusa diferenciam o tipo de liga metálica formada, quanto ao grau de dureza e de tenacidade. Estes são determinados pela composição de metais e pela quantidade de carbono. O processo de purificação é dependente da finalidade de uso da liga metálica ${ }^{166}$. 
A fumaça do tabaco é fonte de $\mathrm{CO}$ de grande importância, visto a larga difusão do hábito de fumar na sociedade ${ }^{92.159}$. GUILLERM et $a l^{81} \mathrm{e}$ MUMPOWER et al ${ }^{130}$, com base na quantidade média de fumaça inalada, sua retenção pulmonar e freqüência da tragada, calcularam ser a quantidade inalada por cigarro comparável à exposição a $450 \mathrm{ppm}$ de $\mathrm{CO}$ no ar durante 6 minutos. $\mathrm{O}$ número e o tipo de cigarro, assim como a intensidade da tragada, condicionam a fração de CO disponível para a absorção pulmonar.

A concentração de $\mathrm{CO}$ na fumaça de cigarro é de 3 a $6 \%$, variando com a temperatura da queima e outros fatores como a porosidade do papel e o tipo do tabaco ${ }^{7}$. Em cachimbo ou charuto, a sua concentração na fumaça é duas a três vezes maior, por ser a temperatura da queima inferior à do cigarro. Entretanto, o usuário de cachimbo ou de charuto tende a estar exposto a menores quantidades do toxicante, uma vez que, usualmente, a fumaça não é tragada ${ }^{159}$.

KARNIK \& COIN $^{98}$ simularam a exposiçāo de voluntários não-fumantes à fumaça de um cigarro, e encontraram o aumento médio de $\mathrm{COHb}$ imediatamente e 20 minutos após a inalação da última tragada, de 0,8 e 0,5\%, respectivamente.

O monóxido de carbono é produzido, endogenamente, no catabolismo normal da hemoglobina e de outros heme-compostos (mioglobina e citocromos), pela conversão do grupo heme a biliverdina, por remoção do átomo de carbono da metila em posição alfa ${ }^{205}$. WOLFF \& BIDLACK ${ }^{212}$ evidenciaram outras possíveis fontes endógenas, como a peroxidação lipídica.

Estima-se que a concentração de carboxiemoglobina formada pelo CO endógeno, em adulto sadio, varia de 0,1 a $1,0 \%$, sendo aproximadamente $75 \%$ atribuído ao catabolismo da hemoglobina ${ }^{160}$.

Durante a fase progesterônica do ciclo menstrual e durante a gravidez, podem ser encontradas concentraçōes elevadas de $\mathrm{CO}$ endógeno. Mulheres grávidas produzem $0,9 \mathrm{~mL} / \mathrm{h}$ de $\mathrm{CO}$ e as nāo-grávidas, $0,4 \mathrm{~mL} / \mathrm{h}$. Estes teores parecem estar relacionados com os níveis de progesterona ${ }^{137}$.

Em algumas condições patológicas ocorre aumento na produção de $\mathrm{CO}$ endógeno como, por exemplo, na anemia hemolítica que origina teores de até $6 \%$ de $\mathrm{COHb}^{5,47}$. Os hematomas, a exposição a agentes hemolíticos, os traumatismos e as transfusões sangüíneas incrementam os níveis de 
carboxiemoglobinemia ${ }^{76}$. A medula óssea pode converter-se em importante fonte de CO nas hemopatias, como a anemia sideroblástica, imputada ao comprometimento da eritropoiese ${ }^{206}$.

A produção total de $\mathrm{CO}$ endógeno pode ser acentuada por certos fármacos como a difenilidantoína e o fenobarbital, em conseqüência da indução do heme hepático seguido de seu catabolismo. Em casos de porfiria cutânea, verifica-se efeito similar ${ }^{160.206}$.

\subsection{Mecanismo de ação}

O monóxido de carbono é o exemplo mais conhecido de agente que interfere na capacidade de transporte de oxigênio do sangue, conduzindo à anoxia ou hipóxia tissular ${ }^{132.179}$.

A hipóxia produzida é do tipo anêmica (anoxemia isotônica) e caracteriza-se pela diminuiçāo da quantidade de $\mathrm{O}_{2}$ transportada pela hemoglobina, sendo que a pressão parcial de oxigênio e o fluxo sangüíneo podem permanecer normais ou até elevados 8 ,106,179.

O monóxido de carbono é rapidamente absorvido e liga-se, reversivelmente, à hemoglobina dos eritrócitos, formando a carboxiemoglobina. Ele também compete com o oxigênio, em nível tissular, pelo mesmo sítio ativo das hemeproteínas celulares, que têm em comum a configuração estrutural tetrapirrólica, tais como a mioglobina, o citocromo-oxidase, o citocromo P-450, a peroxidase e a catalase. Para tanto, é necessário que o CO do compartimento intravascular passe, por difusão, para o extravascular ${ }^{5,31}$.

A hemoglobina, proteína oligomérica, possui quatro cadeias polipeptídicas e quatro grupos heme - anel porfirínico no qual o átomo de ferro está no estado ferroso $\left(\mathrm{Fe}^{+2}\right)$. A porção protéica, chamada globina, consiste de 2 cadeias $\alpha$ e $2 \beta^{113,123,144}$. O grupo heme está ligado à cadeia polipeptídica através de uma ligação de coordenação do átomo de ferro ao grupo $\mathrm{R}^{*}$ de um resỉduo * da histidina. A sexta ligação de coordenação do átomo de ferro de cada heme é livre e pode ser

\footnotetext{
* Cadeia lateral específica de cada aminoácido

** Unidade de cada aminoácido em um peptídeo
} 
completada com o oxigênio ou o monóxido de carbono. Portantı), cada molécula de $\mathrm{Hb}$ pode combinar-se com 4 moléculas de $\mathrm{O}_{2}$ ou de $\mathrm{CO}$ (figura 1).

(a)

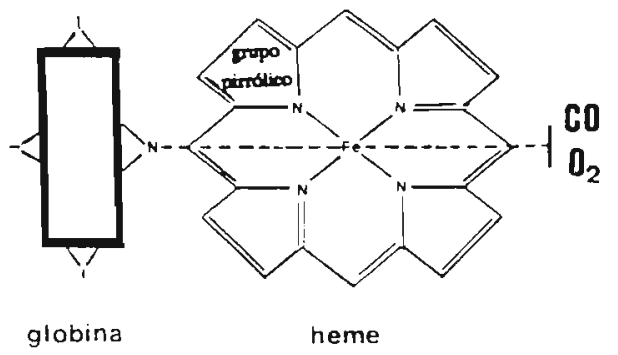

(b)

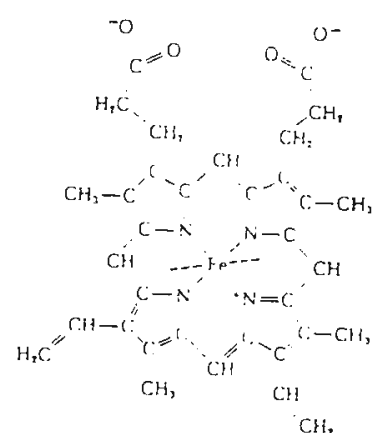

(C)

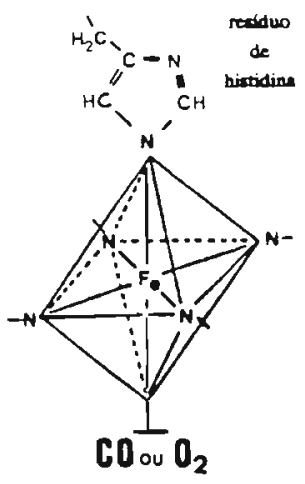

Figura 1 - (a) ligaçāo do oxigênio $\left(\mathrm{O}_{2}\right)$ ou monóxido de carbono $(\mathrm{CO})$ ao ferro de um dos quatro grupos heme da hemoglobina ${ }^{31}$;

(b) fórmula estrutural do grupo heme ${ }^{113}$;

(c) geometria de coordenação octaédrica que permite a $5^{\mathrm{a}}$ ligação do átomo de ferro com o resíduo da histidina da globina e a $6^{3}$ ligação com o $\mathrm{CO}$ ou $\mathrm{O}_{2}^{31.113}$.

Apesar da capacidade de ligaçāo ser de quatro moléculas, a equação da reação do $\mathrm{O}_{2}$ ou de $\mathrm{CO}$ à $\mathrm{Hb}$ é usualmente escrita considerando apenas uma cadeia polipeptídica:

$$
\begin{gathered}
\mathrm{O}_{2}+\mathrm{Hb} \leftrightharpoons \mathrm{O}_{2} \mathrm{Hb} \\
\mathrm{CO}+\mathrm{Hb} \leftrightharpoons \mathrm{COHb}
\end{gathered}
$$

$\mathrm{Na}$ ligação da $\mathrm{Hb}$ com $\mathrm{O}_{2}(\mathbf{X})$ ou com o $\mathrm{CO}(\mathbf{Y})$, as formas intermediárias possíveis até à saturação podem ser diagramadas em forma de triângulo. Na figura 2 a linha horizontal superior representa a ligação com o $\mathrm{O}_{2}$ na ausência de $\mathrm{CO}$ e a linha vertical à esquerda, o inverso. As outras combinaçōes possíveis dos dois ligantes nos quatro sítios de ligação da $\mathrm{Hb}$ estão representadas nas diagonais do triângulo.

A ligação e dissociação do oxigênio ou do monóxido de carbono às hemeproteínas são influenciadas por alguns fatores, tais como as pressōes parciais 
dos gases e as características estruturais de cada proteína ${ }^{55.128}$.

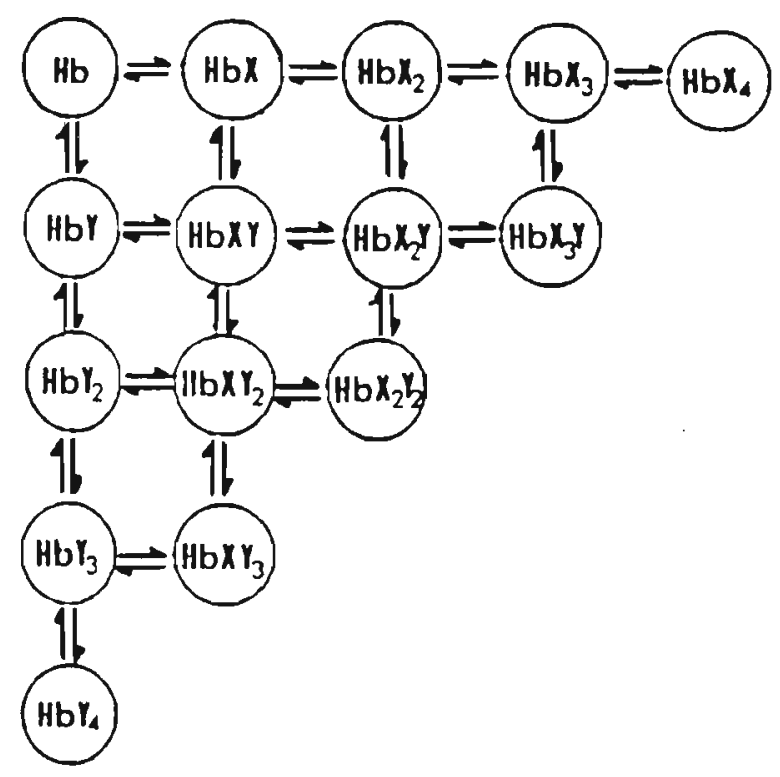

Figura 2 - Diagrama das combinaçōes possíveis entre os ligantes $\mathrm{CO}(\mathrm{Y})$ e $\mathrm{O}_{2}(\mathrm{X})$ e a hemoglobina $(\mathrm{Hb})^{55}$.

A curva de dissociação da oximioglobina apresenta o aspecto sigmóide (figura 3). Na primeira etapa da dissociação, em condições fisiológicas, o oxigênio é rapidamente dissociado da $\mathrm{Hb}$. A diferença de $\mathrm{pO}_{2}$ do sangue arterial $(100 \mathrm{mmHg})$ para o venoso $(40 \mathrm{mmHg})$ representa a liberação de $\mathrm{O}_{2}$ para os tecidos de, aproximadamente, $5 \mathrm{~mL} / 100 \mathrm{~mL}$ de sangue, proporcionando, portanto, um excelente fator de segurança no suprimento de $\mathrm{O}_{2}$ aos tecidos ${ }^{113}$.

Além de transportar o $\mathrm{O}_{2}$ dos pulmões aos tecidos, a $\mathrm{Hb}$ transporta dois produtos finais da respiração celular, $\mathrm{o}^{+}$e $\circ \mathrm{CO}_{2}$, dos tecidos para os pulmōes e rins, órgãos encarregados de excretá-los.

A função característica de cada hemeproteína está condicionada à sua conformação. A mioglobina e os citocromos têm estrutura protéica monomérica, com um sítio de ligação. Estas hemeproteínas intracelulares, apresentam maior afinidade pelo $\mathrm{O}_{2}$ do que a $\mathrm{Hb}$ e exercem a função de reserva e de utilização deste gás em processos metabólicos.

A hemoglobina possui estrutura tetrâmera, permitindo que os quatro sítios ativos de ligaçāo com os gases apresentem a interação cooperativa entre si. A ligação do $\mathrm{O}_{2}$ à $\mathrm{Hb}$ é facilitada gradativamente, à medida que os sítios, ativos vão 
sendo ocupados e, inversamente, a dissociação é dificultada, à medida que o oxigênio é liberado dos sítios. Neste processo de associação/dissociação do $\mathrm{O}_{2}$ ou do $\mathrm{CO}$ ocorre uma mudança conformacional na estrutura da $\mathrm{Hb}^{72,151}$.

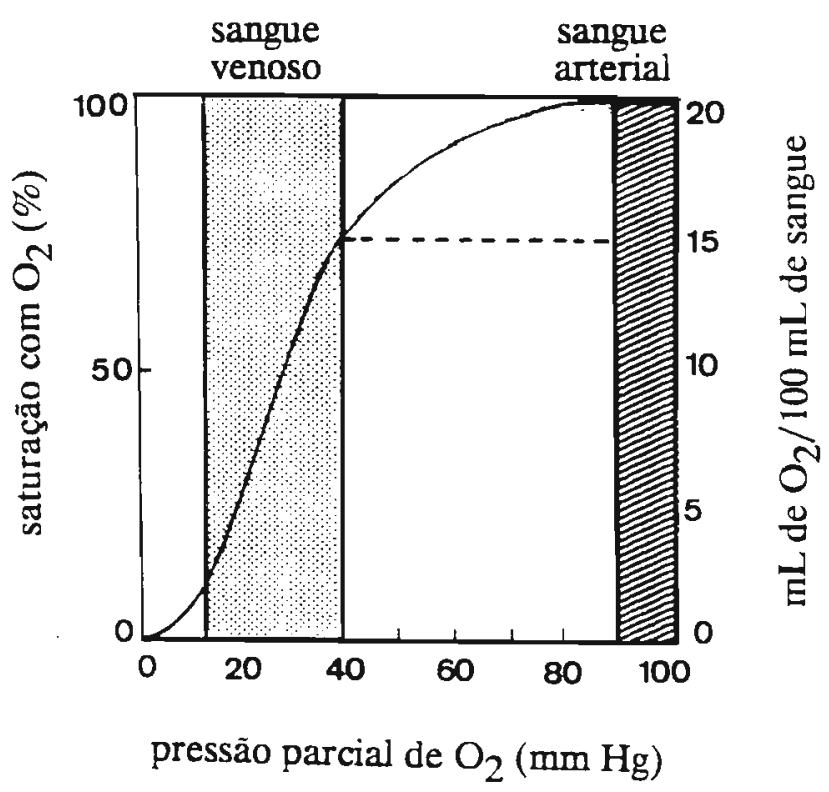

Figura 3 - Curva de dissociaçāo da hemoglobina $(\mathrm{Hb})$ a $37^{\circ} \mathrm{C},(\mathrm{pH}=7,4)^{113}$.

O hidrogênio e o dióxido de carbono não se liganı ao mesmo sítio de ligação do oxigênio na molécula de $\mathrm{Hb}$. $\mathrm{O}$ hidrogênio liga-se ao grupo $\mathrm{R}$ dos resíduos da lisina 146 das cadeias $\beta$ e a dois resíduos nas cadeias $\alpha$. O dióxido de carbono é captado pelo grupo $\alpha$-amino na extremidade amino-terminal de cada uma das 4 cadeias polipeptídicas da $\mathrm{Hb}$, formando a carbaminoemoglobina.

Nos capilares dos tecidos periféricos, a afinidade da $\mathrm{Hb}$ pelo $\mathrm{O}_{2}$ diminui à medida que se liga ao $\mathrm{H}^{+}$ou ao $\mathrm{CO}_{2}$; nos capilares pulmonares ocorre $\mathrm{o}$ inverso, com aumento da afinidade pelo $\mathrm{O}_{2}$ à medida que $0 \mathrm{CO}_{2}$ e $\circ \mathrm{H}^{+}$são eliminados. Os íons $\mathrm{H}^{+}$, o $\mathrm{CO}_{2}$ e o 2,3-difosfoglicerato (2,3-DPG) são efetores alostéricos que modulam a ligação do $\mathrm{O}_{2}$ e do $\mathrm{CO}$ à hemoglobina (figura 4).

O efeito do $\mathrm{pH}$ na ligação do $\mathrm{O}_{2}$ à hemoglobina, EFEITO BOHR, foi descoberto pelo fisiologista dinamarquês, Christian Bohr (figura 5) ${ }^{31,72,113,123,151,196}$.

Dotada de baixa afinidade pelo $\mathrm{O}_{2}$, significativo efeito Bohr e elevada afinidade pelo $\mathrm{CO}$, a hemoglobina corresponde perfeitamente às exigências fisiológicas de transportar $\mathrm{O}_{2}$ às células, fornecendo-o às enzimas de respiração, e 
de remover o $\mathrm{CO}_{2}$, produto terminal da atividade metabólica ${ }^{106.113 .196}$.

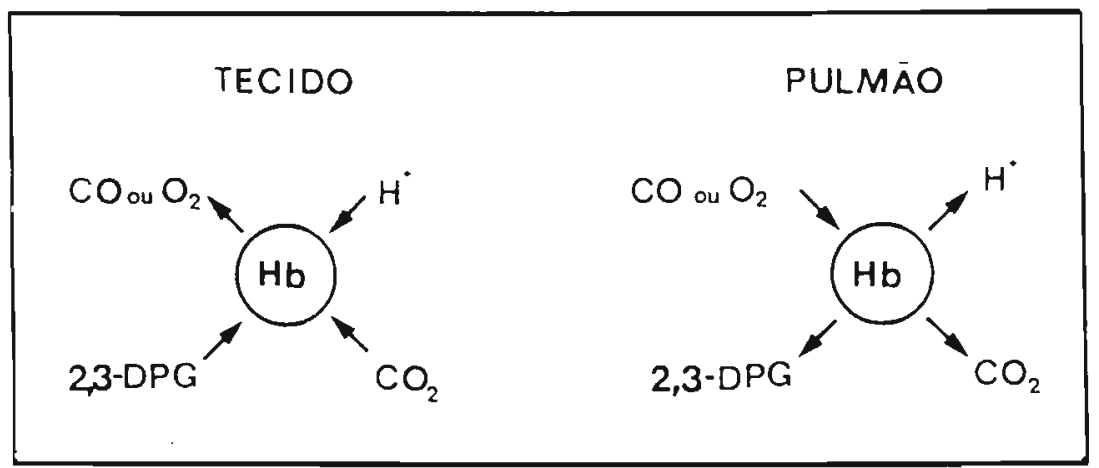

Figura 4 - Ação dos efetores alostéricos $-\mathrm{H}^{+}, \mathrm{CO}_{2}$ e 2,3-difosfoglicerato (2,3-DPG) - na ligação do $\mathrm{O}_{2}$ ou $\mathrm{CO}$ à hemoglobina (Hb) nos capilares tissulares e pulmonares ${ }^{123}$.

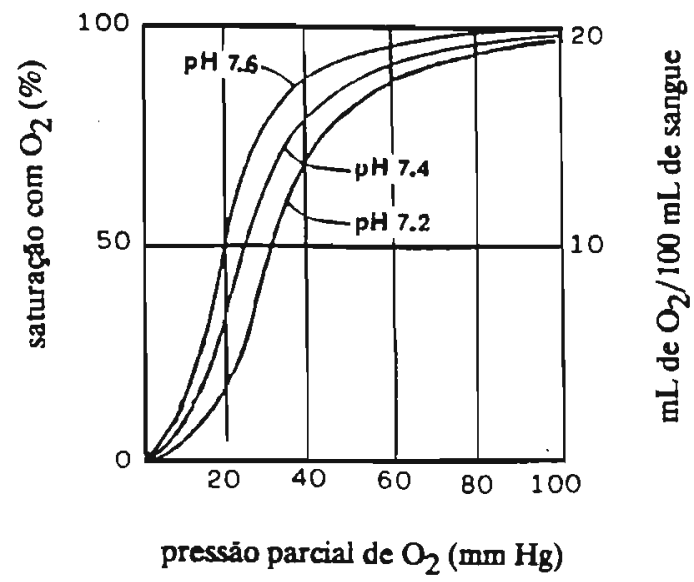

Figura 5 - Efeito da concentraçāo hidrogeniônica $(\mathrm{pH})$ na curva de dissociaçāo da oxiemoglobina de sangue humano EFEITO BOHR ${ }^{113}$.

Outra função importante da $\mathrm{Hb}$ é a de remover o $\mathrm{CO}$ produzido endogenamente na célula. A liberação do $\mathrm{CO}$ da $\mathrm{Hb}$ e a eliminação por via pulmonar depende das diferenças de pressão parcial de $\mathrm{CO}$ no sangue venoso e no ar alveolar 31,205 . 
A elucidaçāo do mecanismo de ação do CO feita por Claude Bernard, em 1865, foi formalizada por HALDANE \& SMITH ${ }^{83}$, em $1897^{31.179}$. HALDANE \& DOUGLAS ${ }^{82}$, em 1912, propuseram as leis relativas à ligação do $\mathrm{CO}$ e do $\mathrm{O}_{2}$ à hemoglobina humana.

A primeira lei estabelece que a razão entre as moléculas de monóxido de carbono $(\mathbf{Y})$ e de oxigênio $(\mathbf{X})$ ligadas à hemoglobina é proporcional à razão das pressōes parciais dos dois gases, como expresso abaixo :

$$
\frac{\mathrm{Y}}{\mathrm{X}}=\mathrm{M} \times \frac{\mathrm{pCO}}{\mathrm{pO}_{2}}
$$

onde, $\mathbf{M}$ é a constante de proporcionalidade denominada coeficiente de partição ou constante de afinidade relativa ${ }^{31}$. Esta relação define quantitativamente a competição entre o oxigênio e o monóxido de carbono pelo mesmo sítio de ligaçāo na hemoglobina ${ }^{82}$.

A constante de afinidade pode ser expressa como sendo o número de moles de $\mathrm{O}_{2}$, para cada mol de $\mathrm{CO}$, necessários à saturação da hemoglobina em $50 \%$ de $\mathrm{O}_{2} \mathrm{Hb}$. O valor determinado por HALDANE \& DOUGLAS ${ }^{82}$ para a constante $M$ no sangue humano foi de 246 . Os valores encontrados na literatura oscilam entre 200 e 300 , o que pode ser atribuído às diferentes condições experimentais ${ }^{31}$ (tabela I). 
Tabela I - $\quad$ Valores da constante de afinidade relativa (M) do $\mathrm{CO}$ e $\mathrm{O}_{2}$ para a hemoglobina ${ }^{31}$.

\begin{tabular}{ll}
\hline \hline $\mathbf{M}$ & autor \\
\hline \hline & \\
$210+2,5$ & Sendroy et al. (1929) \\
233 a 272 & Killick (1936) \\
$204+10$ & Lihenthal \& Riley (1946) \\
255 & Allen \& Root (1946) \\
$218+8$ & Rodkey et al. (1969) \\
\hline \hline
\end{tabular}

Cada espécie animal tem um valor definido para esta constante, imputado às diferenças na composição das moléculas de $\mathrm{Hb}^{80.179}$.

A segunda lei que relaciona à ligação do $\mathrm{O}_{2}$ e do $\mathrm{CO}$ à $\mathrm{Hb}$, é conseqüência da primeira e diz que a saturaçāo total (T) é funçāo somente da pressão parcial de $\mathrm{O}_{2}$ e de $\mathrm{CO}$.

$$
[\mathrm{T}]=[\mathrm{Y}]+[\mathrm{X}]=\mathbf{f}\left(\mathrm{pO}_{2}+\mathrm{M} \mathbf{p C O}\right)
$$

De acordo com as leis de Haldane, espera-se que a curva de ligação da $\mathrm{Hb}$ com o $\mathrm{CO}$ seja paralela à do $\mathrm{O}_{2}$ e que a distância entre as duas seja correspondente ao valor de $\mathbf{M}$.

HALDANE questionou a diferença entre o estado clínico do paciente intoxicado pelo $\mathrm{CO}$ e o devido à anoxia provocada por diminuição no conteúdo hemoglobínico com nível de oxigênio no sangue equivalente. $O$ autor observou que, em situaçōes de $\mathrm{pO}_{2}$ baixa, o $\mathrm{CO}$ dificulta a dissociação do oxigênio da $\mathrm{Hb}^{80}$. Este fenômeno, denominado EFETTO HALDANE, indica desvio à esquerda na curva de dissociação da $\mathrm{O}_{2} \mathrm{Hb}$ na presença de quantidades crescentes de $\mathrm{CO}$. A forma sigmóide da curva de dissociação tende à forma parabólica ${ }^{12,31}$ (figura 6). 


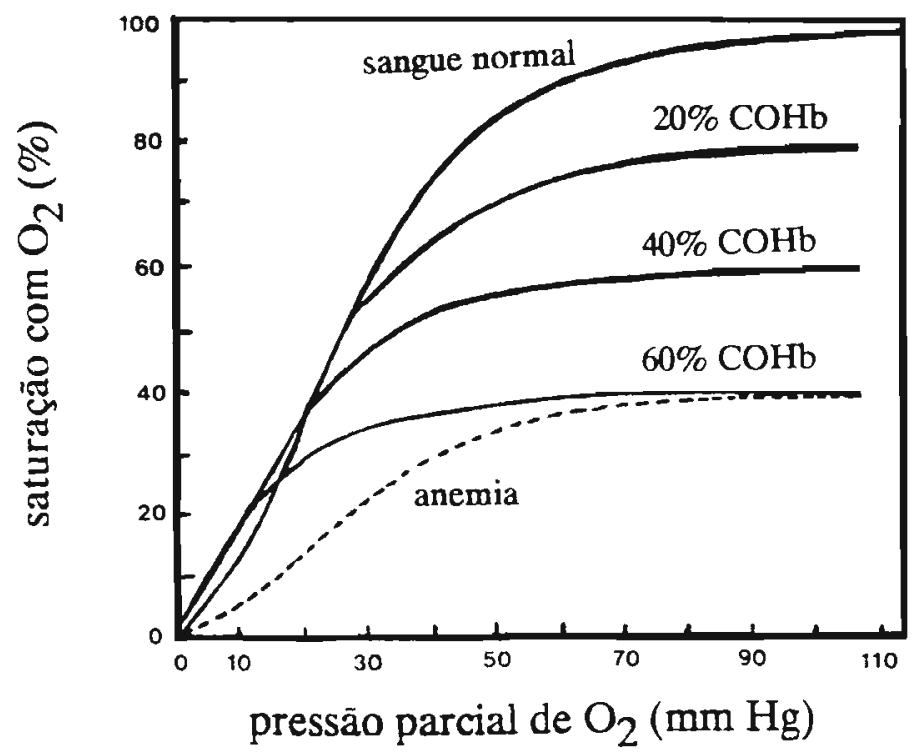

Figura 6 - Curva de dissociação da oxiemoglobina $(\mathrm{O}, \mathrm{Hb})$ na presença de diferentes poŕcentagens de carboxiemoglobina $(\mathrm{COHb})$ e em sangue de indivíduo anêmico ${ }^{31}$.

A Haldane foi atribuído o mérito do reconhecimento dos dois mecanismos pelos quais o $\mathrm{CO}$ conduz à anoxia :

- a redução no transporte de $\mathrm{O}_{2}$ ao tecido devido à formação de $\mathrm{COHb}$;

- a diminuição na liberação de $\mathrm{O}_{2}$, em nível tissular, pelo desvio da curva de dissociação da $\mathrm{O}_{2} \mathrm{Hb}$ à esquerda.

BARCROFT $^{13}$, em 1928, descreveu uma diferença leve, porém distinta, entre as curvas de dissociaçāo de $\mathrm{O}_{2} \mathrm{Hb}$ e $\mathrm{COHb}$ no sangue total, particularmente a baixas saturações. No entanto, os dados disponíveis não eram suficientemente confiáveis e somente mais tarde, em 1976, sua observação foi confirmada com maior segurança ${ }^{94,135,162}$.

ROUGHTON ${ }^{161}$ confrontou o aspecto teórico da interação da $\mathrm{Hb}$ com o CO ou $\mathrm{O}_{2}$ com base na teoria da formação de compostos intermediários, em quatro etapas, de $\mathrm{Hb}_{4}$ a $\mathrm{Hb}(\mathrm{CO})_{4}$, através da mesma teoria proposta por ADAIR ${ }^{1}$ para a ligação da $\mathrm{Hb}$ com o $\mathrm{O}_{2}$.

Cada reaçāo se caracteriza por uma constante de equilíbrio L que é obtida pela razão das constantes de velocidade de associação e dissociação l' e l respectivamente: 


$$
\begin{array}{lll}
\mathrm{Hb}_{4}+\mathrm{CO} \leftrightharpoons & \mathrm{COHb} & \mathrm{L}_{1}=\mathrm{l}_{1}^{\prime} / \mathrm{l}_{1} \\
\mathrm{COHb} & +\mathrm{CO} \leftrightharpoons(\mathrm{CO})_{2} \mathrm{Hb} & \mathrm{L}_{2}=\mathrm{l}_{2}^{\prime} / \mathrm{l}_{2} \\
(\mathrm{CO})_{2} \mathrm{Hb}_{4}+\mathrm{CO} \leftrightharpoons & (\mathrm{CO})_{3} \mathrm{Hb} & \mathrm{L}_{3}=\mathrm{l}_{3}^{\prime} / \mathrm{I}_{3} \\
(\mathrm{CO})_{3} \mathrm{Hb}_{4}+\mathrm{CO} \leftrightharpoons(\mathrm{CO})_{4} \mathrm{Hb} & \mathrm{L}_{4}=\mathrm{l}_{4}^{\prime} / \mathrm{l}_{4}
\end{array}
$$

onde, $\mathbf{H b}_{4}$ representa uma molécula de hemoglobina com quatro sítios de ligação.

De acordo com esta hipótese, a equaçāo geral que descreve o equilíbrio entre hemoglobina livre e ligada ao $\mathrm{CO}$ é dada por ${ }^{31}$ :

$$
\frac{Y}{100}=\frac{L_{1} P+2 L_{1} L_{2} P_{2}+3 L_{1} L_{2} L_{3} P_{3}+4 L_{1} L_{2} L_{3} L_{4} P_{4}}{4\left(1+4 P+L_{1} L_{2} P_{2}+L_{1} L_{2} L_{3} P_{3}+L_{1} L_{2} L_{3} L_{4} 4 P_{4}\right)}
$$

Nesta equação, Y/100 indica a porcentagem de saturação da $\mathrm{Hb}$ com o $\mathrm{CO}, \mathbf{P}$ a pressão parcial de $\mathrm{CO}$ em mmHg e $\mathrm{L}$ a constante de equilíbrio, de 1 a 4 , correspondente aos 4 estágios intermediários.

Considerando esta base teórica, ROUGHTON et al. ${ }^{164}$ desenvolveram métodos analíticos mais sensíveis para construir a curva de dissociação da oxiemoglobina e carboxiemoglobina, calculando em seguida as constantes de equilíbrio $\mathrm{L}_{1}, \mathrm{~L}_{2}, \mathrm{~L}_{3}$ e $\mathrm{L}_{4}$.

Dispondo dos valores das constantes de equilíbrio para o monóxido de carbono (L), ROUGHTON ${ }^{163}$ verificou que a primeira lei de Haldane podia manter-se confirmada somente quando a $\mathrm{Hb}$ está saturada (com 4 ligantes) :

$$
M=\frac{L_{4}}{K_{4}}=\frac{l_{4}^{\prime} \times k_{4}}{k_{4}^{\prime} \times l_{4}}
$$

onde, $\mathrm{L}_{4}$ e $\mathbf{K}_{4}$ representam a constante de equilíbrio do $4^{9}$ estágio da reação da $\mathrm{Hb}$ com $\mathrm{CO}$ e $\mathrm{O}_{2}$ respectivamente; $\mathbf{l}_{4}^{\prime}$ e $\mathbf{k}_{4}^{\prime}$ são as correspondentes constantes de velocidade e de associação e $\mathrm{l}_{4}$ e $\mathbf{k}_{4}$ as de dissociação. 
DI CERA et al..$^{54}$ compararam as curvas de ligaçāo da $\mathrm{Hb}$ com o CO e o $\mathrm{O}_{2}$ nas mesmas condições, próximas às fisiológicas, e demonstraram que não são paralelas, o que corrobora a restrição da validade das leis de HALDANE para a ligaçāo entre $\mathrm{CO}$ e $\mathrm{O}_{2}$ à $\mathrm{Hb}$ humana.

As velocidades de ligação e dissociação do oxigênio à hemoglobina são maiores que as do $\mathrm{CO}$; no entanto, a de dissociação é significativamente maior. Segundo FORSTER ${ }^{69}$, a razão das constantes de velocidade de associaçāo da hemoglobina com o $\mathrm{CO}$ e o $\mathrm{O}_{2}$ é da ordem de $1 / 6$, enquanto que, para a dissociação, a razão diminui para $1 / 1800$.

A constante $\mathbf{M}$, determinada a pressōes parciais elevadas, está de acordo com estudos prévios de HALDANE, mas está diminuida a baixas pressōes parciais dos gases ${ }^{54}$.

BISHOP \& GIL ${ }^{22}$ determinaram os valores de M. isoladamente, paras as cadeias $\alpha$ e $\beta$. Estes valores foram concordantes com os de $123 \pm 34$ e $241 \pm 19$, obtidos por DI CERA et al..$^{54}$ para a hemoglobina antes e após a transição conformacional, respectivamente. Com base nestes dados estes autores sugerem que a ligaçāo do primeiro ligante ocorre, preferencialmente, na cadeia $\alpha$.

Apesar de ser aparentemente simples, o mecanismo de ligação do CO à $\mathrm{Hb}$ envolve os efeitos da estrutura quaternária, da geometria do ligante e das diferenças nas cadeias polipeptídicas moduladas por interaçōes do heme não ligado e pelo impedimento estérico. A variação da conformação da cavidade de localização do heme na hemoglobina, que acompanha a transiçāo do íon ferro da desoxiemoglobina (número de coordenação 5) para a forma ligada (número de coordenação 6), aumenta o impedimento estérico distal para o ligante.

As diferenças entre as constantes $\mathrm{L}_{1}, \mathrm{~L}_{2}, \mathrm{~L}_{3}$ e $\mathrm{L}_{4}$ dependem também de forças intramoleculares resultantes da interação dos ligantes entre si, ou entre outras porções da molécula de hemoglobina ${ }^{128}$.

DI CERA et $a l^{54}$ e GILL et al. ${ }^{73}$ observaram que as espécies de hemoglobina triplamente ligadas com $\mathrm{CO}$ e/ou $\mathrm{O}_{2}$ formavam-se em pequena proporção. Com base no mecanismo estereoquímico proposto por PERUTZ ${ }^{143}$, os autores sugerem que este comportamento seja devido a uma propriedade intrínseca da molécula de $\mathrm{Hb}$. 
A variação da constante de afinidade relativa do $\mathrm{O}_{2}$ e do $\mathrm{CO}$, em função das pressões parciais dos gases, para a hemoglobina de indivíduo adulto e para a hemoglobina fetal, quando representada graficamente, gera uma superfície não plana ${ }^{54}$ (figura 7).
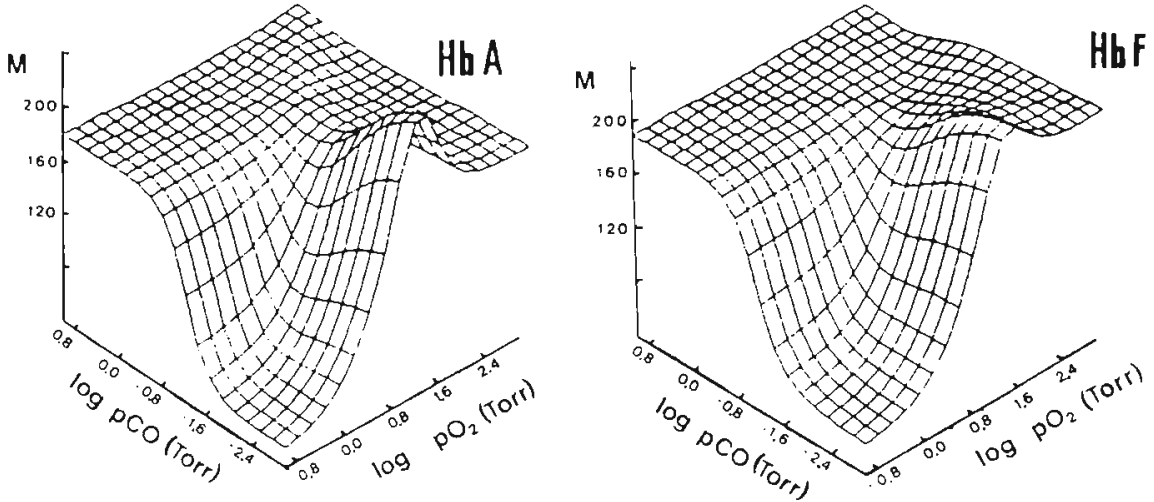

Figura 7 - Constante de afinidade relativa (M) do $\mathrm{CO}$ e $\mathrm{O}$, para a hemoglobina normal de adulto (HbA) e para a fetal (HbF) em função das pressōes parciais dos gases ${ }^{54}$.

Em resumo, com base nas constantes de equilíbrio da ligação da $\mathrm{Hb}$ com $\mathrm{O}_{2}$ e o $\mathrm{CO}$ e nas leis termodinâmicas, os autores comprovaram que a validade das leis de Haldane se restringe a moléculas de $\mathrm{Hb}$ com 4 ligantes $22,54,55,128,163$.

$\mathrm{O}$ monóxido de carbono se liga à mioglobina $(\mathrm{Mb})$ em menor proporção que à hemoglobina. A Mb é uma hemeproteína formada por uma cadeia polipeptídica com apenas um sítio de ligação; portanto, nāo apresenta efeito de cooperatividade $^{215}$.

A reação da $\mathrm{Mb}$ com o $\mathrm{O}_{2}$ apresenta equilíbrio químico e pode ser expressa por ${ }^{31.137}$ :

$$
\mathrm{Mb}+\mathrm{O}_{2} \leftrightharpoons \mathrm{O}_{2} \mathrm{Mb} \quad \mathrm{K}=\mathrm{k}^{\prime} / \mathrm{k}
$$

onde k' e k são, respectivamente, as constantes de velocidade de associação e 
dissociação.

A constante de partiçāo (M') entre $\mathrm{O}_{2}$ e $\mathrm{CO}$ para a mioglobina também é dada pela primeira lei de Haldane:

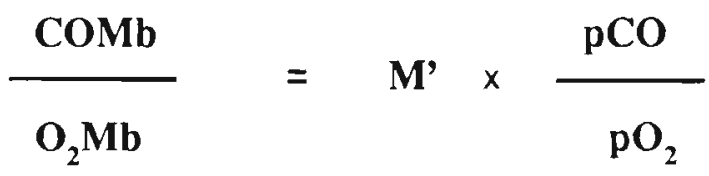

onde $\mathbf{M}$ ' tem valor de aproximadamente 40.

A curva de dissociação da $\mathrm{O}_{2} \mathrm{Mb}$ apresenta a forma hiperbólica e não é influenciada pela concentração hidrogeniônica.

COBURN et al. ${ }^{40}$ determinaram a razão entre o $\mathrm{CO}$ no tecido muscular e no sangüíneo como função da $\mathrm{pO}_{2}$ arterial. Esta razão foi de 1 para o músculo esquelético e de 3 para o cardíaco. Assim, um indivíduo com $10 \%$ de $\mathrm{COHb}$ pode apresentar $30 \%$ de COMb no músculo cardíaco ${ }^{101.127 .137 .}$

As conseqüências funcionais da saturação da $\mathrm{Mb}$ pelo $\mathrm{CO}$ não estão bem definidas ${ }^{187}$. WILKS ${ }^{208}$ relata que a $\mathrm{Mb}$ além de armazenar $\mathrm{O}_{2}$, exerce a funçāo de facilitar a difusão do $\mathrm{O}_{2}$ para o interior das fibras musculares.

Dentre as outras hemeproteínas com as quais o $\mathrm{CO}$ pode se ligar, as de maior importância são o citocromo-oxidase, o citocromo P-450, a catalase e a peroxidase.

A reação do monóxido de carbono com a enzima citocromo-oxidase, na forma reduzida, pode inibir a função respiratória na mitocôndria, diminuindo a utilização total de oxigênio em nível celular. Nestas condições, ocorre a formação de peróxido de hidrogênio $\left(\mathrm{H}_{2} \mathrm{O}_{2}\right)$ e o radical peróxido $\left(: \mathrm{O}_{2}^{-}\right)$, os quais são tóxicos à célula por danificarem a estrutura da membrana. $O$ citocromo-oxidase é responsável pela transferência de elétrons na cadeia respiratória e somente ele pode reagir diretamente com o oxigênio.

COOPER et al. ${ }^{46}$ relataram que a proporção de $\mathrm{CO}$ e $\mathrm{O}_{2}$ necessária à inibiçāo de $50 \%$ da atividade enzimática se aproxima de 1 para o citocromo-oxidase e de 2,2 a 2,8 para o citocromo $\mathrm{a}_{3}$. A importância do efeito do $\mathrm{CO}$ sobre as hemeproteínas intracelulares é ressaltada pela hipótese de serem suas afinidades 
pelo $\mathrm{CO}$ aumentadas em condiçōes de $\mathrm{pO}_{2}$ tissular diminuída.

$\mathrm{O}$ aumento de $10 \%$ de $\mathrm{COHb}$ pode tornar mais significativa, fisiologicamente, tal ligação, ainda que o consumo de $\mathrm{O}_{2}$ possa permanecer inalterado com $50 \%$ de inibição do citocromo $a_{3}{ }^{69}$.

De maneira similar, o citocromo P-450, considerado o mais importante sistema enzimático envolvido nas reaçōes da fase $I$ de biotransformaçāo, pode reagir com o CO. TRELA et al. ${ }^{193.194}$ demonstraram in vitro que as reações das diferentes isoenzimas do citocromo P-450 nāo são influenciadas de igual maneira pelo $\mathrm{CO}$. Este fato explica a variação na inibição da biotransformação de diferentes fármacos após a exposiçāo ao monóxido de carbono ${ }^{176}$.

A reação do $\mathrm{CO}$ com a peroxidase e a catalase é pouco significativa, porque ocorre com as formas reduzidas das enzimas e estas são prontamente oxidadas no organismo.

\subsection{Absorção, distribuição, biotransformação e eliminação}

A absorção do $\mathrm{CO}$ através da membrana alveolar é rápida, sendo praticamente nula nas vias aéreas superiores ${ }^{5.173}$. Cerca de $80 \%$ do $\mathrm{CO}$ absorvido se liga reversivelmente à $\mathrm{Hb}$ e o restante à mioglobina (15\%) e às outras hemeproteínas (5\%), particularmente as hepáticas. Em situação de hipóxia tissular, ocorre aumento na porcentagem de CO ligado à mioglobina ${ }^{6,127.191}$.

A velocidade de absorção e o correspondente aumento na concentraçāo de $\mathrm{COHb}$ dependem, principalmente, do tempo de exposição e da concentração de CO no ar. O tipo de atividade física altera o ritmo respiratório e, conseqüentemente, a ventilação alveolar, fator importante ná absorção pulmonar do CO. No estado de repouso físico é absorvida apenas a metade da quantidade inalada (figura 8) ) $^{5,127.182}$.

Desta forma, numa exposição a concentração constante de $\mathrm{CO}, \mathrm{o}$ tempo necessário para atingir o equilíbrio entre a absorçāo e a eliminaçāo será influenciado pela ventilação pulmonar; o aumento mais significativo na \% de COHb ocorre nas 3 primeiras horas de exposiçāo $0^{5,137.179}$. 


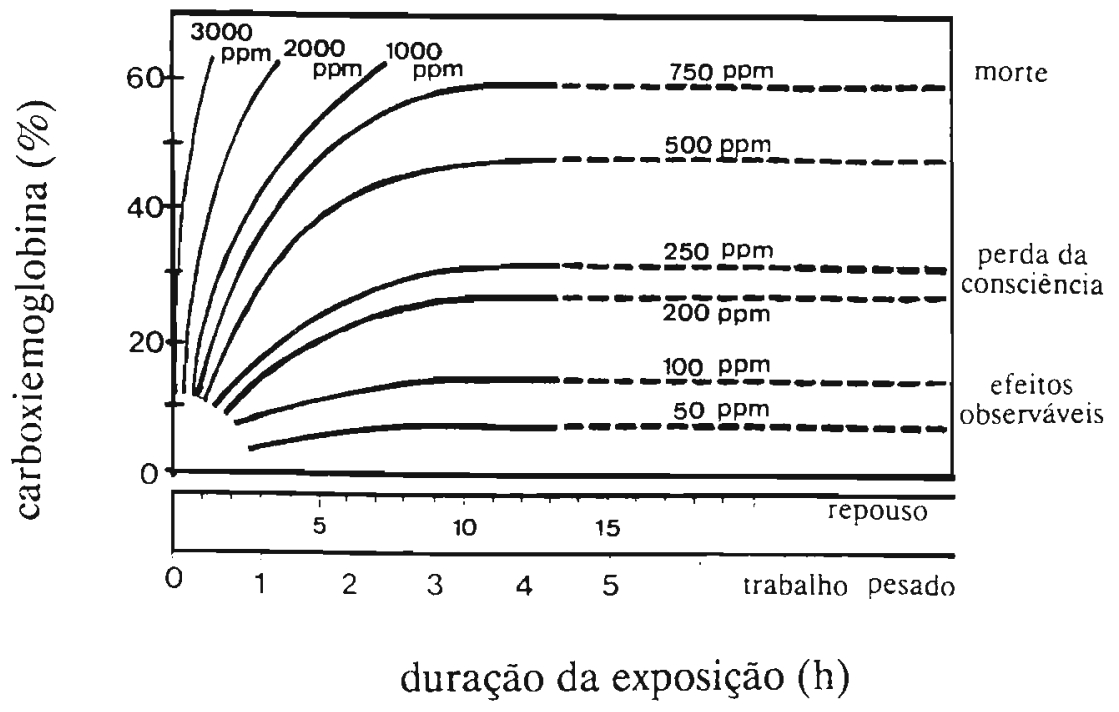
Figura 8 - Relação entre o nível de carboxiemoglobina ( $\mathrm{COHb}$ ) e o tempo de exposição em diferentes concentraçōes de monóxido de carbono nas condições de repouso e de trabalho pesado ${ }^{182}$.

$O$ estudo da cinética da absorção e da eliminaçāo do CO tem fornecido a base necessária para a proposiçāo de modelos matemáticos, que permitem estabelecer relações entre os níveis de exposição e a quantidade de gás no sangue $^{31}$.

Vários autores descrevem equações matemáticas com as quais é possível, considerando-se as variáveis físicas e fisiológicas, estimar a absorção de $\mathrm{CO}$ e a formação da $\mathrm{COHb}$ em função do tempo de exposição ${ }^{39,68.114 .138}$ (anexo II).

A equaçāo de FORBES et al. ${ }^{68}$ é uma das mais simples e, portanto, a mais usada na prática. Esta relaciona a concentração de $\mathrm{COHb}$ como função linear da concentração de $\mathrm{CO}$ no ar inalado [\% CO ] e do tempo de exposição (t) em minutos. Antes de se estabelecer o equilíbrio, a variação na porcentagem de $\mathrm{COHb}$ numa determinada exposiçāo pode ser calculāda por:

\section{$\Delta \mathrm{COHb}(\%)=\mathrm{K} \times[\mathrm{CO}] \times \mathrm{t}$}

O valor de $\mathbf{K}$ varia de acordo com o tipo de atividade física, sendo de 3, 5, 8 e 11 para as condiçōes de repouso, trabalho leve, moderado e pesado, respectivamente, para a concentração de $\mathrm{CO}$ deve ser expressa em \%.

A carboxiemoglobinemia decorrente da produção endógena ou do 
hábito de fumar influi na velocidade de absorção de $\mathrm{CO}$ antes de ser estabelecido o equilíbrio, uma vez que a absorção é regida pelas pressões parciais dos gases no ar e no sangue ${ }^{101}$.

Cerca de $80 \%$ do $\mathrm{CO}$ formado na queima do cigarro, que corresponde aproximadamente a $7 \mathrm{~mL}$ de $\mathrm{CO}$ por cigarro, é absorvido. A concentraçāo de $\mathrm{COHb}$ em indivíduos fumantes varia em média de 3,8 a 6,8\%. Em fumantes de vida sedentária, o nível pode ser ainda mais elevado, tendo sido detectados teores de até $15 \%{ }^{137}$.

Indivíduos idosos podem apresentar diminuição da absorção e/ou eliminação pela alteração da capacidade de difusão da membrana alveolar, ocasionada por enfisema ou outra doença pulmonar obstrutiva crônica ${ }^{137}$.

Menos de $1 \%$ do $\mathrm{CO}$ absorvido é oxidado a dióxido de carbono, e eliminado pelos pulmōes, juntamente com o agente tóxico inalterado ${ }^{9,16}$.

O monóxido de carbono não se acumula no organismo sendo eliminado após cada exposição, mantendo o equilíbrio com o ar ambiente. Se este não contiver $\mathrm{CO}$, a sua eliminação dar-se-á completamente, até os níveis de carboxiemoglobinemia decorrentes da produção endógena ${ }^{104.179}$.

Em contraste às detalhadas informações sobre a absorção de $\mathrm{CO}$, existem poucos estudos experimentais relativos à sua eliminação em humanos ou em animais. Entretanto, os mesmos fatores determinantes da absorção devem atuar, também, na eliminação ${ }^{137}$.

A maioria dos autores aceita que a eliminação se faz segundo uma curva exponencial. Os valores da meia-vida biológica ( $\mathrm{T} 1 / 2$ ), para a condição de repouso, variam de 3 a 4 horas; com a inalação de oxigênio puro, esse tempo cai para 1 hora ou para 23 minutos se a pressão for de 3 atmosferas $^{16,74,127,202}$.

MALORNY et al ${ }^{119}$ avaliaram a influência de diferentes composições de ar inspirado no tempo de eliminaçāo de $50 \%$ do $\mathrm{CO}$ em animais com elevada carboxiemoglobinemia (60 a 74\%). As T 1/2 de eliminação obtidas foram de 41, 28 e 19 minutos, respectivamente, para as condições de inalação de ar ambiente, oxigênio puro e mistura de $\mathrm{O}_{2}$ com $5 \%$ de $\mathrm{CO}_{2}$.

PETERSON \& STEWART ${ }^{146}$ expuseram 39 voluntários a 
concentraçōes de CO que variaram de 1 a 1000 ppm, durante 0,25 a 24 horas, com colheita de amostras de sangue até 23 horas após a exposição. Os autores reportaram $T$ 1/2 de eliminação média de 5,3 horas concluindo que a mesma não depende do teor inicial de $\mathrm{COHb}$ no sangue, da duração da exposição, do número de exposições ou da concentração no ar inalado 5 .

As evidências experimentais sugerem que a velocidade de eliminação varia de acordo com o sexo, sendo maior para as mulheres. RODE et al. ${ }^{156}$ criticaram o fato de se determinar a $\mathrm{T} 1 / 2$ de eliminação indistintamente para homens e mulheres. Com base em análise de dados de indivíduos fumantes propuseram valores de 3,7 horas para homens e de 2,5 horas para mulheres.

A meia-vida biológica da $\mathrm{COHb}$ varia inversamente com a $\mathrm{pO}_{2}$ no ar ambiente. Em indivíduo adulto, sadio, sedentário e ao nível do mar, é de 4 a 5 horas, podendo ser reduzida por um aumento da ventilação alveolar $r^{4.16,160}$.

\subsection{Efeitos tóxicos}

A formação da carboxiemoglobinemia e o aparecimento de sinais e sintomas clínicos depende, principalmente, da concentração do monóxido de carbono no ar, do tempo de exposição, do tipo de atividade física e da susceptibilidade individual. Os efeitos do monóxido de carbono estão diretamente relacionados à concentração de carboxiemoglobina no sangue e com o grau de hipóxia ou anoxia tissular (tabela II).

A intoxicação aguda, observada em acidentes ou suicídios, é relatada por vários autores ${ }^{149,174,203}$. A exposição a concentrações elevadas de CO pode levar à perda da consciência quase que instantaneamente. Concentrações de 10000 a 40000 ppm de $\mathrm{CO}$ levam à morte em poucos minutos e acima de $50000 \mathrm{ppm}$ pode ocorrer morte por arritmia cardíaca antes do aumento significativo da carboxiemoglobinemia ${ }^{127,160}$. A tabela III relaciona o tempo mínimo de exposição, em diferentes concentrações de CO no ar, aos sinais e sintomas observados.

Os órgãos críticos à ação de $\mathrm{CO}$ são o cérebro e o coração, que dependem de suprimento contínuo e ininterrupto de oxigênio. O coração é afetado por dois mecanismos: trabalho aumentado para prover a demanda periférica de oxigênio e redução no seu próprio suprimento ${ }^{102.104,187,191}$. 
Complicaçōes neurológicas ou cardiovasculares podem resultar de episódios de intoxicação aguda, evidentes após a recuperação do paciente ${ }^{86}$.

Tabela II - Principais sinais e sintomas relacionados à carboxiemoglobinemia ${ }^{104}$.

\begin{tabular}{|c|c|}
\hline$\underset{(\%)}{\operatorname{carboxiemoglobinemia}}$ & sinais e sintomas ${ }^{*}$ \\
\hline 0,3 a 0,7 & $\begin{array}{l}\text { Nenhum sinal ou sintoma. Niveis normais de } \mathrm{COHb} \\
\text { devido à produção endógena. }\end{array}$ \\
\hline 2,5 a 5,0 & $\begin{array}{l}\text { Nenhum sintoma. Aumento compensatório no fluxo } \\
\text { sanguíneo a certos órgãos vitais. Pacientes com doença } \\
\text { cardiovascular grave podem ter necessidade da reserva } \\
\text { compensatória. Angina pectoris é provocada ao menor } \\
\text { esforço físico. }\end{array}$ \\
\hline 5,0 a 10,0 & Percepção visual diminuída. \\
\hline 10,0 a 20,0 & $\begin{array}{l}\text { Tensão frontal. Ligeira cefaléia. Resposta anormal ao } \\
\text { estímulo visual. Possivelmente falta de respiração ao } \\
\text { esforço físico. Pode ser letal para o feto e para pacientes } \\
\text { com doença cardíaca grave. }\end{array}$ \\
\hline 20,0 a 30,0 & $\begin{array}{l}\text { Cefaléia leve ou prolongada e latejamento nas têmporas. } \\
\text { Rubor. Náusea. Destreza manual fina anormal. }\end{array}$ \\
\hline 30,0 a 40,0 & $\begin{array}{l}\text { Cefaléia forte, vertigem, náusea e vômito. Fraqueza. } \\
\text { Irritabilidade e diminuição do discernimento. }\end{array}$ \\
\hline 50,0 a 60,0 & $\begin{array}{l}\text { Possivelmente coma com convulsōes intermitentes e } \\
\text { respiração tipo "cheyne-stokes". }\end{array}$ \\
\hline 60,0 a 70,0 & $\begin{array}{l}\text { Coma com convulsōes intermitentes. Respiração } \\
\text { diminuída e ação cardíaca. Possivelmente morte. }\end{array}$ \\
\hline 70,0 a 80,0 & $\begin{array}{l}\text { Pulso fraco e respiração lenta. Depressão do centro } \\
\text { respiratório levando à morte. }\end{array}$ \\
\hline
\end{tabular}

$\left({ }^{*}\right)$ Existe considerável variação individual na ocorrência dos sintomas. 
Tabela III - Tempo mínimo de exposição, em minutos, às diferentes concentraçōes de monóxido de carbono no ar para o aparecimento de sinais e sintomas ${ }^{85,104}$.

\begin{tabular}{|c|c|c|c|c|c|c|c|}
\hline \multirow{2}{*}{$\begin{array}{l}\text { sinais e } \\
\text { sintomas }\end{array}$} & \multirow[b]{2}{*}{200} & \multicolumn{6}{|c|}{ concentração de monóxido de carbono no ar (ppm) } \\
\hline & & 500 & 800 & 1600 & 3200 & 6400 & 12800 \\
\hline dor de cabeça & 50 a 180 & 20 a 120 & 45 & 20 & 5 a 10 & 1 a 2 & \\
\hline tontura e náusea & & 20 a 120 & 45 & 20 & 5 a 10 & 1 a 2 & \\
\hline perda da consciência & & & 120 & 120 & 30 & 15 & 1 a 3 \\
\hline morte & & & & 120 & 30 & 15 & 1 a 3 \\
\hline
\end{tabular}

Estudos histopatológicos, em casos fatais, mostram a predominância de lesões no tecido branco do SNC, ao contrário das lesōes em nível neuronal encontradas em pessoas após intoxicações não fatais ${ }^{104.141,191}$. Pneumonia pode ser desenvolvida poucas horas ou dias após o episódio da intoxicação; também pode ocorrer glicosúria ou albuminúria temporária. Distúrbios renais agudos que complicam a recuperação do intoxicado são de rara ocorrência, assim como as manifestações cutâneas. Estudos com animais indicam que a hipotensāo pelo $\mathrm{CO}$ pode comprometer o fluxo sangüíneo e exacerbar a acidose metabólica ${ }^{104,141}$.

Após uma intoxicação aguda pelo $\mathrm{CO}$, o paciente apresenta algumas vezes, edema pulmonar ou cerebral de extensão variável, com dano irreversível ${ }^{141,191}$. Após a recuperação, pode apresentar efeitos retardados como a alteração do comportamento, confusão, desorientação, febre e distúrbios neurológicos. Estes são, principalmente; ataxia, tremores lembrando a doença de Parkinson, incoordenaçāo e fraqueza, com evolução progressiva, podendo culminar com a morte em poucas semanas ${ }^{8,104}$. Nos primeiros estágios da intoxicação, o paciente parece pálido; posteriormente, a pele, a base das unhas e as mucosas podem se tornar vermelho-cereja devido à $\mathrm{COHb}$ aumentada. Este sinal pode ser observado em concentraçōes acima de $30 \%$ de COHb embora não seja confiável nem constante. $O$ paciente apresenta pulso acelerado e hiperpnéia leve ou ausente, mesmo em níveis superiores a $50 \%$ de $\mathrm{COHb}^{104,141}$.

As intoxicações que não levam à perda de consciência podem, no entanto, resultar em morte de células cerebrais com alguns sintomas, tais como, cefaléia, tontura, irritabilidade e prejuízo da memória; pode ainda sobrevir mudança de personalidade ou estado de fraqueza nos membros. Grande número de casos não chegam a ser diagnosticados como intoxicação pelo $\mathrm{CO}^{89}$. 
PENNY ${ }^{141}$ concluiu que a intoxicação aguda por CO resulta em progressiva hipotensāo, provavelmente como resultado da profunda vasodilatação periférica. O batimento cardíaco usualmente aumenta no início da exposição, diminuindo com o aumento da \% de COHb. A taquicardia, presumivelmente, resulta da estimulação simpática geral como resposta reflexa da queda da pressão arterial, enquanto a bradicardia parece ser devida à hipoxia no miocárdio.

Ao contrário da intoxicaçāo aguda, a ocorrência de intoxicação em exposição prolongada a baixas concentrações de $\mathrm{CO}$ é muito discutida na literatura e pouco documentada ${ }^{102.170 .203}$. HANIG \& HERMAN $^{86}$ relatam que nestas condições o CO pode afetar a estrutura dos vasos sangüíneos, o que pode promover o desenvolvimento da ateroesclerose.

Os estudos experimentais de exposição a longo prazo em animais são de difícil extrapolação para o homem, pois, além das diferentes respostas interespécies, há variaçāo na ventilação pulmonar que altera significativamente a absorção de $\mathrm{CO}^{111}$.

Indivíduos que são repetidamente expostos ao $\mathrm{CO}$ podem desenvolver mecanismos de compensação semelhantes àqueles submetidos à hipóxia decorrente de altitudes elevadas ${ }^{178.204}$.

Os principais mecanismos de adaptação à hipóxia envolvem alterações na curva de dissociação do oxigênio da hemoglobina, no fluxo sangüíneo e no teor de hemoglobina. O desvio à direita, observado em indivíduos que moram em altitudes elevadas, pode ser provocado pelo aumento da concentração de 2,3-difosfoglicerato na célula vermelha. Desvio similar é observado em pacientes com doenças arteriocoronárias. A liberação de $\mathrm{O}_{2}$ para os tecidos periféricos pode ser preservada por aumento de fluxo sangüíneo, que constitui o principal mecanismo de adaptação à hipóxia ${ }^{12,204}$.

Nos últimos anos vêm sendo realizados estudos sobre os efeitos do monóxido de carbono em exposiçōes prolongadas a baixas concentrações (teores de $\mathrm{COHb}<10 \%$ ) em indivíduos sadios ou com distúrbios cardiovasculares ou pulmonares $^{52,104,125}$. Os sistemas nervoso central, cardiorrespiratúrio e límbico são os mais estudados nessas condições. No cêrebro as áreas mais susceptíveis são os gânglios basais e o hipotálamo ${ }^{8,86}$.

O neurônio é uma célula de alta taxa de metabolismo, mas com pouca 
capacidade para metabolismo em anaeróbiose. O consumo de oxigênio dos neurônios é dez vezes maior que o do tecido glial. Os danos aos neurônios começam poucos minutos após a interrupção do fluxo sangüíneo ao cérebro e a morte de alguns neurônios ocorre anteriormente à falta total de $\mathrm{O}_{2}$. Certas células são mais susceptíveis à anoxia de que outras; em ordem crescente têm-se neurônios, oligodentrócitos, astrócitos, mieroglia e células do endotélio capilar ${ }^{8}$.

Episódios repetidos de anoxia afetam a barreira hematencefálica e conduzem ao desenvolvimento de esclerose difusa da matéria branca, ou leucoencefalopatia. Ainda em condições de hipóxia, o coração é solicitado a aumentar a força de contraçāo e a freqüência cardíaca no intuito de suprir o fornecimento do oxigênio aos tecidos periféricos; este aumento na atividade do miocárdio demanda quantidade de oxigênio ainda maior através da circulaçāo coronáriana $^{132}$.

Em condição de repouso, os tecidos periféricos absorvem, em média, $25 \%$ do conteúdo de oxigênio e o miocárdio, $75 \%$. O sangue venoso dos tecidos periféricos tem pO2 de $40 \mathrm{mmHg}$, enquanto o da circulação coronária é de $20 \mathrm{mmHg}$. Desta forma, o metabolismo aeróbico do miocárdio é mantido até determinada condição de hipóxia. Nesta condição, o miocárdio tende a aumentar somente o fluxo sangüíneo, enquanto que os tecidos periféricos aumentam a absorçāo de oxigênio. Assim sendo, um indivíduo com doença coronariana torna-se mais susceptível à hipóxia do tecido muscular cardíaco ${ }^{132}$.

A influência das variaçōes circadianas nos efeitos tóxicos das substâncias entre estas, o monóxido de carbono, tem sido amplamente estudada nos últimos anos, sendo reportadas variaçōes tanto do ponto de vista da toxicocinética (capacidade de difusão pulmonar ao $\mathrm{CO}$ e ventilação pulmonar) como da toxicodinâmica (concentração de hemoglobina e ciclo sono-vigília) 37.117.154,184.185.192.

\subsection{População susceptível}

A população considerada susceptível aos efeitos do monóxido de carbono pode ser dividida em dois grupos. O primeiro grupo, caracterizado pela susceptibilidade individual, tem capacidade diminuida de transporte de $\mathrm{O}_{2}$ ou elevada ventilação pulmonar e o segundo grupo é identificado pela exposição ao $\mathrm{CO}$ em altitudes elevadas ${ }^{65}$. 
Os efeitos do CO e a hipoxia induzida pela altitude são similares. A diminuição da pressão parcial de $\mathrm{O}_{2}$ no ar ambiente e o aumento de $\mathrm{COHb}$ no sangue produzem efeitos fisiológicos por mecanismos diferentes, com relação à $\mathrm{pO}_{2}$ sangüínea, à afinidade da $\mathrm{Hb}$ pelo $\mathrm{O}_{2}$ e ao grau de saturação da hemoglobina. A hipóxia provocada pelo CO desloca a curva de dissociação da oxiemoglobina para a esquerda, enquanto a diminuição da $\mathrm{pO}_{2}$ do ar ambiente desloca-a para a direita ${ }^{104,137}$.

A atividade física em altitudes elevadas requer acentuada ventilação pulmonar, o que favorece a absorção e a subseqüente eliminação de $\mathrm{CO}$. No entanto, a retenção de $\mathrm{CO}$ é favorecida pela menor pressão parcial de oxigênio no ar ambiente. As populações que vivem em tais altitudes, além de mais susceptíveis aos efeitos do $\mathrm{CO}$, estāo sujeitas a maior exposição ocasionada pela combustão incompleta da matéria carbonada em atmosfera rarefeita.

Os portadores de doença cardiovascular ou respiratória, anêmicos ou portadores de hemoglobinopatias, hipertireodismo, gestantes, fetos, crianças e idosos constituem grupos de indivíduos susceptíveis ao $\mathrm{CO}^{102.191}$.

Pacientes com doenças cardiovasculares e/ou respiratórias, segmento significativo da população em geral e de grande importância na exposição ocupacional, apresentam deficiência de oxigenação dos tecidos devida à própria doença e à ineficiência dos mecanismos de compensação, com o aumento de fluxo sangüíneo ${ }^{11,191}$.

O individuo anêmico tem, além do prejuízo inicial no transporte de $\mathrm{O}_{2}$, maior porcentagem de $\mathrm{COHb}$ em relação ao não anêmico, para a mesma pressão de $\mathrm{CO}$ no ar ambiente.

As crianças e as gestantes constituem também grupos susceptíveis, principalmente à exposiçāo aguda ao $\mathrm{CO}$, por terem uma ventilação pulmonar aumentada. Adicionalmente, as gestantes têm produção endógena do $\mathrm{CO}$ maior e uma tendência à anemia ${ }^{137}$.

A velocidade de absorção e eliminação do $\mathrm{CO}$ pelo feto é equivalente a $1 / 3$ da do adulto ${ }^{5}$. Na exposição a curto prazo a concentraçāo máxima de $\mathrm{COHb}$ é menor no feto que na mãe, mas por outro lado, é mantida por tempo maior. Os efeitos tóxicos observados no feto são acentuados pela baixa $\mathrm{pO}_{2}$ arterial e por não 
existir, na circulaçāo fetal, mecanismos de compensaçāo ${ }^{137}$.

\subsection{Monitorização biológica}

A monitorização biológica é definida como " a avaliação sistemática e periódica do toxicante ou de seus produtos de biotransformação em material biológico, para estimar a exposição e o risco à saúde do indivíduo, por comparação dos resultados com um valor de referência apropriado" 213

É necessário o conhecimento da toxicocinética e/ou da toxicodinâmica do xenobiótico para se determinar o indicador biológico apropriado à avaliação do risco da exposição $0^{87,109}$. Uma vez estabelecido o IB, a monitorização é condicionada à facilidade de se obter e conservar o material biológico em que se encontra o indicador, ao conhecimento dos fatores que interferem na interpretação dos resultados, à disponibilidade de método de análise, exato, preciso e sensível e à existência de padrōes de segurnaça (Limites biológicos de exposição) ${ }^{129}$.

\subsubsection{Indicadores biologicos e seus limites}

O indicador biológico da exposição ao monóxido de carbono mais utilizado é a carboxiemoglobina no sangue ${ }^{16.32}$. Este parâmetro constitui excelente indicador, tanto de dose interna quanto de efeito. Como indicador de dose interna reflete a absorção e a quantidade do xenobiótico ligado ao seu principal sítio de ação e exposição recente ${ }^{18}$.

Outro indicador biológico é o monóxido de carbono no sangue. Visto que a quantidade de $\mathrm{CO}$ dissolvida no sangue representa uma fração desprezível, em relação à quantidade ligada à hemoglobina, a porcentagem de $\mathrm{COHb}$ pode ser estimada indiretamente, pela medida do CO.

A determinação da concentração de $\mathrm{CO}$ no ar expirado (ar alveolar), não é muito usada devido às dificuldades da colheita da amostra e outras desvantagens relacionadas à metodologia analítica, que serão descritas no item 2.7.2. . O monóxido de carbono no ar exalado não deve ser usado como indicador biológico de exposição em indivíduos com doenças pulmonares crônicas.

Para interpretar os resultados obtidos na monitorização biológica da 
exposição ao $\mathrm{CO}$ é necessário o conhecimento dos valores encontrados em indivíduos não expostos a esse gás. Abaixo, são mostrados estes níveis em algumas situações $5,105,147,181$ :

\begin{tabular}{|c|c|c|}
\hline$\%$ de $\mathrm{COHb}$ & $\begin{array}{l}\text { CO no ar } \\
\text { exalado } \\
\text { (ppm) }\end{array}$ & observações \\
\hline \multicolumn{3}{|l|}{ produção endógena } \\
\hline $0,4-0,7$ & $<2$ & \\
\hline $4-6$ & 30 & anemia hemolítica \\
\hline \multicolumn{3}{|l|}{ exposição : } \\
\hline \multicolumn{3}{|l|}{ à fumaça de cigarro } \\
\hline $5-6$ & $30-35$ & um maço por dia \\
\hline $7-9$ & $45-50$ & $\begin{array}{l}\text { dois a três maços por } \\
\text { dia }\end{array}$ \\
\hline \multicolumn{3}{|l|}{ em áreas urbanas } \\
\hline$>5$ & 30 & $\begin{array}{l}\text { concentração de CO no } \\
\text { ar ambiente de } 25 \text { ppm } \\
\text { (em inversões térmicas } \\
\text { pode chegar a } 100 \mathrm{ppm} \text { ) }\end{array}$ \\
\hline $\begin{array}{c}\text { ao cloreto de metileno } \\
3-5\end{array}$ & $15-30$ & $\begin{array}{l}\text { concentração de } 100 \mathrm{ppm} \text { de } \\
\mathrm{CH}_{2} \mathrm{Cl}_{2} \text { no ar. }\end{array}$ \\
\hline
\end{tabular}

No âmbito ocupacional, em nosso país, a Portaria 3214/78 do Ministério do Trabalho fixa o limite de tolerância (LT) para o CO no ambiente de trabalho em $39 \mathrm{ppm}\left(43 \mathrm{mg} / \mathrm{m}^{3}\right)$, considerando a exposiçāo de até 48 horas semanais. Este valor é baseado na concentração de $\mathrm{CO}$ no ar ambiente que não resulte em nível sangüíneo de carboxiemoglobina superior a $5 \%$, sendo este considerado o Limite de Tolerância Biológico (LTB) para nāo-fumante. Os valores para os outros indicadores não constam na legislação brasileira.

As amostras de sangue, para a determinaçāo dos reores de COHb ou de $\mathrm{CO}$ no sangue, devem ser colhidas no final da jornada de trabalho ou durante a 
exposição a altas concentrações.

Não existem dados disponíveis que possam indicar um valor limite adequado à população susceptível, como em trabalhadores com atividade física exagerada, ou portadores de doenças cardiovasculares e/ou respiratórias crônicas, em gestantes e em populaçōes localizadas em altitudes elevadas. Desta forma, aconselha-se a manutenção da vigilância médica paralelamente à monitorização da exposição.

O limite biológico de exposição ao $\mathrm{CO}$ no ar alveolar, recomendado pela ACGIH, é de $40 \mathrm{ppm}^{5.95}$. Para refletir a exposição ao CO, as amostras devem ser colhidas no final da jornada de trabalho e não antes de 3 horas após o início desta ou até 10 minutos após o final da jornada de trabalho.

A monotorização biológica fornece resultados complementares à monitorização ambiental, esta última auxília na avaliação da exposição e envolve estratégias de amostragem que devem ser criteriosamente estabelecidas para que os resultados sejam significativos e possam ser comparados aos padrōes de segurança 10.28.34.63.91.145.152.155. Os limites máximos permissíveis de $\mathrm{CO}$ no ar e os limites biológicos de exposição são mostrados nos anexos III e IV.

\subsubsection{Metodologia analítica}

A disponibilidade de metodologia analítica adequada à quantificação de determinado indicador biológico é condição importante na monitorização biológica ${ }^{108}$. A escolha do método deve ser fundamentada nos parâmetros de especificidade, precisão, exatidão, sensibilidade, praticabilidade, tempo de execução e custo.

A técnica de colheita da amostra tem papel importante, e quando não executada adequadamente, pode invalidar um resultado analiticamente exato ${ }^{4}$.

A colheita do ar exalado requer técnica complexa e não é tão bem definida como a colheita da amostra de sangue. A porção de ar amostrado bem como a ventilação pulmonar do indivíduo modificam significativamente os resultados obtidos. Por isso alguns autores sugerem a análise simultânea de alguns parâmetros que sejam indicadores da taxa de respiraçāo, como por exemplo, o $\mathrm{CO}_{2}$ $60,21,211$. 
Pelo fato do ar na via respiratória não ser homogêneo na sua composição, a técnica mais comum envolve a colheita de ar alveolar de indivíduo em repouso, com freqüência respiratória normal. Para tal, o indivíduo deve, após uma inspiração total, manter-se em apnéia durante 20 segundos e, em seguida, proceder uma prolongada e ininterrupta expiração. A porçāo final desta expiraçāo forçada, cerca de $200 \mathrm{~mL}$, corresponde ao ar alveolar ${ }^{61,70,112.120}$.

Os tipos de coletores variam desde sacos plásticos especiais a cateter nasofaríngeo. Outros, como tubos de vidro, tubos com seringas acopladas (tubo de Haldane-Priestley), tubos de alumínio e máscaras faciais sāo descritos por vários autores, sendo quase que específicos a cada $\mathrm{um}^{84,169,197,211}$.

As dificuldades na colheita da amostra do ar exalado juntamente com o custo elevado e a complexidade dos amostradores dificultam seu emprego em análises de rotina. Além disso, são requeridas técnicas de quantificação muito sensíveis visto os baixos teores de $\mathrm{CO}$ neste tipo de amostra.

A concentração de $\mathrm{CO}$ seja no ar alveolar, no ar ambiente ou no sangue é determinada, praticamente, com as mesmas técnicas de identificação, sendo de uso mais comum: a espectroscopia de absorção de infravermelho não dispersiva (IRND) na análise contínua de $\mathrm{CO}$ no ar ambiente; a cromatografia gasosa com detectores de ionização de chama ou de condutividade térmica na análise instantânea do gás no ar ambiente, no ar alveolar ou liberado da $\mathrm{COHb}^{26}$; a colorimetria, técnica semiquantitativa, na determinação instantânea no ar ambiente com o uso de tubos indicadores ${ }^{59,64,122}$.

A colheita de sangue apresenta a desvantagem de ser processo invasivo e requerer pessoas qualificadas para executá-la. $\mathrm{Na}$ determinaçāo da carboxiemoglobinemia a amostra pode ser de sangue venoso ou arterial e deve ser colhida em recipiente fechado contendo anticoagulante (heparina ou o sal dissódico do ácido etilenodiaminotetracético) sendo o mais usado os tubos para colheita a vácuo ${ }^{14,29,33,41,43,150,168}$.

A carboxiemoglobinemia pode ser determinada diretamente por métodos espectrofotométricos $20,29,53,118,142,158$, ou indiretamente, pela quantificação do $\mathrm{CO}$ liberado da $\mathrm{COHb}^{38,41,49,92,133}$. 
A tabela IV reune os principais métodos de análise de $\mathrm{COHb}$ no sangue. O seu número é restrito devido à escassez de trabalhos de desenvolvimento e padronização. A maioria compara os resultados obtidos por dois ou mais métodos, previamente descritos, ou aplica a metodologia a determinados grupos de indivíduos expostos ao monóxido de carbono.

Os métodos espectrofotométricos diferem entre si nas faixas de comprimento de onda de leitura das absorvâncias, no número de derivados hemoglobínicos quantificados e, principalmente, no processo de quantificaçāo. Este tem por base o quociente das absorções em determinados comprimentos de onda ou o espectro de absorção diferencial, ou ainda, o espectro derivativo.

Os métodos que envolvem a relação das absorçōes máxima e mínimas dos pares carboxiemoglobina e oxiemoglobina ou carboxiemoglobina e hemoglobina reduzida são os mais comuns ${ }^{20.56 .99,103.150}$.

RODKEY et al. ${ }^{158}$ propuseram um método com base na comparação dos espectros de $\mathrm{Hb}$ reduzida $\left(\mathrm{Hb}^{\text {red }}\right)$ e de $\mathrm{COHb}$. A reduçāo das hemoglobinas para a otenção do sistema bicomponente, é obtida pelo uso do hidrossulfito de sódio (ditionito), e a absorvância determinada em 420 e $432 \mathrm{~nm}$. As razões das absorvâncias nestes comprimentos de onda sāo particularmente sensíveis à quantidade de $\mathrm{COHb}$ presente na amostra. A porcentagem de $\mathrm{COHb}$ é calculada correlacionando-se as absorvâncias da amostra com os coeficientes de absortividade molar da $\mathrm{Hb}^{\text {red }}$ e da $\mathrm{COHb}$ nos comprimentos de onda apropriados. O método é trabalhoso em termos de cálculos matemáticos, mas os resultados são exatos e reprodutíveis ${ }^{158}$.

WIGFIED et al. ${ }^{207}$ reproduziram o método de RODKEY et al. considerando-o de escolha frente a outros por eles estudados. BEUTLER \& WEST ${ }^{20}$ introduziram modificaçōes que permitiram a exposição da amostra ao ar, o que tornou a técnica mais prática.

O segundo processo de quantificaçāo nos métodos espectrofotométricos é o da obtenção de espectro diferencial, desenvolvido por vários autores ${ }^{29,43,66,186}$. O método descrito por COMMINS \& LAWTHER $^{43} \mathrm{em}$ 1965, revalidado por LILY ${ }^{115}$ em 1972, tem a vantagem de utilizar somente $0,01 \mathrm{~mL}$ de sangue que pode ser obtido por punção digital. A concentraçāo de $\mathrm{COHb}$ é calculada pela diferença de dois espectros de absorção na faixa de comprimento de onda de 415 a $430 \mathrm{~nm}$. A figura 9 mostra os espectros de absorção das soluçōes de oxiemoglobina e carboxiemoglobina e o espectro diferencial. 
Tabela IV - Principais métodos para determinação da carboxiemoglobinemia

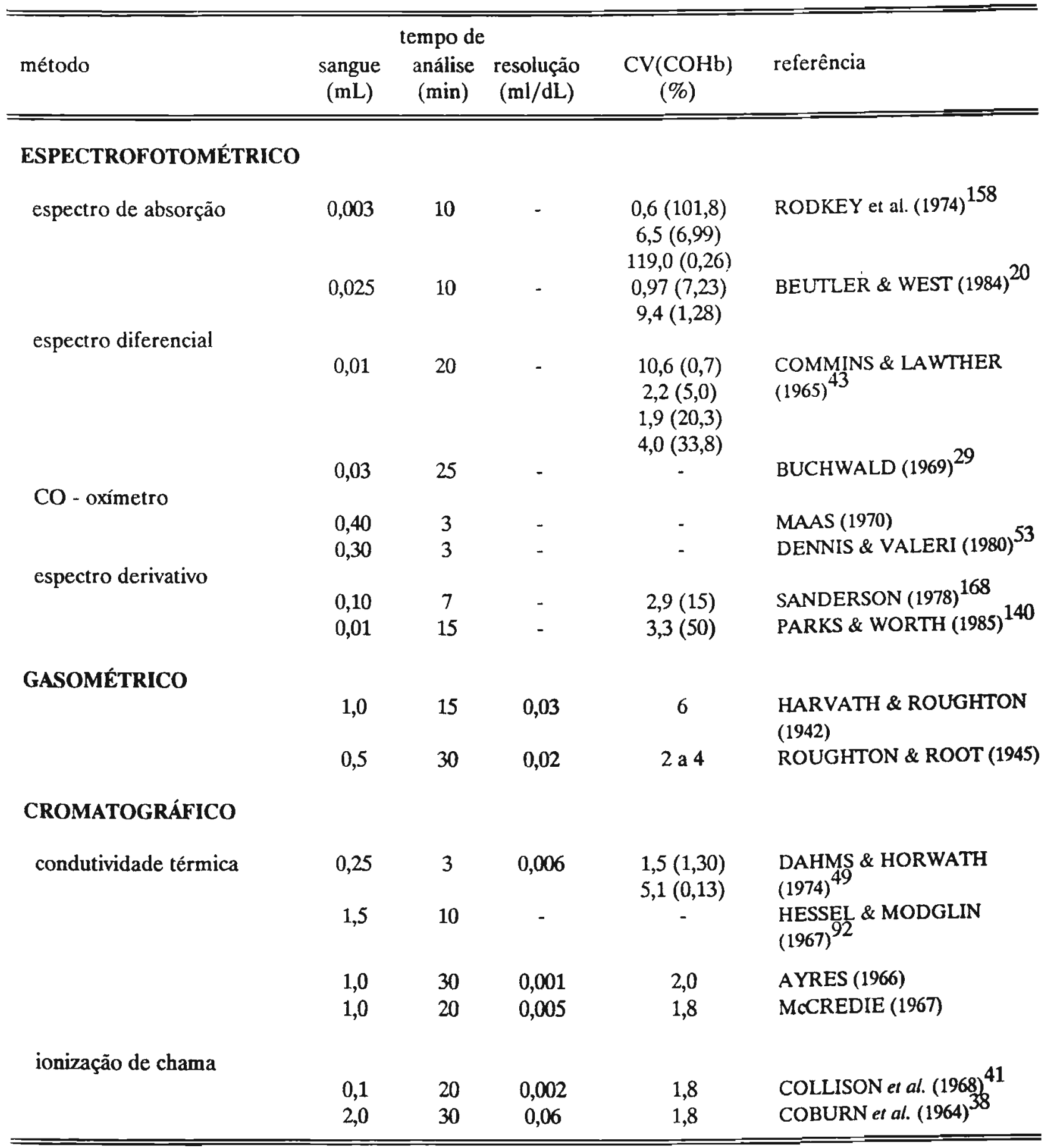

adaptado de DAHMS \& HORVATH ${ }^{49}$ 


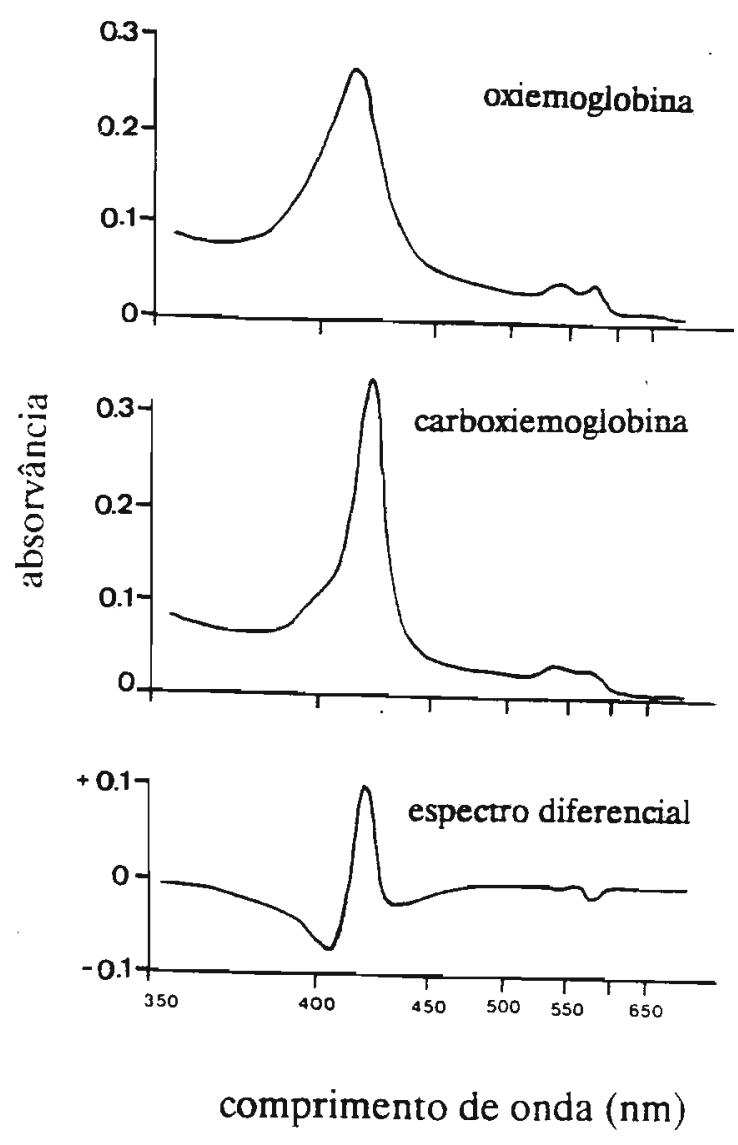

Figura 9 - Espectro de absorção das soluções de oxiemoglobina, carboxiemoglobina e o espectro diferencial ${ }^{41}$.

COMMINS \& LAWTHER obtiveram boa correlaçāo $(r=0,94)$ entre os valores de $\mathrm{COHb}$ esperados e os encontrados. WIGFIELD et al. ${ }^{207}$, estudando este método, relataram nāo obter a mesma linearidade reportada pelos autores, detectando valores elevados para baixas \% de $\mathrm{COHb}$, valores baixos para as altas concentrações e valores equivalentes para teores médios de $\mathrm{COHb}$.

Este método foi mais tarde simplificado por $\operatorname{BUCHWALD}^{29}(1969)$. FENTON $^{66}(1972)$ aponta que falsos resultados podem ser encontrados pela presença de traços de detergente, levando a erros de até $200 \%$.

Os métodos chamados multicomponentes usam a técnica diferencial e permitem a determinação simultânea da concentração de vários derivados hemoglobínicos, incluindo hemoglobina reduzida, oxiemoglobina, carboxiemoglobina e metaemoglobina ${ }^{78,201,215}$. 
Esta técnica, automatizada, é encontrada no aparelho CO-oxímetro, usado por vários autores ${ }^{45.53,200.214}$, principalmente, em estudos com grande número de amostras. O aparelho determina simultâneamente a hemoglobina, oxiemoglobina e metaemoglobina e requer apenas $300 \mu \mathrm{L}$ de sangue. $\mathrm{O}$ conteúdo total de $\mathrm{O}_{2}$ é também fornecido pelo aparelho. A leitura das absorvâncias é feita em quatro comprimentos de onda 535,0,585,2, 594,5 e 626,6 nm, à temperatura controlada de $37^{\circ} \mathrm{C}$. A figura 10 mostra a disposiçāo eletrônica e mecânica do aparelho $^{53}$.

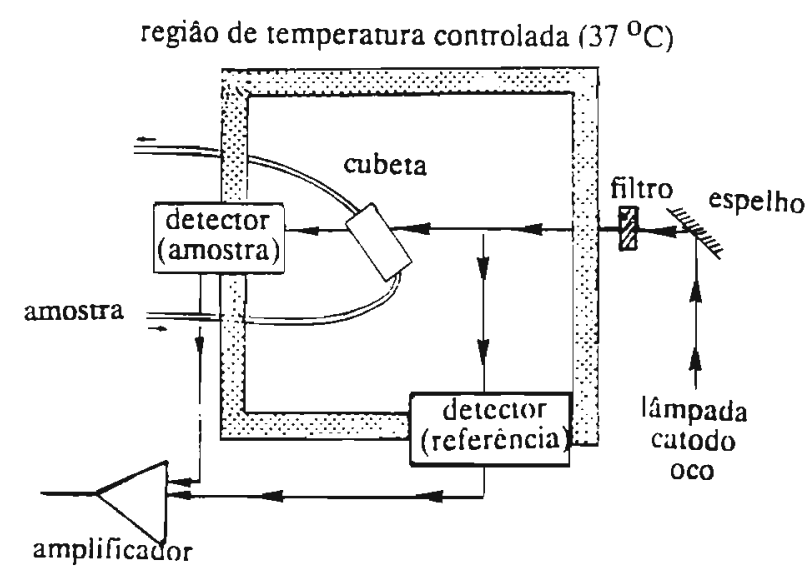

Figura 10 - Esquema simplificado do CO-oxímetro (IL-282), usado na determinação da carboxiemoglobinemia ${ }^{53}$.

Esse tipo de análise segue a lei de Lambert-Beer. Se os componentes da mistura não interagirem, a soluçāo que contenha n componentes, com espectros de absorçāo suficientemente diferentes, pode ser analisada pela medida da absorvância em pelo menos n comprimentos de onda. A concentração de cada componente da mistura pode ser determinada se a absortividade molar de cada um for conhecida ${ }^{77}$.

Apesar de prático, o CO-oxímetro apresenta algumas desvantagens. BARETA et $a l^{14}$, relatam que um problema freqüentemente encontrado é a dificuldade do ajuste do zero entre as leituras, por deficiência no processo de limpeza automática da câmara da amostra. A presença da hemoglobina fetal, nesta técnica, pode hiperestimar os resultados da \% de $\mathrm{COHb}^{214}$.

Nos últimos anos, tem sido desenvolvida a técnica de derivação matemática dos espectros de absorção com o objetivo de evidenciar a absorção 
mínima de determinado componente presente em misturas com absorção de fundo elevada, aumentando a seletividade da técnica. Atualmente são disponíveis espectrofotômetros que permitem obter até a quarta derivada do espectro de absorçāo, automaticamente.

Os procedimentos com derivação dos espectros de absorção foram desenvolvidos com o intuito de aumentar a seletividade dos métodos espectrofotométricos ${ }^{121,124,140.168 .188}$.

A primeira derivada pode eliminar ou minorar a contribuição da absorvância de fundo que não varie com o comprimento de onda. Adicionalmente, a $2^{\mathrm{a}}$ derivada tem a vantagem de diminuir ou eliminar a influência das substâncias com espectros de absorção que variam com o comprimento de onda, cujas curvaturas são pequenas quando comparadas às dos espectros de interesse. Em outras palavras, um componente com um pico de absorção achatado ${ }^{124}$.

PERRIGO \& YOYNT ${ }^{142}$ estudaram vários métodos que usam a técnica de derivação na medida espectrofotométrica da $\mathrm{COHb}$ na região Soret $(380$ a $450 \mathrm{~nm}$ ), comparando-os com os sem derivação e encontraram excelente correlação entre os resultados obtidos pelos dois métodos. Entretanto não relataram vantagem no uso do espectro derivativo, ressaltando que a possibilidade teórica de se ter um resultaḍo mais exato por esta técnica não é evidente no caso da determinação da $\mathrm{COHb}$, porque depende do tipo da absorção característica da substância a ser quantificada. A figura 11 mostra os espectros de absorção e os derivados obtidos por PERRIGO \& YOYNT para as soluçōes de 0, 50 e $100 \%$ de $\mathrm{COHb}$.

Os métodos até aqui descritos constituem os de determinação direta da carboxiemoglobina.

Outros métodos existem em que a carboxiemoglobinemia é determinada indiretamente através da quantificação do $\mathrm{CO}$ liberado da $\mathrm{COHb}$, o que torna necessário o conhecimento do conteúdo hemoglobínico da amostra ${ }^{16,17}$. Nos métodos indiretos predomina a técnica de cromatografia gasosa com detectores de condutividade térmica, ionização de chama e infravermelho; são também usadas a espectrofotometria na faixa do infravermelho. Todas elas utilizam um agente liberador de $\mathrm{CO}$ que varia segundo o autor (tabela $\mathrm{V}$ ). 

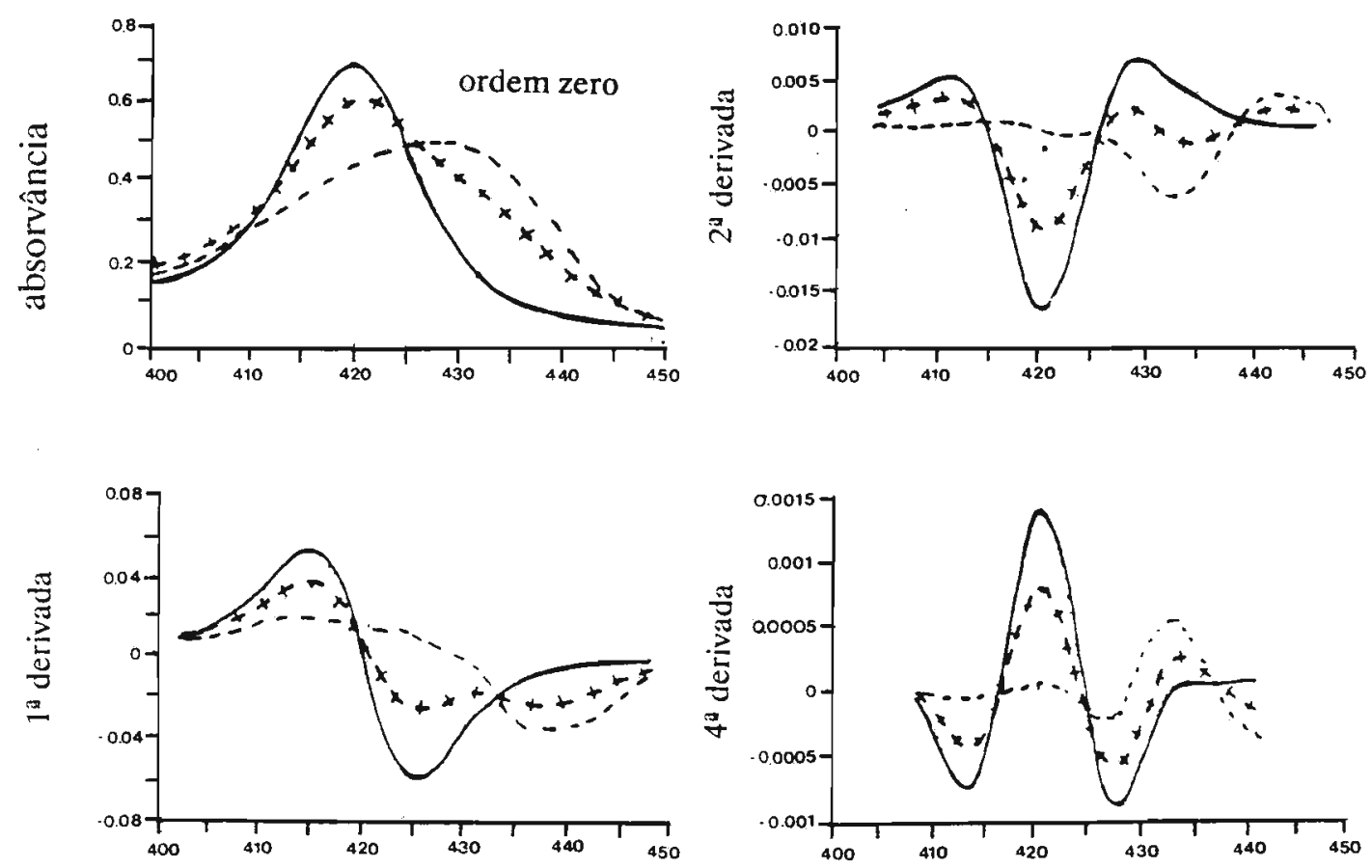

comprimento de onda (nm)

Figura 11 - Espectros de absorção normal e as derivadas de $1^{\mathrm{a}}, 2^{\mathrm{a}}$ e $4^{\mathrm{a}}$ ordem da carboxiemoglobina concentraçôes de $0 \%$ e $100 \%(\ldots)^{142}$.

A técnica de identificação colorimétrica do CO liberado do sangue é uma das mais antigas. $\mathrm{O}$ gás liberado da $\mathrm{COHb}$ pelo ácido sulfúrico na célula de microdifusão (câmara de Conway), reduz o cloreto de paládio com a formação de

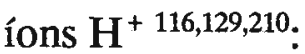

$$
\mathrm{CO}+\mathrm{PdCl}_{2}+\mathrm{H}_{2} \mathrm{O} \longrightarrow \mathrm{Pd}+\mathrm{CO}_{2}+2 \mathrm{HCl}
$$

A quantificação pode ser feita por titulação dos íons $\mathrm{H}^{+}$, determinação colorimétrica do $\mathrm{PdCl}_{2}$ residual ou espectrofotométrica após a adição de solução neutra de iodeto de potássio ${ }^{116}$.

Nas técnicas cromatográficas em fase gasosa, o monóxido de carbono e outros gases liberados são conduzidos por um gás de arraste através do 
Tabela V - Reagentes usados na liberação do monóxido de farbono da hemoglobina e as técnicas para identificá- $10^{23}$.

\begin{tabular}{|c|c|c|}
\hline $\begin{array}{l}\text { técnica de } \\
\text { identificaçāo }\end{array}$ & reagente & autor \\
\hline colorimétrica & $\begin{array}{l}\text { ácido sulfúrico } \\
\text { ácido sulfúrico } \\
\text { ácido sulfúrico } \\
\text { ácido sulfúrico }(10 \%)\end{array}$ & $\begin{array}{l}\text { BERKA } \\
\text { CONWAY } \\
\text { GRAY \& SANDIFORD } \\
\text { NOBEL \& RIKER }\end{array}$ \\
\hline \multirow[t]{3}{*}{ gasométrica } & $\begin{array}{l}\text { ferricianeto de potássio } \\
\text { bicarbonato de potássio } \\
\text { saponina }\end{array}$ & $\begin{array}{l}\text { SCHOLANDER \& } \\
\text { ROUGHTON }\end{array}$ \\
\hline & $\begin{array}{l}\text { ferricianeto de potássio } \\
\text { ácido lático } \\
\text { saponina }\end{array}$ & SENDROY \& LIU \\
\hline & $\begin{array}{l}\text { ferricianeto de potássio } \\
\text { tampāo acetato }(4: 1)\end{array}$ & ROUGHTON \& ROOT \\
\hline espectrofotométrica & $\begin{array}{l}\text { ferricianeto de potássio } \\
\text { tampão acetato }(\mathrm{pH}-6,0)(3: 1)\end{array}$ & COBURN et al. \\
\hline \multirow[t]{4}{*}{ cromatográfica } & $\begin{array}{l}\text { ácido lático, ácido clorídrico, } \\
\text { água (2:1:1). }\end{array}$ & AINSWORTH et al. \\
\hline & ferricianeto de potássio. & COLLISON et al. \\
\hline & $\begin{array}{l}\text { ferricianeto de potássio, } \\
\text { ácido lático. }\end{array}$ & McCREDIE et al. \\
\hline & $\begin{array}{l}\text { ferricianeto de potássio, } \\
\text { tampão bicarbonato }(\mathrm{pH}=9,5) \text {, } \\
\text { saponina. }\end{array}$ & BLACKMORE \\
\hline
\end{tabular}


cromatógrafo e a separaçāo dos gases é geralmente feita por colunas de peneira molecular (pedras de polímero poroso).

Apesar do detector de ionização de chama (DIC) não apresentar resposta ao $\mathrm{CO}$, seu uso foi proposto por $\mathrm{RUSSEV}^{167}$ para a análise de gases inorgânicos, em condições especiais. Os métodos que utilizam o DIC $41,58,67,79,148,157.167 .171,186,199,209$ em geral necessitam de modificações, como a inserçāo de unidade catalítica entre a coluna de separação e o detector (figura 12).

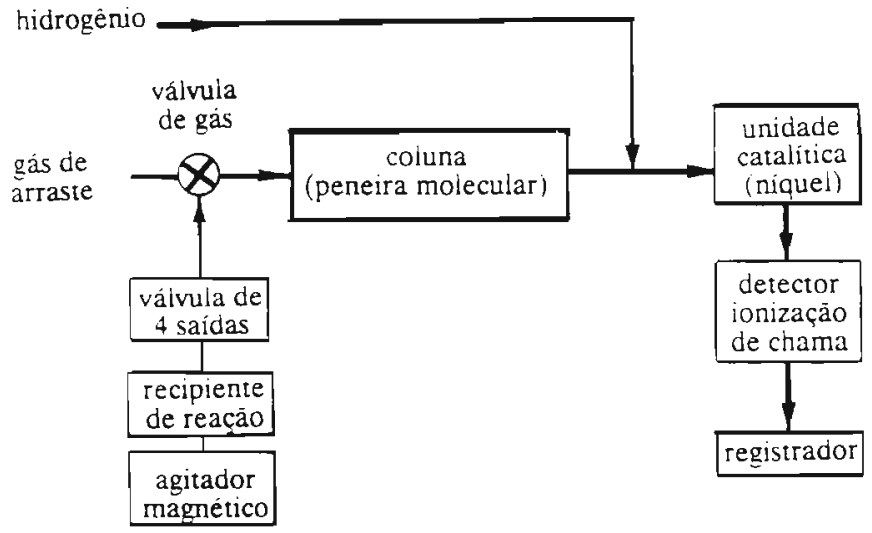

Figura 12 - Esquema do sistema cromatográfico para análise de $\mathrm{CO}$ após a conversão de $\mathrm{CO}$ liberado da carboxiemoglobina a $\mathrm{CH}_{4}$ e usando um detector de ionização de chama.

Para tornar o DIC mais eficaz na determinação, propōe-se adicionar, continuamente, pequenas quantidades de hidrocarboneto à chama para aumentar a intensidade da corrente de fundo, permitindo o aparecimento de um sinal inverso ou negativo na passagem do $\mathrm{CO}^{171}$. Outro recurso, muito empregado, é converter o $\mathrm{CO}$ a metano pela passagem de $\mathrm{H}_{2}$ em catalisador de níquel, anteposto ao DIC; o sinal resultante é positivo.

O detector de condutividade térmica (DCT, Katarômetro) é o mais freqüentemente usado e os limites de detecção, para gases inorgânicos, variam consideravelmente com o tipo de célula ${ }^{33,49,75,92,93,133,165,167}$.

STEHER et al ${ }^{180}$ adaptaram um detector eletroquímico para o $\mathrm{CO}$ ligado (em série) a um detector de condutividade térmica o detector eletrnnmíminn 
é usado no aparelho portátil Ecolyser. O detector eletroquímico é composto por um eletrodo catalítico de platina que converte $\mathrm{CO}$ em $\mathrm{CO}_{2}$. A corrente gerada pela reação é diretamente proporcional à concentração de $\mathrm{CO}$ presєnte na amostra.

Em geral, as técnicas cromatográficas têm-se mostrado exatas na determinação da carboxiemoglobinemia. Entretanto, são demoradas e trabalhosas na etapa de liberação do gás do sangue e de sua introdução no sistema cromatográfico $^{49}$.

DIJKHUIZEN et $a l^{56}$ usaram a titulometria para a determinaçāo do $\mathrm{CO}$ no sangue. $\mathrm{O} \mathrm{CO}$ ligado à hemoglobina é liberado e oxidado a $\mathrm{CO}_{2}$ em forno contendo $\mathrm{CuO}$ a $400^{\circ} \mathrm{C}$. O gás é recolhido em solução alcoólica de cloreto de bário e, subseqüentemente, titulado com solução de hidróxido de sódio.

A preparação do padrão de $\mathrm{COHb}$ sangue (método direto) e de $\mathrm{CO}$ em ar (método indireto) é etapa importante que reflete diretamente na exatidão do método.

SUNDSTROM ${ }^{186}$ cita 3 maneiras diferentes de preparação da solução com $100 \%$ de $\mathrm{COHb}$. O primeiro, pelo estabelecimento do equilíbrio entre sangue total e $1 \%$ de volume de $\mathrm{CO}$ em tonômetro. O segundo, pela mistura de solução de hemoglobina com $1 \%$ de volume de $\mathrm{CO}$ em $\mathrm{N}_{2}$ numa seringa; a baixa pressão parcial do $\mathrm{CO}$ resulta em pequena quantidade de gás dissolvido. A terceira, pela mistura da solução de hemoglobina e CO puro numa seringa, seguido pela lavagem $\operatorname{com~} \mathrm{N}_{2}$.

BEUTLER \& WEST ${ }^{20}$ recomendam a preparação dos padrões de $100 \% \mathrm{COHb}$ e $100 \% \mathrm{O}_{2} \mathrm{Hb}$ pelo borbulhamento dos gases puros $\mathrm{CO}$ e $\mathrm{O}_{2}$ em sangue diluído. SUNDSTROM ${ }^{186}$ mostra a importância dos cuidados a serem tomados para evitar a presença de $\mathrm{CO}$ dissolvido, na soluçāo e a de derivados hemoglobínicos que não se ligam ao $\mathrm{CO}$, como a sulfaemoglobina e a metaemoglobina. Nestes casos a determinação de $\mathrm{COHb}$, baseada na relação entre CO liberado e a concentração de hemoglobina total, forneceria resultados errôneos. Esta relação é feita pelo fator teórico de que um grama de hemoglobina pode se ligar a $1,39 \mathrm{~mL}$ de $\mathrm{CO}$. 
Resumidamente pode-se concluir que os métodos espectrofotométricos apresentam a vantagem de requerer pequeno volume de amostra, pouco tempo de análise e não necessitar de modificações nos aparelhos e a desvantagem da interferência de substâncias presentes na amostra que tenham espectros de absorção semelhantes, ou seja, menor especificidade. Apresentam precisão semelhante aos métodos cromatográficos, mas menor sensibilidade. Os métodos cromatográficos, apesar da maior sensibilidade, são limitados pela desvantagem da pré-reação de liberação de $\mathrm{CO}$ da $\mathrm{COHb}$ presente no sangue, da necessidade de quantificaçāo, em paralelo, de $\mathrm{Hb}$ total e da necessidade de modificaçōes nos cromatógrafos para conversão de $\mathrm{CO}$ em $\mathrm{CH}_{4}$, uma vez que a sensibilidade do detector de ionização de chama é mínima para gases inorgânicos. 


\section{OBJETIVO}

O principal objetivo deste trabalho é de otimizar um método analítico adequado à determinação da carboxiemoglobina no sangue, para uso rotineiro em monitorização biológica da exposição ocupacional ao monóxido de carbono. Para atender esta finalidade o método deve ser sensível, preciso, exato e simples.

O plano de trabalho consta das seguintes etapas:

- revisão bibliográfica de métodos analíticos para a determinação da carboxiemoglobinemia;

- seleçāo e otimizaçāo de método analítico adequado à monitorizaçāo biológica da exposição ocupacional ao monóxido de carbono;

- estudo da interferência de constituintes da matriz biológica na quantificação da carboxiemoglobina pelo método estudado;

- aplicação do método otimizado à determinação da carboxiemoglobina em amostras de sangue de indivíduos expostos ocupacionalmente ao monóxido de carbono, fumantes e não fumantes;

- análise estatística dos resultados obtidos. 


\section{MATERIAL E MÉTODOS}

4.1. Otimização da determinação espectrofotométrica da

\subsubsection{Material}

\subsubsection{Amostras}

As amostras de sangue usadas para a otimizaçāo do método foram obtidas de indivíduos não-fumantes não-expostos ocupacionalmente ao $\mathrm{CO}$. Utilizaram-se tubos Vacutainer ${ }^{R}$ contendo heparina sódica para a colheita. As amostras foram armazenadas sob refrigeraçāo de 4 a $8^{\circ} \mathrm{C}$.

\subsubsection{Aparelhos e acessórios}

- espectrofotômetro Beckman, modelo DU-70, monofeixe;

- espectrofotômetro Intralab, modelo DMS-80, duplo feixe;

- impressora Beckman;

- cilindros de gás comprimido de oxigênio medicinal, de monóxido de carbono (grau de pureza 99,99\%) e de nitrogênio $\mathrm{R}$ do Oxigênio do Brasil S.A.;

- tubos Vacutainer contendo heparina sódica (143 unidades para $7 \mathrm{~mL}$ de sangue);

- pipetas automáticas Eppendorf de 100 e $200 \mu \mathrm{L}$;

- repipetadores automáticos Dispenser $L N$ de 10 e $20 \mathrm{~mL}$ da Labnew.

\subsubsection{Reagentes}

- tampão fosfato $\left(\mathrm{KH}_{2} \mathrm{PO}_{4} / \mathrm{K}_{2} \mathrm{HPO}_{4}\right), 0,1 \mathrm{M}, \mathrm{pH}=6,85$. Esta solução é estável quando conservada em recipiente plástico à temperatura de 4 a $8^{\circ} \mathrm{C}$;

- ditionito de sódio $\left(\mathrm{NA}_{2} \mathrm{~S}_{2} \mathrm{O}_{4}\right)$;

- formiato de sódio;

- ácido sulfúrico concentrado;

- solução hemolisante: diluir o tampão fosfato $\left(\mathrm{KH}_{2} \mathrm{PO}_{4} / \mathrm{K}_{2} \mathrm{HPO}_{4}\right)$ de 1:10 com água desionizada. Preparar semanalmente e conservar em recipiente plástico, entre 4 e $8{ }^{\circ} \mathrm{C}$; 
- solução redutora: adicionar $25 \mathrm{mg}$ de ditionito de sódio a $20 \mathrm{~mL}$ de tampão $\mathrm{KH}_{2} \mathrm{PO}_{4} / \mathrm{K}_{2} \mathrm{HPO}_{4}$. Preparar imediatamente antes de usar.

Todos os reagentes usados foram de grau p.a., da Merck .

As soluções foram preparadas com água destilada e desionizada.

\subsubsection{Métodos}

\subsubsection{Procedimento analítico}

Foi utilizado o método de BEUTLER \& WEST $(1984)^{20}$ sem modificaçōes:

- adicionar $100 \mu \mathrm{L}$ de sangue a $12,0 \mathrm{~mL}$ de solução hemolisante, em tubo de ensaio $(100 \times 13 \mathrm{~mm})$;

- tampaṛ o tubo e homogeneizar, por inversão, 2 a 3 vezes;

- deixar em repouso por 10 minutos;

- pipetar $200 \mu \mathrm{L}$ desta solução para tubo de ensaio (77 X $10 \mathrm{~mm})$ contendo $2,3 \mathrm{~mL}$ de solução redutora;

- tampar o tubo e homogeneizar, por inversão, 2 a 3 vezes;

- deixar em repouso por 10 minutos;

- ler as absorvâncias em 420 e 432 nm, usando a solução redutora como referência.

O esquema da sequiência analítica é mostrado na figura 13. 


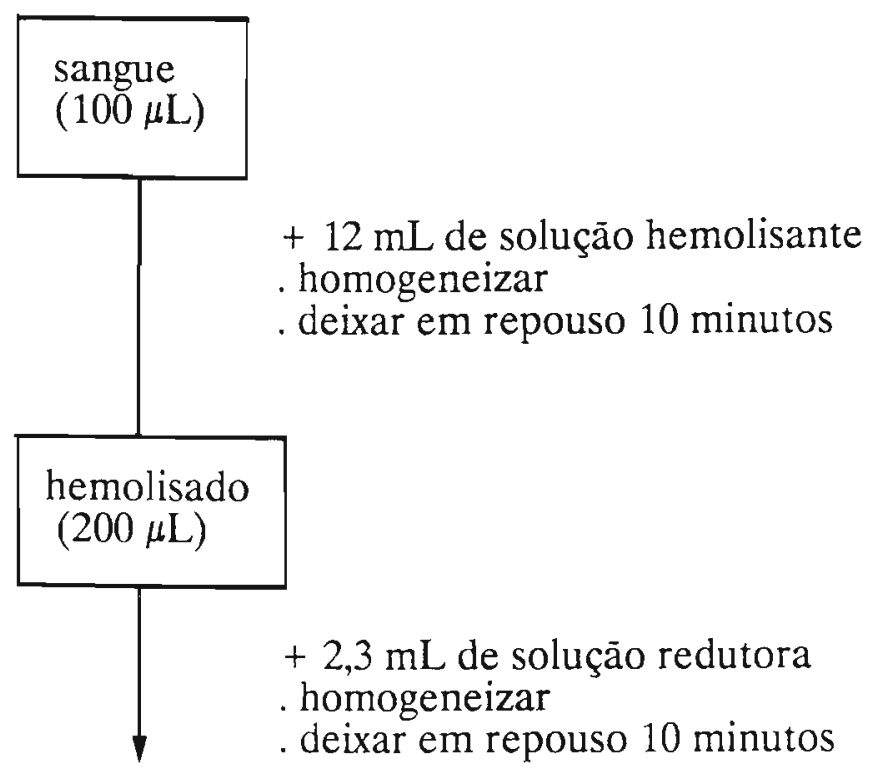

ler as absorvâncias em 420 e $432 \mathrm{~nm}$

Figura 13 - Esquema da seqüência analítica usada na determinação da concentraçāo de carboxiemoglobina.

A concentração da carboxiemoglobina é obtida através da equação:

$$
\% \mathrm{COHb}=\frac{1-\left(\mathrm{AR} \times \mathrm{F}_{1}\right)}{\operatorname{AR}\left(\mathrm{F}_{2}-\mathrm{F}_{1}\right)-\mathrm{F}_{3}+1} \times 100
$$

onde, AR é a razão entre as absorvâncias da solução em 420 e $432 \mathrm{~nm} ; \mathbf{F}_{1}, \mathbf{F}_{2}$ e $\mathbf{F}_{\mathbf{3}}$ representam as razōes entre duas absortividades molares ou, simplificadamente, a razão das absorvâncias das soluçōes com 100\% de hemoglobina reduzida e 100\% de carboxiemoglobina, em 420 e $432 \mathrm{~nm}$. Estes fatores podem ser determinados para cada aparelho e os valores cálculados pelas absortividades molares de referência são 20,158 :

$$
F_{1}=\frac{A_{432}^{\text {Hbred }}}{A_{420}^{\text {Hbred }}}=1,3330
$$




$$
\begin{aligned}
& \mathrm{F}_{2}=\frac{\mathrm{A}_{432}^{\mathrm{COHb}}}{\mathrm{A}_{420}^{\mathrm{Hbred}}}=0,4787 \\
& \mathrm{~F}_{3}=\frac{\mathrm{A}_{420}^{\mathrm{COHb}}}{\mathrm{A}_{420}^{\mathrm{Hbred}}}=1,9939
\end{aligned}
$$

\subsubsection{Determinação dos fatores de calibração do espectrofotômetro}

- adicionar $500 \mu \mathrm{L}$ de sangue a $60 \mathrm{~mL}$ de solução hemolisante; pipetar $3 \mathrm{~mL}$ desta solução em 16 tubos de ensaio (100 X $13 \mathrm{~mm})$;

- nos primeiros 10 tubos borbulhar CO proveniente de cilindro de gás por 3 minutos usando um borbulhador", com agitação frequente da solução; tampar os tubos imediatamente após o borbulhamento;

- nos 6 tubos restantes borbulhar $\mathrm{O}_{2}$ por 15 minutos por meio de um borbulhador; tampar os tubos imediatamente ápós o borbulhamento;

- submeter as soluçōes com $100 \%$ de $\mathrm{COHb}$ e $100 \%$ de $\mathrm{O}_{2} \mathrm{Hb}$ à corrente de $\mathrm{N}_{2}$ por 2,5 minutos, usando o borbulhador; tampar os tuboš imediatamente após o borbulhamento;

- transferir exatamente $2,0 \mathrm{~mL}$ de cada solução para balōes volumétricos de $25 \mathrm{~mL}$; completar o volume com solução redutora, tampar e homogeneizar;

- ler as absorvâncias em 420 e 432 nm imediatamente após a diluição para as soluçōes com $100 \%$ de COHb e após 10 minutos, para as soluçōes com $100 \%$ de $\mathrm{Hb}^{\text {red; }}$

- calcular os fatores $F_{1}, F_{2}, F_{3}$ segundo as fórmulas descritas no item 4.1.2.1.

Os tempos de borbulhamento dos gases para a preparação das soluçōes saturadas devem ser padronizados.

- Preparação das soluções de carboxiemoglobina e de hemoglobina reduzida.

Para determinar o tempo de borbulhamento de $\mathrm{CO}$ e $\mathrm{O}_{2}$ adequado à preparação da solução com $100 \%$ de $\mathrm{COHb}$ e $100 \%$ de $\mathrm{Hb}^{\text {red }}$ foram diluídos $500 \mu \mathrm{L}$

\footnotetext{
* Tubo de vidro $(110 \times 5 \mathrm{~mm}$ ) com placa de vidro poroso numa extremidade, com o qual se obteve 0 fluxo de $50 \mathrm{~mL} / \mathrm{min}$ de $\mathrm{O}_{2}$ e do $\mathrm{CO}$ e de $30 \mathrm{~mL} / \mathrm{min}$ de $\mathrm{N}_{2}$
} 
de sangue em $60 \mathrm{~mL}$ de soluçāo hemolisante.

Alíquotas de 3,0 mL do hemolisado foram submetidas à corrente de monóxido de carbono, proveniente de cilindro de gás comprimido, durante os tempos 1, 2, 3, 4, 5 e 6 minutos; para a saturação com o $\mathrm{O}_{2}$, os tempos de borbulhamento foram de $10,15,20,30,45$ e 60 minutos.

A seguir, foi passada corrente de $\mathrm{N}_{2}$ por 2,5 minutos em todas as alíquotas e 2,0 mL de cada uma foram diluídos, a 25,0 $\mathrm{mL}$ com soluçāo redutora em balão volumétrico.

As leituras das absorvâncias das soluções de $\mathrm{COHb}$ foram feitas imediatamente após a diluição, enquanto das soluções de $\mathrm{Hb}^{\text {red }}$ foram feitas 10 minutos após a diluição.

Os ensaios, para cada tempo estudado, foram realizados em triplicata para as soluçōes de $\mathrm{COHb}$ e em duplicata para as de $\mathrm{O}_{2} \mathrm{Hb}$.

- Uso do monóxido de carbono obtido por reação química na preparação da solução de carboxiemoglobina.

Por via química, o $\mathrm{CO}$ pode ser obtido pelo tratamento de formiato de sódio com ácido sulfúrico. Num funil de separação de $125 \mathrm{~mL}$, colocar $25 \mathrm{~mL}$ de $\mathrm{H}_{2} \mathrm{SO}_{4}$ e adaptá-lo a um kitassato de $125 \mathrm{~mL}$ contendo $20 \mathrm{~g}$ de formiato de sódio e pérolas de vidro. O monóxido de carbono formado deixa o sistema pela saída lateral do kitassato, ligada a um tubo de borracha com uma pipeta Pasteur na extremidade. Esta deve tocar o fundo de um tubo de ensaio $(100 \times 13 \mathrm{~mm})$ contendo $3 \mathrm{~mL}$ do hemolisado. (figura 14).

Para determinar o tempo de borbulhamento de $\mathrm{CO}$ adequado à preparação da solução com $100 \%$ de $\mathrm{COHb}$, foram preparados cinco hemolisados de $24 \mathrm{~mL}$, dividindo-se cada um em alíquotas de 3,0 mL (5 séries). Para cada reaçāo de geração de $\mathrm{CO}$, as alíquotas de uma série foram submetidas seqüencialmente ao borbulhamento durante tempos diferentes. A soma dos tempos de borbulhamento nas alíquotas de uma série corresponde ao tempo de geraçāo contínua de CO de uma reação. 
As concentrações de $\mathrm{COHb}$ obtidas em cada alíquota, após o borbulhamento, foram determinadas em duplicata.

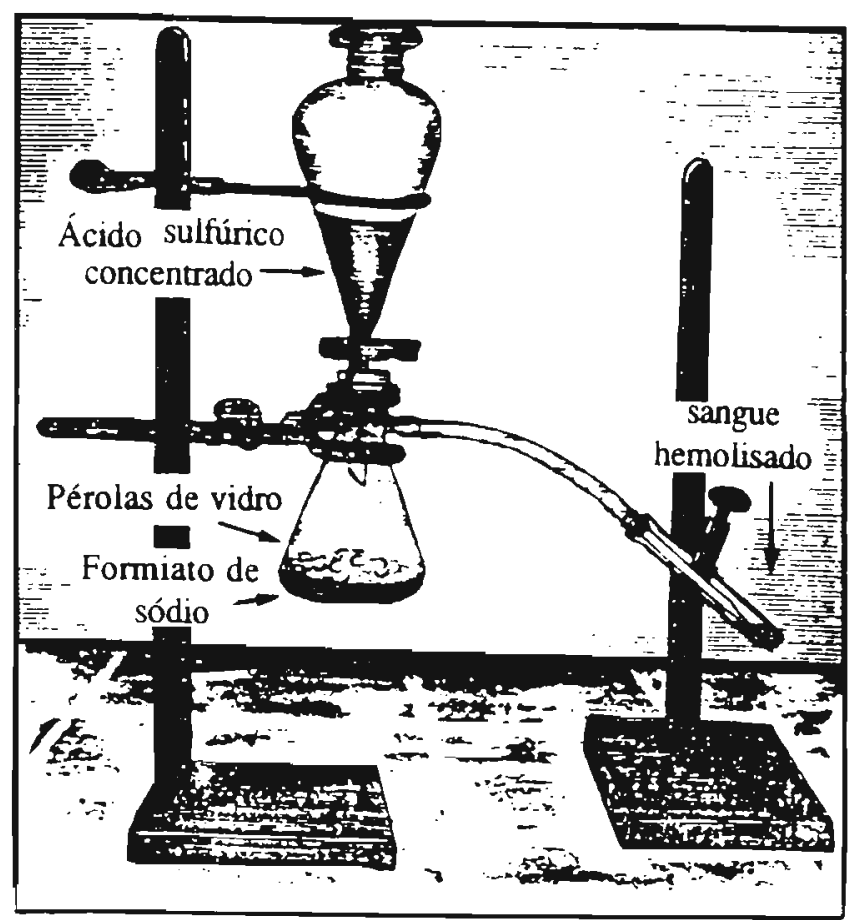

Figura 14 - Esquema do sistema para produção de monóxido de carbono.

A série de tempos de borbulhamento para cada reação foi:

série $\mathrm{A}$ - 5, 10, 15, 20, 30 e $30 \mathrm{~min}$;

série $\mathrm{B}$ - 10, 10 e $15 \mathrm{~min}$;

série C - 20, 20 e 30 min;

série D - 10, 15, 15, 15, 15 e $30 \mathrm{~min}$;

série $\mathrm{E}-10,30$ e $15 \mathrm{~min}$.

- Deslocamento de monóxido de carbono dissolvido em soluçāo

Várias alíquotas do hemolisado com $100 \%$ de $\mathrm{COHb}$ foram submetidas à passagem de corrente de nitrogênio, em diferentes tempos, para verificar qual seria o adequado ao deslocamento do $\mathrm{CO}$ dissolvido em solução. Os tempos de borbulhamento estudados foram de 0,5 - 1,0 - 2,0 - 2,5 e 3,0 minutos. 
As leituras das absorvâncias das soluçōes antes e após o borbulhamento de $\mathrm{N}_{2}$, foram efetuadas para averiguar a real concentração da solução com $100 \%$ de $\mathrm{COHb}$.

Em seguida, estas soluções foram diluídas para obter-se $50 \%$ de $\mathrm{COHb}$ usando o hemolisado com $100 \%$ de $\mathrm{O}_{2} \mathrm{Hb}$, previamente submetido à passagem de corrente de $\mathrm{N}_{2}$ por 2,5 minutos.

A preparação das soluções contendo $50 \%$ de $\mathrm{COHb}$ foi feita pela adição de $100 \mu \mathrm{L}$ do hemolisado com $100 \%$ de $\mathrm{O}_{2} \mathrm{Hb}$ a $2,3 \mathrm{~mL}$ da solução redutora e, após 10 minutos, a adição de $100 \mu \mathrm{L}$ do hemolisado com $100 \%$ de $\mathrm{COHb}$, fazendo-se, imediatamente, as leituras das absorvâncias.

\subsubsection{Linearidade da técnica de quantificação}

Para verificar a linearidade da resposta e o paralelismo entre as concentraçōes esperadas e as encontradas de $\mathrm{COHb}$ foram feitas misturas das soluções com $100 \%$ de $\mathrm{COHb}$ e $100 \%$ de $\mathrm{Hb}^{\text {red }}$ de modo a obterem-se concentraçōes na faixa de 0 a $100 \%$ de $\mathrm{COHb}$ (tabela VI). Para este estudo foram preparadas 3 séries, sendo que concentração foi preparada em duplicata.

As absorvâncias das soluções foram lidas em 420 e $432 \mathrm{~nm}$, obtendo-se os respectivos valores de $\mathrm{AR}$, com os quais foram calculadas as concentrações de $\mathrm{COHb}$. 
Tabela VI - Volume das soluções reduzidas de carboxiemoglobina $(\mathrm{COHb})$ e hemoglobina reduzida $\left(\mathrm{Hb}^{\text {red }}\right)$ usados na preparação das diferentes concentrações de $\mathrm{COHb}$.

\begin{tabular}{rrr}
\hline \hline \multirow{2}{*}{$\begin{array}{c}\text { \% COHb } \\
\text { esperada }\end{array}$} & \multicolumn{2}{c}{ solução (mL) } \\
\cline { 2 - 3 } & $\mathbf{1 0 0 \% \mathbf { H b } ^ { \text { red } }}$ & $\mathbf{1 0 0 \%} \mathbf{C O H b}$ \\
\hline & & \\
1 & 5,00 & 0,00 \\
2 & 4,95 & 0,05 \\
4 & 4,90 & 0,10 \\
6 & 4,80 & 0,20 \\
8 & 4,70 & 0,30 \\
10 & 4,60 & 0,40 \\
14 & 4,50 & 0,50 \\
20 & 4,30 & 0,70 \\
40 & 4,00 & 1,00 \\
50 & 3,00 & 2,00 \\
60 & 2,50 & 2,50 \\
100 & 2,00 & 3,00 \\
\hline \hline
\end{tabular}

\subsubsection{Precisão do método}

O estudo da precisão intra-série foi efetuado pela análise de 6 amostras autênticas de diferentes concentrações de carboxiemoglobina. Cada amostra foi analisada 9 vezes em média.

Para avaliar, isoladamente, a influência das etapas de diluição na precisão do método foram preparados 10 hemolisados de sangue de indivíduo fumante, e a diluição seguinte, de um destes hemolisados, foi repetida 14 vezes.

Para estudar a influência da técnica de pipetagem foi comparado o uso de pipeta automática e repipetador ao uso de pipeta comum. A determinação da carboxiemoglobinemia foi feita em um indivíduo fumante e um nāo-fumante, usando-se as duas técnicas. Foram feitas em média, 11 determinações de cada amostra. 
A determinação do valor mínimo confiável foi fundamentada nos coeficientes de variação obtidos em concentrações decrescentes de COHb.

\subsubsection{Estabilidade das leituras de absorvância}

Para este estudo foram preparadas concentrações de $0,2,5,10,15$, 25,50 e $100 \%$ de $\mathrm{COHb}$, de maneira similar à descrita no item 4.1.2.3.

As soluçōes finais, para a leitura das absorvâncias foram mantidas à temperatura ambiente em cubetas abertas e as absorvâncias lidas de 10 em 10 minutos, perfazendo o tempo de 90 minutos.

\subsubsection{Estabilidade da carboxiemoglobinemia nas amostras}

A estabilidade da $\mathrm{COHb}$ nas amostras de sangue foi estudada determinando-se sua concentração, até oito dias após a colheita, em 3 amostras de sangue de indivíduo nāo-fumante e em 5 de fumante. De cada doador foram colhidas no mesmo ato, em seqüência, 3 amostras ( $a, b, c)$, das quais a primeira (a) foi analisada, dia após dia, até o $8^{Q}$ dia; a segunda (b) foi mantida em vácuo até o $3^{\circ}$ dia, para a partir de então ser analisada diariamente; a terceira (c) foi conservada em vácuo até o $8^{\circ}$ dia, quando todas as amostras foram analisadas.

\subsubsection{Influência da matriz biológica}

\subsubsection{Conteúdo hemoglobínico}

A influência do conteúdo hemoglobínico na detєrminação da \% de $\mathrm{COHb}$ foi estudada de duas maneiras: 
- pela determinação da \% $\mathrm{COHb}$ em amostras preparadas com valores de hemoglobina total variáveis. Para tanto uma amostra de sangue foi dividida em 5 alíquotas de 2,0 $\mathrm{mL}$ (A a E) às quais foram adicionados ou retirados volumes diferentes de plasma de maneira a se obterem, respectivamente, valores menores e maiores de hemoglobina total. Em cada alíquota, além da \% de $\mathrm{COHb}$, foram determinadas as concentrações de hemoglobina total e o valor do hematócrito, pelo método da cianometaemoglobina ${ }^{35}$ e de microematócrito ${ }^{48.183}$ respectivamente:

- pela determinação da \% COHb em 3 amostras de sangue após diluições em diferentes proporções com a solução hemolisante. Para se obterem soluções de sangue hemolisado com teores de hemoglobina variáveis, $100 \mu \mathrm{L}$ de cada amostra foram diluídos em volumes variáveis - 8,0 - 10,0 - 12,0 - 14,0 - 16,0 - 18,0 e 20,0 mL - de soluçāo hemolisante. Desta forma, para cada amostra, foram obtidas sete soluções de sangue hemolisado de conteúdo hemoglobínico diferente.

\subsubsection{Lipemia}

Para avaliar a influência do plasma lipêmico na determinação da concentração de $\mathrm{COHb}$ foram colhidas duas amostras de três indivíduos, sendo uma em condição de jejum e outra, uma a duas horas, após a refeição. A concentração de lipídios totais foi determinada em todas as amostras pelo método de FRINGS et $a l^{71}$.

A determinação da $\% \mathrm{COHb}$ das amostras colhidas em jejum foi feita também após a adição, à solução de sangue hemolisado, de 100 e $200 \mu \mathrm{L}$ de plasma de amostra do mesmo indivíduo colhido após a refeição. 
4.2. Determinação da carboxiemoglobinemia em indivíduos expostos ocupacionalmente ao monóxido de carbono.

\subsubsection{Material}

\subsubsection{População estudada}

A determinação da carboxiemoglobina foi realizada em amostras de sangue de indivíduos expostos ocupacionalmente ao $\mathrm{CO}$. As amostras foram colhidas em tubo Vacutainer $^{R}$ contendo heparina sódica e armazenada sob refrigeraçāo, de 4 a $8^{\circ} \mathrm{C}$, no máximo por cinco dias após a colheita.

Os grupos e subgrupos estudados foram:

grupo controle - de indivíduos não-expostos ocupacionalmente ao $\mathrm{CO}$, sendo:
não-fumantes
80 amostras
fumantes
19 amostras

grupo I - indivíduos que trabalham em fornos de fundição de minérios de metais de 3 empresas, subdivididos em:

$\begin{array}{cc}\mathbf{I}_{\mathbf{a}} \text { - não-fumantes } & 23 \text { amostras } \\ \text { fumantes } & 34 \text { amostras } \\ \mathbf{I}_{\mathbf{b}} \text { - nāo-fumantes } & \\ \text { fumantes } & 14 \text { amostras } \\ & 7 \text { amostras } \\ \mathbf{I}_{c} \text { - não-fumantes } & \\ \text { fumantes } & 42 \text { amostras } \\ & 30 \text { amostras }\end{array}$

grupo II- indivíduos que trabalham na regulagem de motores de combustão interna de veículos:
nāo-fumantes
30 amostras
fumantes
29 amostras

Nos grupos de indivíduos expostos ocupacionalmente ao $\mathrm{CO}$, a colheita das amostras foi realizada no final da jornada de trabalho, sendo que nos subgrupos $I_{a}$ e $I_{b}$ foram colhidas, também, no início da jornada.

Paralelamente à colheita do sangue, foram obtidas dos trabalhadores algumas informações, necessárias à interpretaçāo dos resultados de 
carboxiemoglobinemia, como:

- dados pessoais : nome, idade e hábito de fumar (número médio de cigarros fumados por dia e no dia até o momento da colheita da amostra, marca do cigarro)

- dados profissionais : tempo de serviço na empresa, cargo ou função atual, descrição da atividade exercida e uso de equipamento de proteção individual.

As amostras dos fumantes do grupo controle foram colhidas, aproximadamente, 6 horas após o início das atividades diárias e as dos nãofumantes em horário variável. As informações registradas foram referentes aos dados pessoais, incluindo as do hábito de fumar e do uso de medicamentos, e a exclusāo de possível exposição ocupacional ao $\mathrm{CO}$ ou ao diclorometano. O grupo é composto por estudantes e funcionários da Universidade de São Paulo.

\subsubsection{Aparelhos e acessórios}

- espectrofotômetro Intralab modelo DMS 80, duplo feixe;

- tubos Vacutainer com heparina sódica (143 unidades para $7 \mathrm{~mL}$ de sangue);

- pipetas automáticas Eppendorf de 100 e $200 \mu \mathrm{L}$;

- repipetadores automáticos Dispenser LN de 10 e $20 \mathrm{~mL}$ da Labnew.

\subsubsection{Reagentes}

Os reagentes usados foram os descritos no item 4:1.1.3.

\subsubsection{Métodos}

Foi utilizado o método descrito em 4.1.2.1. e a porcentagem de $\mathrm{COHb}$ calculada com os fatores de calibração determinados, periodicamente, para o espectrofotômetro usado. 


\section{RESULTADOS}

\subsection{Otimização da determinação espectrofotométrica da carboxiemoglobinemia}

\subsubsection{Preparação das soluções de carboxiemoglobina e de hemoglobina reduzida}

As tabelas VII e VIII apresentam as concentrações de COHb obtidas, respectivamente, nas soluções de carboxiemoglobina e de hemoglobina reduzida, após os diferentes tempos de borbulhamento de $\mathrm{CO}$ e de $\mathrm{O}_{2}$ provenientes de cilindros de gás comprimido.

Tabela VII - Valores de absorvâncias, respectivas razões (AR) e concentraçōes de carboxiemoglobina $(\mathrm{COHb})$ das soluçōes de $\mathrm{COHb}$ obtidas após diferentes tempos de borbulhamento de $\mathrm{CO}$ proveniente de cilindro de gás comprimido. As concentrações de $\mathrm{COHb}$ foram calculadas pelos fatores do espectrofotômetro (a) e pelos de referência ${ }^{158}$ (b).

\begin{tabular}{|c|c|c|c|c|c|}
\hline \multirow{2}{*}{$\begin{array}{l}\text { tempo de } \\
\text { borbulhamento } \\
\text { de monóxido de } \\
\text { carbono (min) }\end{array}$} & \multicolumn{2}{|c|}{ absorvância } & \multirow{2}{*}{ AR } & \multicolumn{2}{|c|}{$\mathrm{COHb}(\%)$} \\
\hline & $420 \mathrm{~nm}$ & $432 \mathrm{~nm}$ & & $\mathrm{a}$ & b \\
\hline \multirow[t]{3}{*}{1} & 0,7759 & 0,8896 & 0,8722 & 8,79 & 9,35 \\
\hline & 0,9536 & 0,7336 & 1,2999 & 34,73 & 34,82 \\
\hline & 1,3769 & 0,3236 & 4,2549 & 99,88 & 100,93 \\
\hline \multirow[t]{3}{*}{2} & 1,3830 & 0,3240 & 4,2685 & 100,01 & 101,07 \\
\hline & 1,3569 & 0,3179 & 4,2683 & 100,01 & 101,06 \\
\hline & 1,3847 & 0,3249 & 4,2619 & 99,95 & 101,00 \\
\hline \multirow[t]{3}{*}{3} & 1,3934 & 0,3262 & 4,2716 & 100,04 & 101,10 \\
\hline & 1,3916 & 0,3265 & 4,2622 & 99,95 & 101,00 \\
\hline & 1,3758 & 0,3214 & 4,2807 & 100,13 & 101,19 \\
\hline \multirow[t]{3}{*}{4} & 1,3648 & 0,3204 & 4,2597 & 99,92 & 100,98 \\
\hline & 1,3759 & 0,3227 & 4,2637 & 99,96 & 101,02 \\
\hline & 1,3596 & 0,3185 & 4,2689 & 100,01 & 101,07 \\
\hline \multirow[t]{3}{*}{5} & 1,3988 & 0,3295 & 4,2452 & 99,78 & 100,83 \\
\hline & 1,3893 & 0,3276 & 4,2408 & 99,74 & 100,78 \\
\hline & 1,3697 & 0,3220 & 4,2537 & 99,87 & 100,92 \\
\hline \multirow[t]{3}{*}{6} & 1,3460 & 0,3167 & 4,1238 & 98,66 & 99,67 \\
\hline & 1,3734 & 0,3225 & 4,2586 & 99,91 & 100,97 \\
\hline & 1,3712 & 0,3226 & 4,2506 & 99,84 & 100,88 \\
\hline
\end{tabular}


Tabela VIII - Valores de absorvâncias, respectivas razōes (AR) e concentrações de carboxiemoglobina $(\mathrm{COHb})$ das soluçōes de hemoglobina reduzida obtidas após diferentes tempos de borbulhamento de $\mathrm{O}_{2}$. As concentraçōes de $\mathrm{COHb}$ foram calculadas pelos fatores do espectrofotômetro (a) e pelos de referência (b) ${ }^{20}$.

\begin{tabular}{|c|c|c|c|c|c|}
\hline \multirow{2}{*}{$\begin{array}{l}\text { tempo de } \\
\text { borbulhamento } \\
\text { de oxigènio } \\
\text { (min) }\end{array}$} & \multicolumn{2}{|c|}{ absorvância } & \multirow{2}{*}{$\mathrm{AR}$} & \multicolumn{2}{|c|}{$\mathrm{COHb}(\%)$} \\
\hline & $420 \mathrm{~nm}$ & $432 \mathrm{~nm}$ & & $\mathbf{a}$ & b \\
\hline \multirow[t]{2}{*}{10} & 0,7172 & 0.9369 & 0,7655 & 0,43 & 1,24 \\
\hline & 0,7370 & 0,9645 & 0,7641 & 0.31 & 1,13 \\
\hline \multirow[t]{2}{*}{15} & 0,7266 & 0,9556 & 0,7604 & 0.00 & 0,93 \\
\hline & 0.7160 & 0,9401 & 0,7616 & 0.11 & 0,83 \\
\hline \multirow[t]{2}{*}{20} & 0,7188 & 0.9450 & 0.7606 & 0.02 & 0,84 \\
\hline & 0,7177 & 0,9449 & 0,7596 & -0.06 & 0,76 \\
\hline \multirow[t]{2}{*}{30} & 0,7195 & 0,9460 & 0,7606 & 0,02 & 0,84 \\
\hline & 0,7142 & 0,9392 & 0,7604 & 0,00 & 0,83 \\
\hline \multirow[t]{2}{*}{45} & 0,7172 & 0,9439 & 0,7598 & $-0,05$ & 0,78 \\
\hline & 0,7120 & 0,9367 & 0,7601 & $-0,02$ & 0,80 \\
\hline \multirow[t]{2}{*}{60} & 0,7206 & 0,9491 & 0,7592 & $-0,10$ & 0,73 \\
\hline & 0,7138 & 0,9373 & 0,7616 & $-0,11$ & 0,93 \\
\hline
\end{tabular}

As concentrações de $\mathrm{COHb}$ foram calculadas a partir dos valores das absorvâncias e suas razōes, usando-se os fatores do espectrofotômetro Intralab e os de referência 158 .

Os tempos de borbulhamento dos gases, suficientes para promover a formação de $100 \%$ de $\mathrm{COHb}$ e $100 \%$ de $\mathrm{Hb}^{\text {red }}$ foram de 3 e 15 minutos respectivamente. 


\subsubsection{Uso do monóxido de carbono obtido por reação química na preparação da solução de carboxiemoglobina}

O monóxido de carbono gerado por reação química foi usado na preparação de soluções $100 \%$ de $\mathrm{COHb}$.

$\mathrm{Na}$ tabela IX estão dispostas as \% de $\mathrm{COHb}$ calculadas a partir das absorvâncias em 420 e $432 \mathrm{~nm}$ das soluçōes de $\mathrm{COHb}$ obtidas após diferentes séries de tempos de borbulhamento de $\mathrm{CO}$.

Tabela IX - Concentraçōes de carboxiemoglobina (COHb), absorvâncias e respectivas razões (AR) das soluções obtidas após diferentes séries de tempos de borbulhamento de $\mathrm{CO}$ gerado por reação química.

\begin{tabular}{|c|c|c|c|c|c|c|}
\hline \multirow{2}{*}{ série } & \multirow{2}{*}{$\begin{array}{c}\text { tempo de } \\
\text { borbulhamento } \\
\text { de } \mathrm{CO} \\
\text { (min) }\end{array}$} & \multirow{2}{*}{$\begin{array}{c}\text { tempo } \\
\text { de reação } \\
\text { (min) }\end{array}$} & \multicolumn{2}{|c|}{ absorvância } & \multirow{2}{*}{ AR } & \multirow{2}{*}{$\mathrm{COHb}$} \\
\hline & & & $420 \mathrm{~nm}$ & $432 \mathrm{~nm}$ & & \\
\hline \multirow[t]{5}{*}{ A } & 5 & 5 & 1,0794 & 0,4168 & 2,5897 & 77,49 \\
\hline & 10 & 15 & 1,2063 & 0,2984 & 4,0426 & 99,60 \\
\hline & 15 & 30 & 1,2011 & 0,2999 & 4,0050 & 99,19 \\
\hline & 20 & 50 & 1,2089 & 0,3145 & 3,8439 & 97,35 \\
\hline & 30 & 80 & 1,2131 & 0,3137 & 3,8671 & 97,62 \\
\hline \multirow[t]{3}{*}{ B } & 10 & 10 & 1,1981 & 0,2770 & 4,3253 & 102,52 \\
\hline & 10 & 20 & 1,2185 & 0,3060 & 3,9820 & 98,93 \\
\hline & 15 & 35 & 1,2098 & 0,3034 & 3,9875 & 98,99 \\
\hline \multirow[t]{3}{*}{$\mathrm{C}$} & 20 & 20 & 0,9081 & 0,4198 & 2,1632 & 67,22 \\
\hline & 20 & 40 & 1,1706 & 0,2906 & 4,0282 & 99,44 \\
\hline & 30 & 70 & 1,2484 & 0,3138 & 3,9783 & 98,89 \\
\hline \multirow[t]{6}{*}{$\mathrm{D}$} & 10 & 10 & 1,2084 & 0,3006 & 4,0200 & 99,35 \\
\hline & 15 & 25 & 1,1906 & 0,2859 & 4,1644 & 100,90 \\
\hline & 15 & 40 & 1,2266 & 0,3041 & 4,0335 & 99,50 \\
\hline & 15 & 55 & 1,2138 & 0,3022 & 4,0165 & 99,31 \\
\hline & 15 & 70 & 1,2196 & 0,3077 & 3,963 & 98,73 \\
\hline & 30 & 100 & 1,2271 & 0,3050 & 4,0233 & 99,39 \\
\hline \multirow[t]{3}{*}{$E$} & 10 & 10 & 1,2262 & 0,2994 & 4,0955 & 100,17 \\
\hline & 30 & 40 & 1,2470 & 0,3047 & 4,0923 & 100,14 \\
\hline & 15 & 55 & 1,2363 & 0,3081 & 4,0127 & 99,27 \\
\hline
\end{tabular}


A figura 15 mostra a variação nas concentraçōes de $\mathrm{COHb}$ obtidas nas repetições da reaçāo química, com diferentes séries de tempos de borbulhamento (A a E).

O tempo necessário à saturação da solução de $\mathrm{COHb}$ foi de 15 minutos, excluindo-se os primeiros 5 minutos da produção do gás.
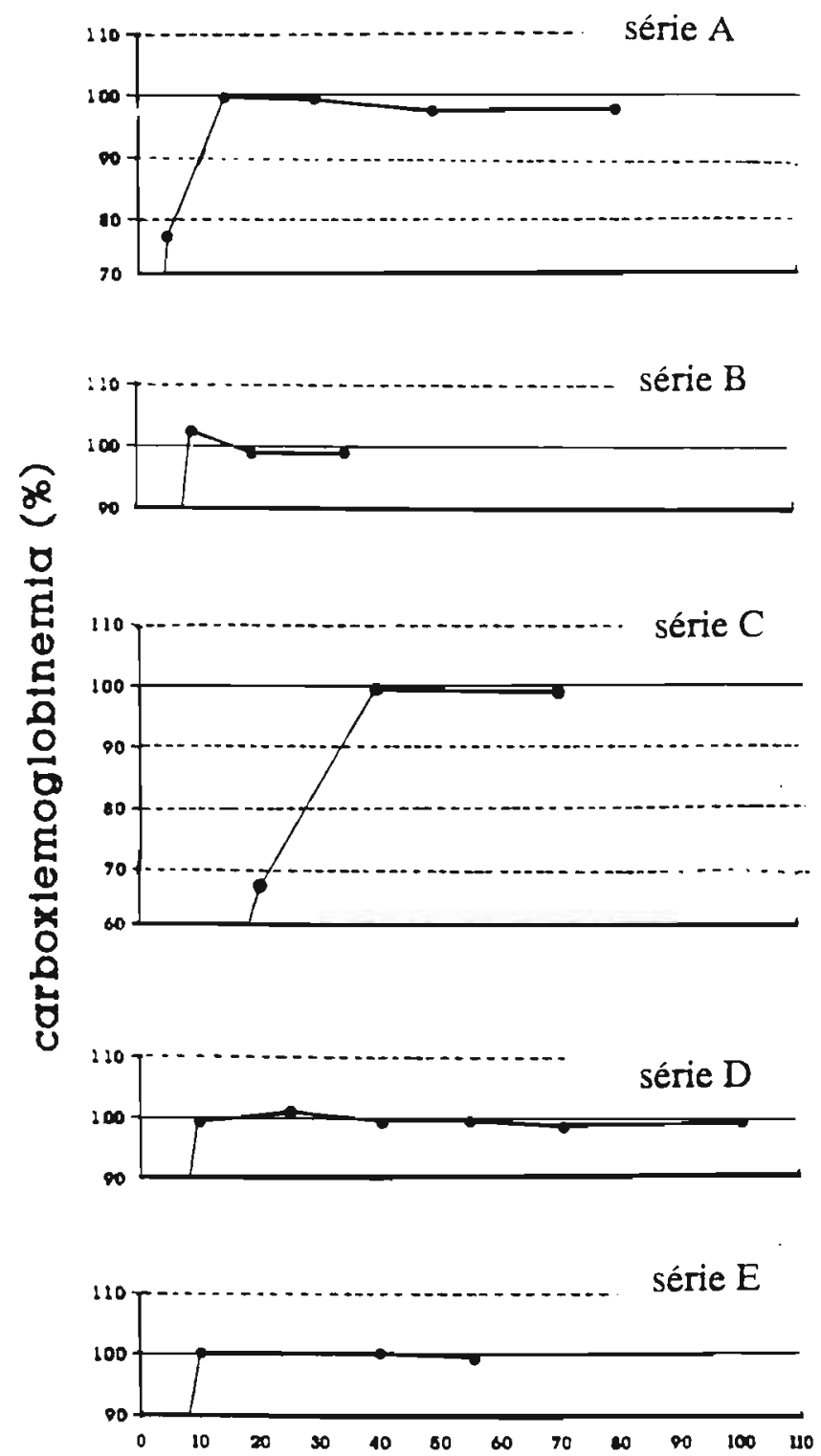

tempo de reaçāo (min)

Figura 15 - Relação entre carboxiemoglobina e tempo de reação após diferentes séries de tempos de borbulhamente (séries $\mathrm{A}$ a $\mathrm{E}$ ) 


\subsubsection{Deslocamento do monóxido de carbono dissolvido em solução}

$\mathrm{Na}$ tabela $\mathrm{X}$ encontram-se as concentraçōes de $\mathrm{COHb}$ das soluçōes com $100 \%$ de $\mathrm{COHb}$ (teórico) após serem submetidas a diferentes tempos de borbulhamento de $\mathrm{N}_{2}$, empregando-se os fatores de calibração do espectrofotômetro duplo feixe. Os valores de $\mathrm{COHb}$ determinados nas soluçōes de concentração esperada de $50 \%$ sāo, também, mostrados nesta tabela.

Tabela X - Concentraçoes de carboxiemoglobina ( $\mathrm{COHb})$ obtidas nas soluçōes com $100 \%$ de $\mathrm{COHb}$ após terem sido submetidas a diferentes tempos de borbulhamento de $\mathrm{N}_{2}$ e nas soluçōes com $50 \%$ de $\mathrm{COHb}$, preparadas pela diluıção com a solução $100 \% \quad \mathrm{O}_{2} \mathrm{Hb} \quad$ de hemoglobina reduzida.

\begin{tabular}{|c|c|c|c|c|c|}
\hline \multirow{3}{*}{$\begin{array}{l}\text { tempo de } \\
\text { borbulhamento } \\
\text { de nitrogênio } \\
\text { (min) }\end{array}$} & \multicolumn{2}{|c|}{ solução $100 \% \mathrm{COHb}$} & \multicolumn{3}{|c|}{ solução $50 \%$ COHb } \\
\hline & \multirow[t]{2}{*}{ AR } & \multirow{2}{*}{$\begin{array}{c}\mathrm{COHb} \\
(\%)\end{array}$} & \multirow[t]{2}{*}{$\mathrm{AR}$} & \multicolumn{2}{|c|}{$\mathrm{COHb}(\%)$} \\
\hline & & & & encontrada & esperada \\
\hline 0 & $\begin{array}{l}4,144 \\
4,149\end{array}$ & 98,80 & $\begin{array}{l}4,098 \\
4,066\end{array}$ & 98,13 & 49,40 \\
\hline 0,5 & $\begin{array}{l}4,115 \\
4,135\end{array}$ & 98,57 & $\begin{array}{l}4,104 \\
4,087\end{array}$ & 98,27 & 49,29 \\
\hline 1,0 & $\begin{array}{l}4,139 \\
4,112\end{array}$ & 98,58 & $\begin{array}{l}4,035 \\
4,020\end{array}$ & 97,61 & 49,29 \\
\hline 1,5 & $\begin{array}{l}4,159 \\
4,131\end{array}$ & 98,78 & $\begin{array}{l}4,019 \\
4,044\end{array}$ & 98,60 & 49,39 \\
\hline 2,0 & $\begin{array}{l}3,936 \\
3,906\end{array}$ & 96,36 & $\begin{array}{l}1,912 \\
1,911\end{array}$ & 58,86 & 48,18 \\
\hline 2,5 & $\begin{array}{l}4,083 \\
4,062\end{array}$ & 98,03 & $\begin{array}{l}1,628 \\
1,626\end{array}$ & 48,99 & 49,02 \\
\hline 3,0 & $\begin{array}{l}4,039 \\
4,028\end{array}$ & 97,62 & $\begin{array}{l}1,685 \\
1,683\end{array}$ & 51,13 & 48,81 \\
\hline
\end{tabular}

$\mathrm{AR}=$ razão das absorvâncias em 420 e $432 \mathrm{~nm}$. 


\subsubsection{Fatores de calibração do espectrofotômetro}

A tabela XI mostra as absorvâncias das soluçōes com $100 \%$ de $\mathrm{COHb}$ e $100 \%$ de $\mathrm{Hb}^{\text {red }}$. em 420 e $432 \mathrm{~nm}$, usadas para a determinação dos fatores de calibraçāo, medidas nos espectrofotômetros Intralab DMS-80 e Beckman DU-70.

Os fatores de calibração $F_{1}, F_{2}$ e $F_{3}$, calculados a partir dos valores médios de absorvância e determinados para cada aparelho, estão apresentados na tabela XII. Nesta tabela estão relacionados também os fatores de referência ${ }^{158}$.

A figura 16 mostra os espectros de absorção correspondentes às soluçōes com $100 \%$ de $\mathrm{O}_{2} \mathrm{Hb}, 100 \%$ de $\mathrm{Hb}^{\text {red }}$. e $100 \% \mathrm{COHb}$.

Tabela XI - Absorvâncias das soluções de carboxiemoglobina (COHb) e de hemoglobina reduzida ( $\left.\mathrm{Hb}^{\text {red }}\right)$ usadas na determinação dos fatores de calibração dos espectrofotômetros.

\begin{tabular}{|c|c|c|c|c|}
\hline \multirow{2}{*}{ soluçāo } & \multicolumn{2}{|c|}{ Beckman DU-70 } & \multicolumn{2}{|c|}{ Intralab DMS-80 } \\
\hline & $420 \mathrm{~nm}$ & $432 \mathrm{~nm}$ & $420 \mathrm{~nm}$ & $432 \mathrm{~nm}$ \\
\hline $100 \% \mathrm{COHb}$ & $\begin{array}{l}1,2155 \\
1,2068 \\
1,2178 \\
1,2055 \\
1,2115 \\
1,2158 \\
1,1945 \\
1,2227 \\
1,2447 \\
1,2008\end{array}$ & $\begin{array}{l}0,2867 \\
0,2880 \\
0,2938 \\
0,2875 \\
0,2944 \\
0,2938 \\
0,2937 \\
0,3035 \\
0,3210 \\
0,3121\end{array}$ & $\begin{array}{l}1,220 \\
1,213 \\
1,222 \\
1,216 \\
1,209 \\
1,220 \\
1,215 \\
1,203 \\
1,225 \\
1,200\end{array}$ & $\begin{array}{l}0,300 \\
0,300 \\
0,303 \\
0,300 \\
0,295 \\
0,303 \\
0,305 \\
0,319 \\
0,309 \\
0,308\end{array}$ \\
\hline $\begin{array}{l}\bar{X} \\
S\end{array}$ & $\begin{array}{l}1,2136 \\
0,0138\end{array}$ & $\begin{array}{l}0,2975 \\
0,0114\end{array}$ & $\begin{array}{l}1,2123 \\
0,0090\end{array}$ & $\begin{array}{l}0,3047 \\
0,0066\end{array}$ \\
\hline $100 \% \mathrm{Hb}^{\mathrm{red}}$ & $\begin{array}{l}0,6365 \\
0,6382 \\
0,6380 \\
0,6405 \\
0,6421 \\
0,6422\end{array}$ & $\begin{array}{l}0,8294 \\
0,8368 \\
0,8348 \\
0,8384 \\
0,8392 \\
0,8377\end{array}$ & $\begin{array}{l}0,640 \\
0,640 \\
0,641 \\
0,643 \\
0,640 \\
0,646\end{array}$ & $\begin{array}{l}0,840 \\
0,848 \\
0,851 \\
0,852 \\
0,851 \\
0,854\end{array}$ \\
\hline $\begin{array}{l}\bar{X} \\
S\end{array}$ & $\begin{array}{l}0,6396 \\
0,0024\end{array}$ & $\begin{array}{l}0,8361 \\
0,0036\end{array}$ & $\begin{array}{l}0,6417 \\
0,0024\end{array}$ & $\begin{array}{l}0,8493 \\
0,0050\end{array}$ \\
\hline
\end{tabular}


Tabela XII - Fatores de calibraçāo obtidos experimentalmente para os espectrofotômetros e os de referência.

\begin{tabular}{lccc}
\hline \hline & \multicolumn{3}{c}{ fatores } \\
\cline { 2 - 4 } espectrofotômetro & $\mathrm{F}_{1}$ & $\bar{F}_{2}$ & $\mathrm{~F}_{3}$ \\
\hline \hline & & & \\
Beckman DU-70 & 1,3072 & 0,4651 & 1,8974 \\
Intralab DMS-80 & 1,3235 & 0,4741 & 1,8923 \\
Referência $^{158}$ & 1,3330 & 0,4787 & 1,9939 \\
\hline \hline
\end{tabular}
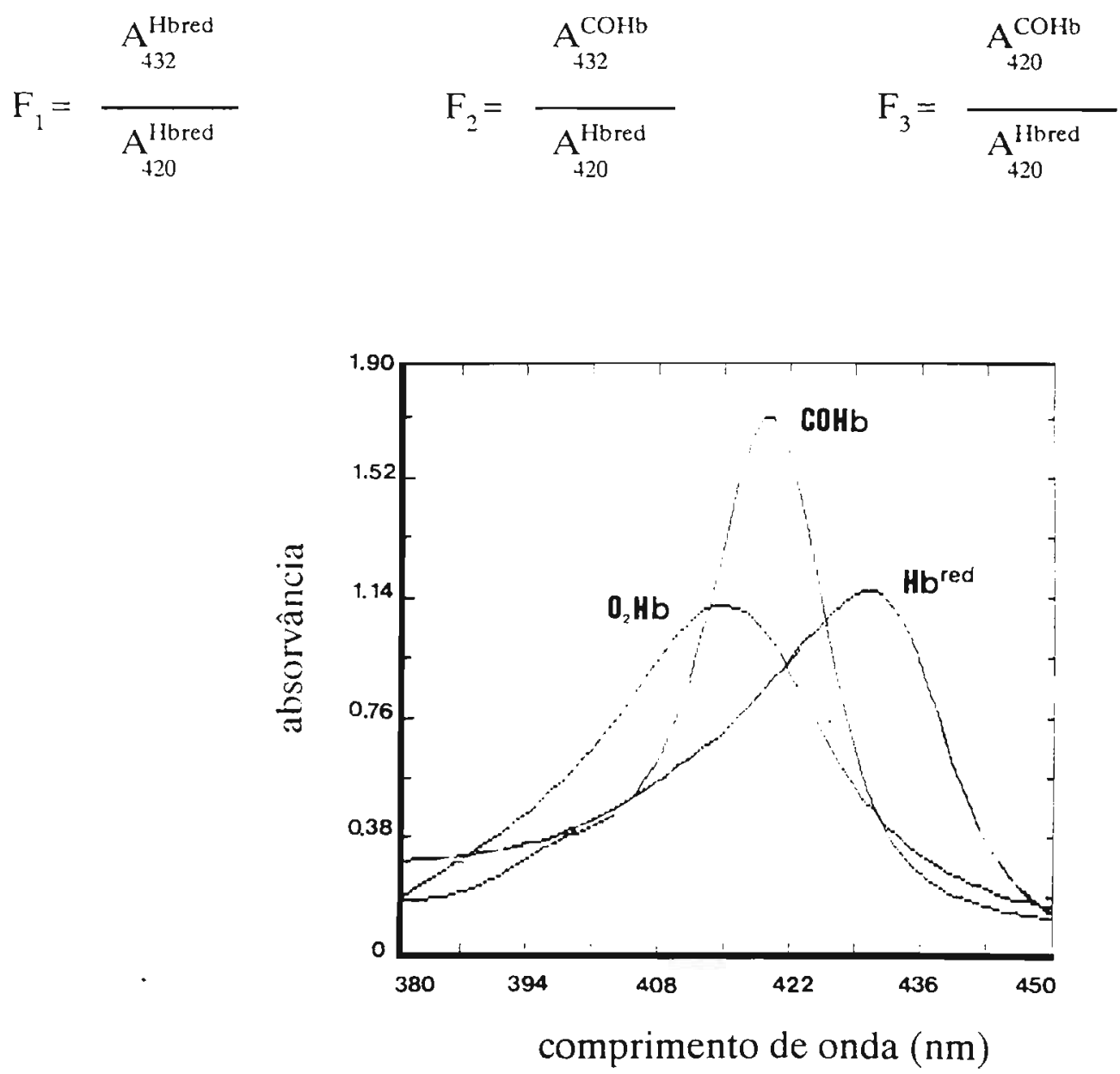

Figura 16 - Espectro de Absorção das soluçōes com $100 \%$ de carboxiemoglobina ( $\mathrm{COHb})$, $100 \%$ de oxiemoglobina $\left(\mathrm{O}_{2} \mathrm{Hb}\right)$ e $100 \%$ de Hemoglobina reduzida $\left(\mathrm{Hb}^{\text {red }}\right)$ 


\subsubsection{Linearidade da técnica de quantificação}

Os valores da \% de $\mathrm{COHb}$ obtidos nas três séries de concentrações estão relacionados na tabela XIII. São apresentados, também, os valores de COHb esperados e corrigidos, tendo em vista que as soluçōes de $100 \%$ de $\mathrm{COHb}$ usadas na preparaçāo das 3 séries mostravam teores de 92,46 / 93,16 e 105,27\% o que levou aos fatores de correção de $0,93 / 0,93$ e 1,05, respectivamente. A figura 17A representa graficamente estes resultados. A correlaçāo entre as concentraçōes de $\mathrm{COHb}$ obticias e os respectivos valores de $\mathrm{AR}$ estão mostrados na figura 17B.

A figura $17 \mathrm{~A}$ representa graficamente estes resultados. A correlação entre as concentraçōes de $\mathrm{COHb}$ obtidas e os respectivos valores de $\mathrm{AR}$ são mostrados na figura 17B.

Tabela XIII - Concentrações de carboxiemoglobina $(\% \mathrm{COHb})$ obtidas experimentalmente pela análise de 3 séries de soluçōes de diferentes concentraçōes e os respectivos valores teoricamente esperados e corrigidos.

\begin{tabular}{|c|c|c|c|c|c|c|c|c|}
\hline \multirow{2}{*}{$\begin{array}{l}\% \mathrm{COHb} \\
\text { esperada }\end{array}$} & \multicolumn{4}{|c|}{$\% \mathrm{COHb}$ esperada corrigida ${ }^{(*)}$} & \multicolumn{4}{|c|}{$\%$ COHb obtida } \\
\hline & 1 & 2 & 3 & média & 1 & 2 & 3 & $\overline{\text { média }}$ \\
\hline 1 & 0,93 & 0,93 & 1,05 & 0,97 & 0,48 & 1,10 & 2,00 & 1,19 \\
\hline 2 & 1,85 & 1,85 & 2,10 & 1,93 & 0,86 & 2,12 & 2,23 & 1,74 \\
\hline 4 & 3,71 & 3,71 & 4,21 & 3,88 & 3,17 & 3,15 & 3,62 & 3,31 \\
\hline 6 & 5,56 & 5,56 & 6,31 & 5,81 & 4,35 & 5,26 & 5,82 & 5,14 \\
\hline 8 & 7,41 & 7,41 & 8,42 & 7,75 & 5,86 & 6,33 & 8,64 & 6,91 \\
\hline 10 & 9,26 & 9,26 & 10,52 & 9,68 & 8,54 & 7,25 & 10,81 & 8,89 \\
\hline 14 & 12,96 & 12,96 & 14,73 & 13,55 & 12,84 & 11,88 & 14,65 & 13,12 \\
\hline 20 & 18,53 & 18,53 & 21,04 & 19,37 & 16,84 & 16,17 & 22,13 & 18,38 \\
\hline 30 & 27,79 & 27,79 & 31,57 & 29,05 & 25,99 & 24,62 & 33,06 & 27,69 \\
\hline 40 & 37,01 & 37,01 & 42,09 & 38,70 & 34,07 & 33,35 & 41,42 & 36,28 \\
\hline 50 & 46,32 & 46,32 & 52,61 & 48,42 & 43,48 & 42,58 & 51,10 & 45,72 \\
\hline 60 & 55,58 & 55,58 & 63,13 & 58,10 & 52,69 & 51,31 & 60,82 & 54,94 \\
\hline
\end{tabular}

$\left.{ }^{*}\right)$ pelos fatores $0,93,0,93$ e 1,05 

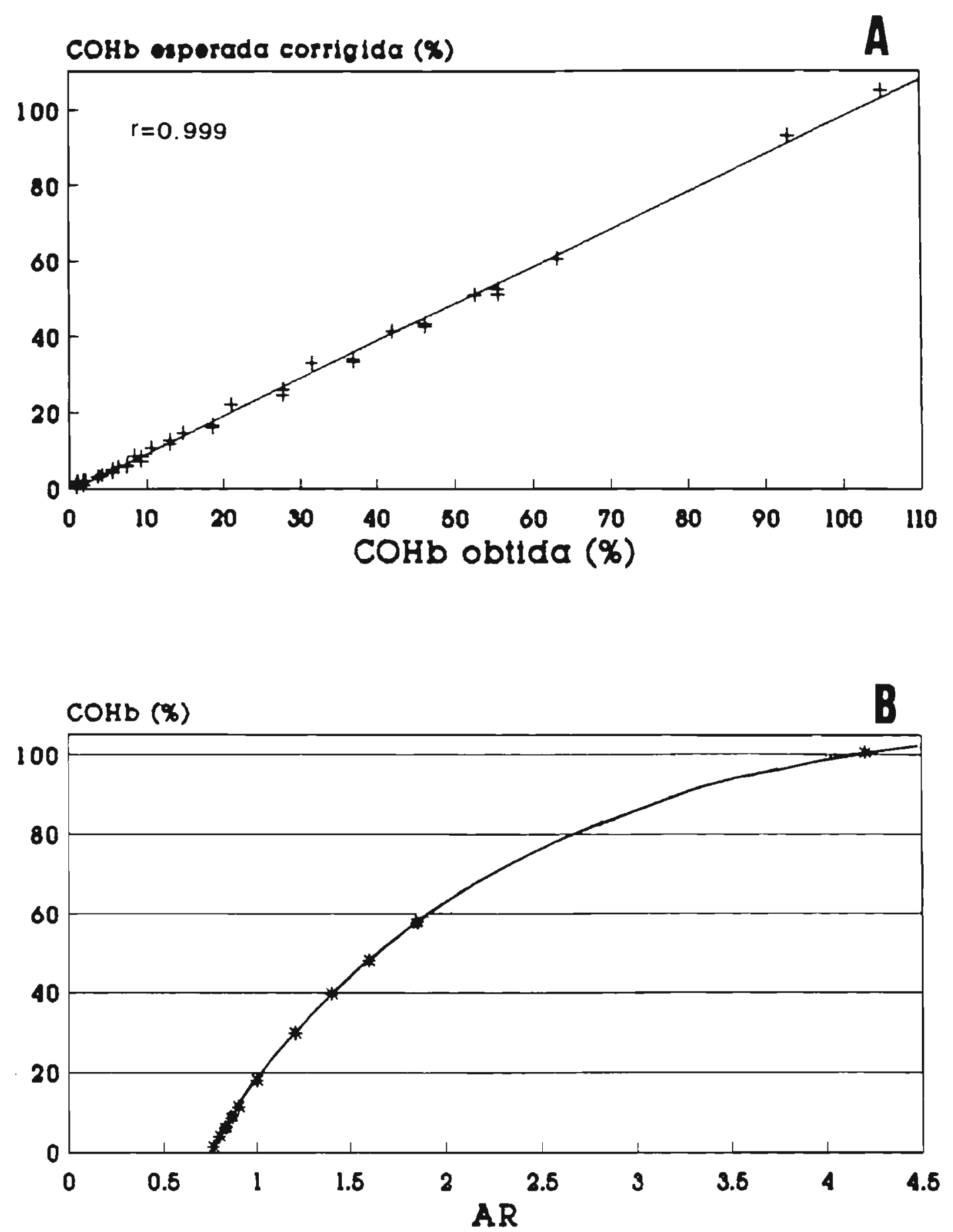

Figura 17 (A) - Correlação entre carboxiemoglobina (COHb) obtida e os teores esperados corrigidos;

(B) - Relação entre $\mathrm{COHb}$ e a razāo da absorvância em 420 e 432 am (AR). 


\subsubsection{Precisão do método}

A Tabela XIV, mostra os valores médios obtidos nas determinações $\mathrm{da} \mathrm{COHb}$ e os respectivos intervalos nas amostras utilizadas no estudo da precisāo do método. São também apresentados os valores do desvio-padrão do coeficiente de variaçāo.

Os coeficientes de variação e os desvios-padrão referentes às concentraçōes de $\mathrm{COHb}$ determinadas nas 10 soluções hemolisadas e nas 14 alíquotas diluídas, preparadas para o estudo da influência de cada etapa da técnica na precisão, estão na tabela XV.

Da mesma forma os coeficientes de variaçāo e os desvios-padrão obtidos na determinação da \% de carboxiemoglobina, para comparar o uso de pipeta automática e repipetador, ao uso de pipetas comuns, estão na tabela XVI.

Tabela XIV - Coeficiente de variação intra-série para as diferentes concentraçōes de carboxiemoglobina $(\mathrm{COHb})$.

\begin{tabular}{ccccc}
\hline \hline \multirow{2}{*}{ amostra } & $\mathrm{n}$ & $\mathrm{\%}$ COHb & $\mathrm{S}$ & $\mathrm{CV}(\%)$ \\
\cline { 3 - 4 } & & $\overline{\mathrm{x}}$ (intervalo) & & \\
\hline & 10 & $4,42(7,21$ a 7,59$)$ & 0,10 & 1,48 \\
2 & 10 & $1,01(0,96$ a 1,08$)$ & 0,09 & 1,83 \\
3 & 10 & $0,53(0,40 \text { a } 0,59)^{*}$ & 0,06 & 6,19 \\
4 & 8 & $0,15(0,06$ a 0,28$)$ & 0,06 & 11,86 \\
5 & 8 & $0,01(0,09$ a 0,07$)$ & 0,07 & 46,67 \\
6 & 8 & & 0,07 & 700,00 \\
\hline \hline
\end{tabular}


Tabela XV - Coeficientes de variação dos valores de carboxiemoglobina (COHb) obtidos nas etapas de diluição do método; diluição do sangue com a solução hemolisante $\left(1^{\mathrm{a}}\right)$ e diluição do hemolisado com solução redutora $\left(2^{\mathfrak{a}}\right)$.

\begin{tabular}{llcll}
\hline \hline \multirow{2}{*}{ etapa } & $\mathrm{n}$ & $\mathrm{\% OCHb}$ & $\mathrm{CV}(\%)$ \\
\cline { 3 - 5 } & $\overline{\mathrm{x} \text { (intervalo) }}$ & & \\
\hline \hline
\end{tabular}

hemólise e redução

reduçäo

$\mathrm{n}$ = número de determinações

Tabela XVI - Coeficiente de variação obtidos na determinação do teor de carboxiemoglobina ( $\mathrm{COHb}$ ) em amostras de sangue (a e b) utilizando pipetas automáticas e repipetadores ou pipetas comuns.

\begin{tabular}{llllll}
\hline \hline pipeta & amostra & $\mathrm{n}$ & $\mathrm{COHb}(\%)$ \\
& & $\mathrm{x}$ (intervalo) & $\mathrm{CV}(\%)$ \\
\hline \hline
\end{tabular}

$\begin{array}{lllll}\text { a } & 13 & 4,54(4,37 \text { a } 4,73) & 0,08 & 1,82\end{array}$

comum

$\begin{array}{lllll}\text { b } & 10 & 0,93(0,76 \text { a } 1,03) & 0,09 & 9,73\end{array}$

$\begin{array}{lllll}\text { a } & 12 & 4,77(4,62 \text { a } 4,95) & 0,08 & 1,69\end{array}$

automática

e repipetador

\begin{tabular}{ccrrrrr} 
b & 10 & $1,16(1,07$ a 1,37$)$ & 0,08 & 7,07 \\
\hline \hline $\mathrm{n}=$ número de determinações
\end{tabular}




\subsubsection{Estabilidade das leituras de absorvância}

A tabela XVII mostra os valores de $\mathrm{COHb}$ obtidos com as leituras das absorvâncias, em diferentes tempos após o preparo das soluções com concentraçōes crescentes de $\mathrm{COHb}$. A Figura 18 representa esses valores em função do tempo.

Tabela XVII - Valores de carboxiemoglobina (COHb) obtidos após períodos de tempo crescentes entre a preparação da solução reduzida e a leitura das absorvâncias.

\begin{tabular}{crrrrrrr}
\hline \hline $\begin{array}{c}\text { COHb } \\
\text { esperada }\end{array}$ & 10 & 20 & 30 & $\begin{array}{c}\text { tempo (min) } \\
40\end{array}$ & 50 & 60 & 90 \\
\hline \hline & & & & & & & \\
2 & 1,98 & 2,07 & 2,02 & 2,15 & 2,04 & 2,01 & 2,18 \\
4 & 4,19 & 4,17 & 4,36 & 4,25 & 4,20 & 4,37 & 4,19 \\
6 & 6,25 & 6,04 & 6,09 & 6,17 & 6,27 & 6,33 & 6,21 \\
10 & 11,24 & 10,93 & 10,54 & 10,96 & 11,10 & 10,59 & 11,01 \\
15 & 15,78 & 16,16 & 15,88 & 15,50 & 15,26 & 15,34 & 15,03 \\
25 & 27,08 & 26,77 & 27,64 & 25,99 & 25,96 & 25,51 & 25,02 \\
50 & 52,50 & 51,72 & 51,05 & 50,78 & 50,00 & 49,29 & 48,23 \\
100 & 94,06 & 93,64 & 92,41 & 91,76 & 91,03 & 89,90 & 87,27 \\
\hline \hline
\end{tabular}

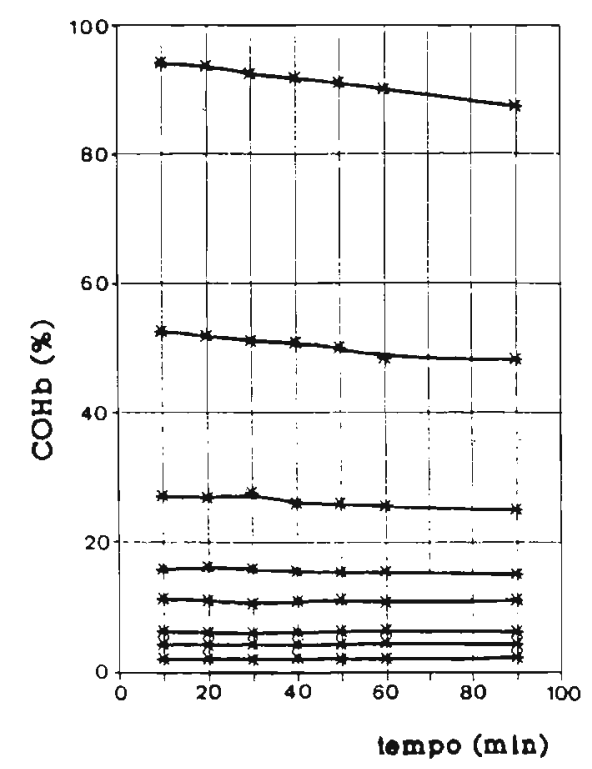

Figura 18 - Variação das concentraçōes de carboxiemoglobina (COHb) em função do tempo entre a preparação da amostra e a leitura das absorvâncias; Soluçōes mantidas em células abertas. 


\subsubsection{Estabilidade da carboxiemoglobinemia nas amostras}

As concentrações de $\mathrm{COHb}$ obtidas em análises diárias das 8 amostras estudadas são mostradas na tabela XVIII. Cada valor de COHb representa a média de três determinaçōes.

Tabela XVIII - Concentraçōes de carboxiemoglobina nas alíquotas (a, b e c) de 8 amostras de sangue, determinadas em dias subseqüentes.

\begin{tabular}{|c|c|c|c|c|c|c|c|}
\hline \multirow{3}{*}{ amostra } & & \multicolumn{6}{|c|}{ carboxiemoglobina $(\%)$} \\
\hline & & \multicolumn{4}{|c|}{ dias após a colheita } & \multirow{2}{*}{7} & \multirow{2}{*}{8} \\
\hline & & 1 & 2 & 3 & 4 & & \\
\hline 1 & $\begin{array}{l}a \\
b \\
c\end{array}$ & 3,41 & 3,36 & $\begin{array}{l}3,26 \\
2,91\end{array}$ & $\begin{array}{l}3,35 \\
3,43\end{array}$ & $\begin{array}{l}3,65 \\
3,58\end{array}$ & $\begin{array}{l}3,53 \\
3,72 \\
3,57\end{array}$ \\
\hline 2 & $\begin{array}{l}a \\
b \\
c\end{array}$ & 2,63 & 3,01 & $\begin{array}{l}3,02 \\
2,67\end{array}$ & $\begin{array}{l}2,76 \\
2,74\end{array}$ & $\begin{array}{l}2,72 \\
2,74\end{array}$ & $\begin{array}{l}3,30 \\
2,60 \\
2,66\end{array}$ \\
\hline 3 & $\begin{array}{l}\mathrm{a} \\
\mathrm{b}\end{array}$ & 4,54 & 4,62 & $\begin{array}{l}4,59 \\
4,73\end{array}$ & $\begin{array}{l}4,73 \\
4,68\end{array}$ & $\begin{array}{l}4,77 \\
4,66\end{array}$ & $\begin{array}{l}4,43 \\
4,68 \\
4,72\end{array}$ \\
\hline 4 & $\begin{array}{l}a \\
b \\
c\end{array}$ & 0,87 & 0,94 & $\begin{array}{l}0,94 \\
0,97\end{array}$ & $\begin{array}{l}0,98 \\
1,00\end{array}$ & $\begin{array}{l}1,16 \\
0,92\end{array}$ & $\begin{array}{l}0,84 \\
1,02 \\
1,11\end{array}$ \\
\hline 5 & $\begin{array}{l}a \\
b \\
c\end{array}$ & 0,99 & 1,2 & $\begin{array}{l}1,21 \\
1,34\end{array}$ & $\begin{array}{l}1,21 \\
1,25\end{array}$ & $\begin{array}{l}1,10 \\
1,21\end{array}$ & $\begin{array}{l}1,32 \\
1,33 \\
1,46\end{array}$ \\
\hline 6 & $\begin{array}{l}a \\
b \\
c\end{array}$ & 1,73 & 1,99 & $\begin{array}{l}2,10 \\
2,09\end{array}$ & $\begin{array}{l}2,16 \\
2,18\end{array}$ & $\begin{array}{l}2,14 \\
1,97\end{array}$ & $\begin{array}{l}1,95 \\
2,26 \\
2,11\end{array}$ \\
\hline 7 & $\begin{array}{l}a \\
b \\
c\end{array}$ & 1,79 & 2,10 & $\begin{array}{l}1,95 \\
2,05\end{array}$ & $\begin{array}{l}2,36 \\
2,17\end{array}$ & $\begin{array}{l}1,91 \\
2,02\end{array}$ & $\begin{array}{l}2,01 \\
2,22 \\
2,01\end{array}$ \\
\hline 8 & $\begin{array}{l}a \\
b \\
c\end{array}$ & 0,85 & 0,77 & $\begin{array}{l}0,68 \\
0,79\end{array}$ & $\begin{array}{l}0,84 \\
0,78\end{array}$ & $\begin{array}{l}0,70 \\
0,70\end{array}$ & $\begin{array}{l}0,98 \\
0,93 \\
0,98\end{array}$ \\
\hline
\end{tabular}




\subsubsection{Influência da matriz biológica}

\subsubsection{Conteúdo hemoglobínico}

Os resultados obtidos na determinação da \% de carboxiemoglobina em amostras de sangue preparadas com conteúdo variável de hemoglobina são mostrados na tabela XIX.

Tabela XIX - Valores de hemoglobina, hematócrito e concentração de carboxiemoglobina (COHb) em 5 alíquotas de amostras de sangue preparadas para conteúdo variável de hemoglobina total.

\begin{tabular}{|c|c|c|c|}
\hline alíquota & $\begin{array}{c}\text { hemoglobina } \\
(\mathrm{g} / \mathrm{c})\end{array}$ & $\begin{array}{c}\text { hematócrito } \\
(\%)\end{array}$ & $\underset{(\%)}{\mathrm{COHb}}$ \\
\hline A & 22,7 & 64 & 1,12 \\
\hline B & 19,0 & 54 & 1,14 \\
\hline $\mathrm{C}$ & 14,9 & 42 & 1,22 \\
\hline $\mathrm{D}$ & 14,8 & 42 & $1,06^{*}$ \\
\hline $\mathrm{E}$ & 2,8 & 8 & 1,16 \\
\hline \multicolumn{2}{|c|}{$\begin{array}{l}\bar{x} \\
\mathrm{~S} \\
\mathrm{CV}(\%)\end{array}$} & & $\begin{array}{l}1,14 \\
0,06 \\
5,12\end{array}$ \\
\hline
\end{tabular}

$\left({ }^{*}\right)$ teor da amostra obtido sem a alteração da hemoglobinemia 
Os resultados obtidos na determinação da concentração de carboxiemoglobina e de hemoglobina total após as diferentes diluições de $100 \mu \mathrm{L}$ de 3 amostras de sangue, em volumes variáveis de solução hemolisante, sāo mostrados na tabela XX.

Tabela XX - Concentrações de hemoglobina (Hb), em g\%, e carboxiemoglobina $(\mathrm{COHb})$, em \%, em soluçōes obtidas pela diluiçāo de sangue $(100 \mu \mathrm{L})$ em volumes variáveis de solução hemolisante.

\begin{tabular}{|c|c|c|c|c|c|c|}
\hline \multirow{3}{*}{$\begin{array}{l}\text { volume de } \\
\text { solução } \\
\text { hemolisante } \\
(\mathrm{mL})\end{array}$} & \multicolumn{6}{|c|}{ amostra de sangue } \\
\hline & \multicolumn{2}{|c|}{1} & \multicolumn{2}{|c|}{2} & \multicolumn{2}{|c|}{3} \\
\hline & $\mathrm{Hb}$ & $\mathrm{COHb}$ & $\mathrm{Hb}$ & $\overline{\mathrm{COHb}}$ & $\mathrm{Hb}$ & $\mathrm{COHb}$ \\
\hline 8,0 & 24,8 & 1,55 & 25,4 & 5,67 & 25,7 & 10,6 \\
\hline 10,0 & 19,9 & $1,35_{*}$ & 20,4 & $5,59_{*}$ & 20,6 & $10,0_{*}$ \\
\hline 12,0 & 16,6 & $1.51^{*}$ & 17,0 & $5,56^{*}$ & 17,2 & $10,2^{*}$ \\
\hline 14,0 & 14,3 & 1,42 & 14,6 & 5,52 & 14,8 & 9,7 \\
\hline 16,0 & 12,5 & 1,31 & 12,8 & 5,90 & 12,9 & 9,7 \\
\hline 18,0 & 11,1 & 1,54 & 11,4 & 5,52 & 11,5 & 9,7 \\
\hline 20,0 & 10,0 & 1,43 & 10,2 & 5,42 & 10,4 & 9,6 \\
\hline$\overline{\mathrm{x}}$ & & 1,44 & & 5,64 & & 9,93 \\
\hline $\mathrm{S}$ & & 0,09 & & 0,19 & & 0,36 \\
\hline $\mathrm{CV}(\mathscr{\%})$ & & 6,47 & & 3,43 & & 3,66 \\
\hline
\end{tabular}

$\left({ }^{*}\right)$ teor da amostra obtido sem alteração do teor hemoglobínico 


\subsubsection{Lipemia}

A tabela XXI mostra os valores da concentração de carboxiemoglobina, hemoglobina, hematócrito e de lipídios totais encontrados nas amostras de sangue colhidas em jejum e entre uma a duas horas após a refeição.

A tabela XXII mostra o resultado obtido na determinaçāo da COHb em amostra adicionada de quantidades diferentes de plasma lipêmico.

A figura 19 mostra o espectro de absorção correspondente a uma amostra colhida em jejum e os da mesma amostra adicionada de 100 a $200 \mu \mathrm{L}$ de plasma, de amostra colhida após a refeiçāo, do mesmo indivíduo.

Tabela XXI - Teores de lipídios totais, hemoglobina $(\mathrm{Hb})$ e hematócrito $(\mathrm{Ht})$ em amostras de sangue colhidas em jejum(a) e entre uma e duas horas após a refeição (b); teores de carboxiemoglobina (COHb) nas amostras colhidas em jejum.

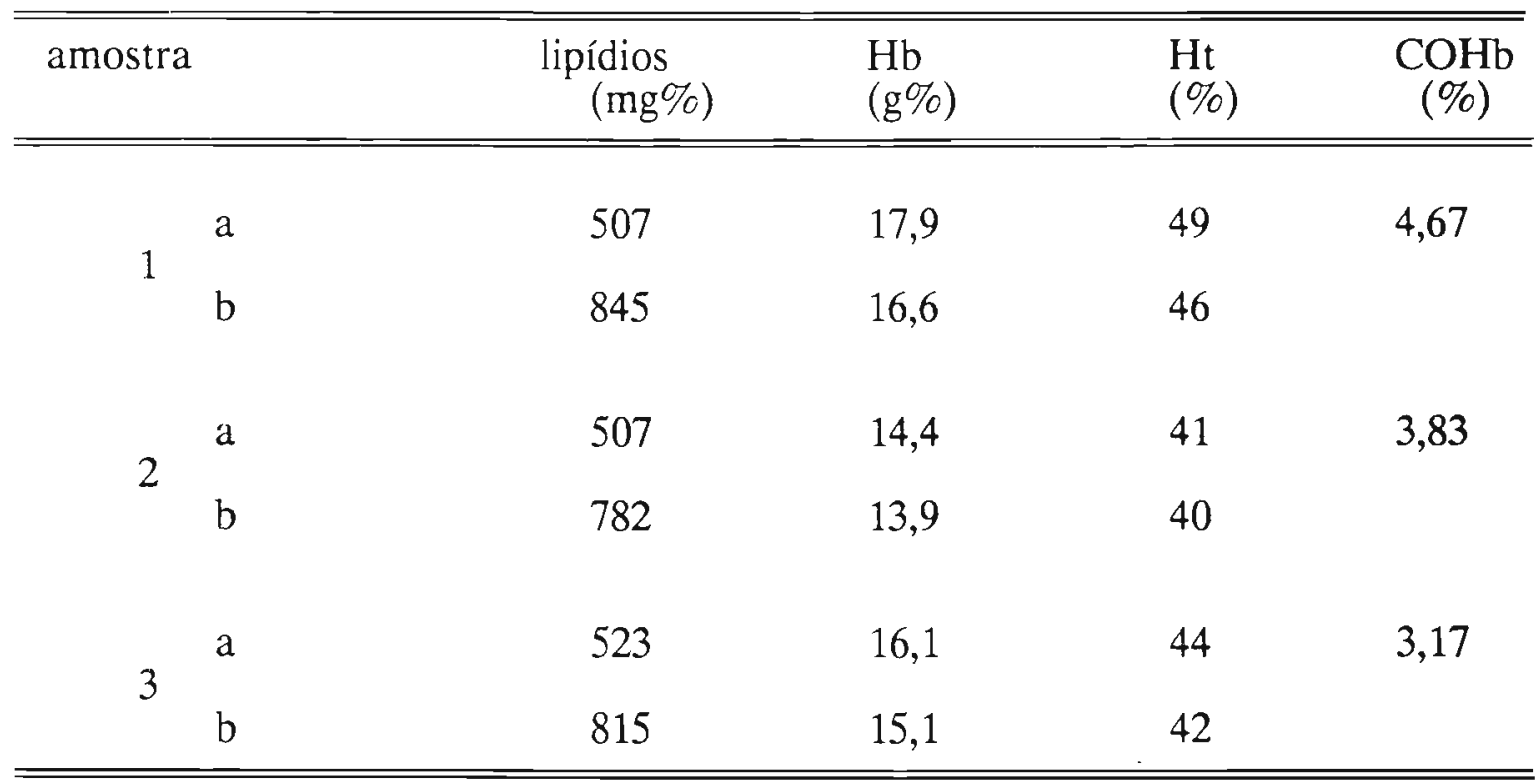


Tabela XXII - Concentraçōes de carboxiemoglobina (COHb) e lipídios totais de amostras de sangue colhidas em jejum (a) e adicionadas de $100 \mu \mathrm{L}$ (b) e $200 \mu \mathrm{L}$ (c) de plasma lipêmico.

\begin{tabular}{cccc}
\hline \hline \multirow{2}{*}{ amostra } & & $\begin{array}{c}\text { lipidios } \\
\text { totais } \\
(\mathrm{mg} \%)\end{array}$ & $\begin{array}{c}\mathrm{COHb} \\
(\%)\end{array}$ \\
\hline \hline & & & \\
& & 507 & 4,67 \\
1 & $\mathrm{a}$ & 1352 & 4,70 \\
& $\mathrm{~b}$ & 2197 & 4,88 \\
& $\mathrm{c}$ & & 3,83 \\
& & 507 & 3,83 \\
2 & $\mathrm{a}$ & 1287 & 4,03 \\
& $\mathrm{~b}$ & 2071 & \\
& $\mathrm{c}$ & & 3,17 \\
& & 523 & 3,25 \\
& & 1338 & 3,44 \\
\hline \hline
\end{tabular}

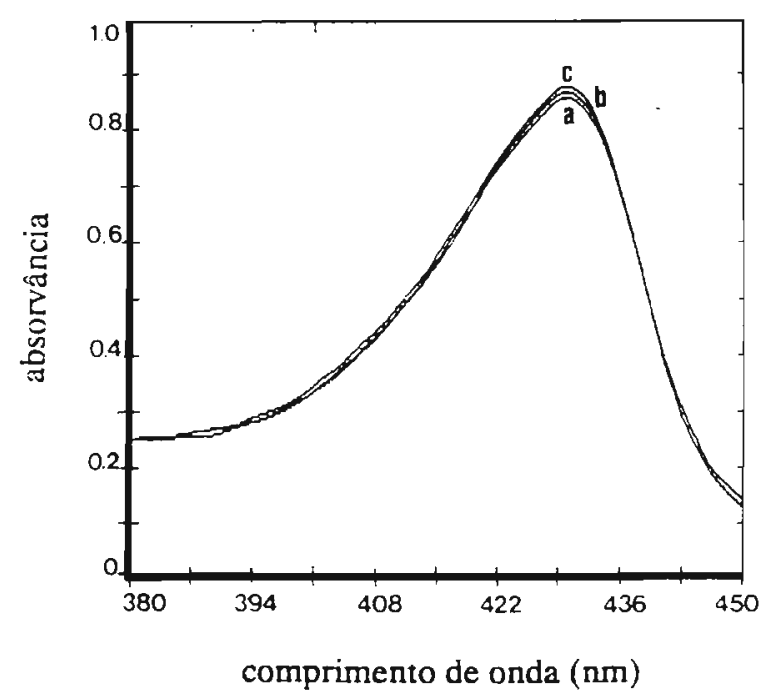

Figura 19 - Espectro da absorçāo de amostra de sangue colhida em jejum (a) e após a adição de quantidades crescentes de lipídios (b) e (c). 


\subsection{Carboxiemoglobinemia em indivíduos expostos ocupacionalmente ao monóxido de carbono}

Os resultados obtidos na determinação da concentração de COHb em trabalhadores de fornos de fundição de minérios de metais, do subgrupo Ia, fumantes, são mostrados na tabela XXIII. A tabela XXIV apresenta os resultados obtidos para os não-fumantes do mesmo grupo.

Tabela XXIII - Concentração de carboxiemoglobina (COHb) em amostras de sangue de trabalhadores do subgrupogrupo Ia, fumantes, determinada no início (i) e no final (f) da jornada de trabalho.

\begin{tabular}{|c|c|c|c|c|c|}
\hline \multirow{2}{*}{ amostra } & \multirow{2}{*}{$\begin{array}{l}\text { idade } \\
\text { (ano) }\end{array}$} & \multirow{2}{*}{$\begin{array}{l}\text { consumo } \\
\text { diário de } \\
\text { cigarro }\end{array}$} & \multicolumn{3}{|c|}{$\mathrm{COHb}(\%)^{\circ}$} \\
\hline & & & $\bar{i}$ & $\mathrm{f}$ & $(\mathrm{f}-\mathrm{i})$ \\
\hline 1 & 44 & 2 & 0,17 & 0,39 & 0,22 \\
\hline 2 & 41 & 20 & 0,90 & 0,48 & 0,42 \\
\hline 3 & 42 & 5 & 0,39 & 0,61 & 0,22 \\
\hline 4 & 27 & 20 & 1,26 & 0,95 & 0,31 \\
\hline 5 & 31 & 20 & 0,76 & 1,00 & 0,24 \\
\hline 6 & 33 & 20 & 3,43 & 1,09 & 2,34 \\
\hline 7 & 36 & 20 & 1,55 & 1,18 & 0,37 \\
\hline 8 & 36 & 20 & 1,03 & 1,29 & 0,26 \\
\hline 9 & 29 & 10 & 0,98 & 1,36 & 0,38 \\
\hline 10 & 32 & 6 & 1,33 & 1,45 & 0,12 \\
\hline 11 & 30 & 17 & 1,42 & 1,62 & 0,20 \\
\hline 12 & 34 & 20 & 1,22 & 1,90 & 0,68 \\
\hline 13 & 30 & 20 & 2,12 & 2,16 & 0,04 \\
\hline 14 & 30 & 13 & 1,00 & 2,26 & 1,26 \\
\hline 15 & 28 & 10 & 1,48 & 2,31 & 0,83 \\
\hline 16 & 27 & 15 & 2,44 & 2,32 & 0,88 \\
\hline 17 & 29 & 10 & 0,58 & 2,53 & 1,95 \\
\hline 18 & 26 & 40 & 2,01 & 2,57 & 0,56 \\
\hline 19 & 30 & 7 & 2,50 & 2,80 & 0,30 \\
\hline 20 & 37 & 60 & 1,45 & 3,14 & 1,69 \\
\hline 21 & 30 & 20 & 2,01 & 3,18 & 1,17 \\
\hline 22 & 41 & 30 & 2,40 & 3,30 & 0,90 \\
\hline 23 & 29 & 20 & 2,00 & 3,40 & 1,40 \\
\hline 24 & 26 & 15 & 4,07 & 3,69 & 0,38 \\
\hline 25 & 31 & 20 & 3,24 & 4,17 & 0,93 \\
\hline 26 & 35 & 20 & 2,70 & 4,29 & 1,59 \\
\hline 27 & 27 & 13 & 3,60 & 4,40 & 0,80 \\
\hline 28 & 35 & 20 & 2,62 & 4,46 & 1,84 \\
\hline 29 & 46 & 20 & 4,09 & 5,06 & 0,97 \\
\hline 30 & 24 & 15 & 4,07 & 5,90 & 1,83 \\
\hline 31 & 49 & 20 & 3,33 & 5,95 & 2,64 \\
\hline 32 & 33 & 30 & 5,20 & 6,00 & 0,80 \\
\hline 33 & 29 & 20 & 1,80 & 6,03 & 4,24 \\
\hline 34 & 28 & 20 & 4,00 & 7,10 & 3,10 \\
\hline $\bar{x}$ & 33 & 19 & 2,15 & 2,95 & 0,78 \\
\hline$S$ & 6 & 10 & 1,26 & 1,84 & 1,20 \\
\hline
\end{tabular}

(*) valor mínimo confiável $0,50 \%$ 
Tabela XXIV - Concentração de carboxiemoglobina (COHb) em amostras de sangue de trabalhadores do grupo la, não-fumantes, determinada após a jornada de trabalho.

\begin{tabular}{rrr}
\hline \hline amostra & $\begin{array}{c}\text { idade } \\
\text { (ano) }\end{array}$ & $\begin{array}{c}\text { COHb } \\
(\%)\end{array}$ \\
\hline \hline & & \\
1 & 28 & 0,26 \\
3 & 37 & 0,48 \\
4 & 34 & 0,49 \\
5 & 34 & 0,51 \\
6 & 36 & 0,52 \\
7 & 26 & 0,54 \\
8 & 33 & 0,56 \\
9 & 29 & 0,60 \\
10 & 32 & 0,60 \\
11 & 29 & 0,62 \\
12 & 23 & 0,68 \\
13 & 25 & 0,70 \\
14 & 26 & 0,71 \\
15 & 30 & 0,75 \\
16 & 40 & 0,76 \\
17 & 33 & 0,90 \\
18 & 55 & 0,92 \\
19 & 37 & 1,00 \\
20 & 46 & 1,10 \\
21 & 46 & 2,05 \\
22 & 44 & 2,10 \\
23 & 30 & 2,20 \\
$\bar{x}$ & 28 & 5,99 \\
S & 34 & 1,09 \\
\hline \hline
\end{tabular}

(*) valor mínimo confiável $0,50 \%$

Os resultados obtidos na determinação da concentraçāo de $\mathrm{COHb}$ em trabalhadores de fornos de fundição de minérios de metais, do subgrupo Ib, são mostrados nas tabelas XXV e XXVI, fumantes e não-fumantes, respectivamente. 
Tabela XXV - Concentração de carboxiemoglobina em amostras de sangue de trabalhadores do grupo $\mathrm{Ib}$, fumantes, determinada no início (i) e no final (f) da jornada de trabalho.

\begin{tabular}{|c|c|c|c|c|}
\hline \multirow{2}{*}{$\begin{array}{c}\text { área } \\
\text { de } \\
\text { trabalho }\end{array}$} & \multirow{2}{*}{ amostra } & \multirow{2}{*}{$\begin{array}{l}\text { idade } \\
\text { (ano) }\end{array}$} & cigarro & carboxiemoglobina(\%) \\
\hline & & & $\begin{array}{l}\text { consumo marca } \\
\text { diário }\end{array}$ & $(\mathrm{f}-\mathrm{i})$ \\
\hline
\end{tabular}

fornos

$\begin{array}{lllclll}1 & 33 & 25 & \text { Continental } & 4,20 & 4,60 & 0,40 \\ 2 & 22 & 20 & \text { Carlton } & 4,22 & 4,67 & 1,11 \\ 3 & 50 & 20 & \text { Belmont } & 5,41 & 6,50 & 1,09 \\ 4 & 39 & 20 & \text { Hollywood } & 4,73 & 6,70 & 1,97\end{array}$

vazamento

\begin{tabular}{ccccccc}
5 & 24 & 5 & Continental & 1,34 & 1,03 & $-0,31$ \\
6 & 35 & 10 & Monterey & 3,32 & 3,31 & $-0,01$ \\
7 & 45 & 20 & Continental & 4,86 & 4,78 & $-0,08$ \\
\hline $\bar{x}$ & 35 & 17 & & 4,01 & 4,51 & 0,60 \\
$\mathrm{~S}$ & 10 & 7 & & 1,34 & 1,93 & 0,83 \\
\hline \hline
\end{tabular}

Tabela XXVI - Concentraçāo de carboxiemoglobina ( $\mathrm{COHb})$ em amostras de sangue de trabalhadores do grupo $\mathrm{Ib}$, não-fumantes, determinada no final de jornada de trabalho.

\begin{tabular}{lccc}
\hline \hline $\begin{array}{l}\text { área de } \\
\text { trabalho }\end{array}$ & amostra & $\begin{array}{l}\text { idade } \\
\text { (ano) }\end{array}$ & $\begin{array}{l}\text { COHb } \\
(\%)\end{array}$ \\
\hline \hline & & & \\
fornos & 1 & 43 & 1,09 \\
& 2 & 57 & 1,11 \\
& 3 & 37 & 1,16 \\
& 4 & 42 & 1,24 \\
& 5 & 46 & 1,26 \\
vazamento & 6 & 42 & 1,30 \\
& 7 & 48 & 0,86 \\
& 8 & 32 & 1,10 \\
& 9 & 41 & 1,10 \\
& 10 & 29 & 1,20 \\
& 11 & 42 & 1,23 \\
& 12 & 41 & 1,48 \\
\hline & 13 & 46 & 1,18 \\
& 14 & 43 & 0,15 \\
\hline \hline
\end{tabular}


As tabelas XXVII e XXVIII, mostram os resultados obtidos na determinação da concentração de $\mathrm{COHb}$ em trabalhadores de fornos de fundição de minérios de metais do subgrupo Ic, fumantes e não-fumantes, respectivamente.

Tabela XXVII - Concentraçāo de carboxiemoglobina (COHb) em amostras de sangue de trabalhadores do subgrupo Ic, fumantes, determinada no final da jornada de trabalho.

\begin{tabular}{|c|c|c|c|c|c|}
\hline \multirow{2}{*}{$\begin{array}{l}\text { área de } \\
\text { trabalho }\end{array}$} & \multirow{2}{*}{ amostra } & \multirow{2}{*}{$\begin{array}{l}\text { idade } \\
\text { (ano) }\end{array}$} & & & \multirow{2}{*}{$\begin{array}{r}\mathrm{COHb} \\
(\%)\end{array}$} \\
\hline & & & $\begin{array}{l}\text { consumo } \\
\text { diário }\end{array}$ & marca & \\
\hline
\end{tabular}

fornos

vazamento

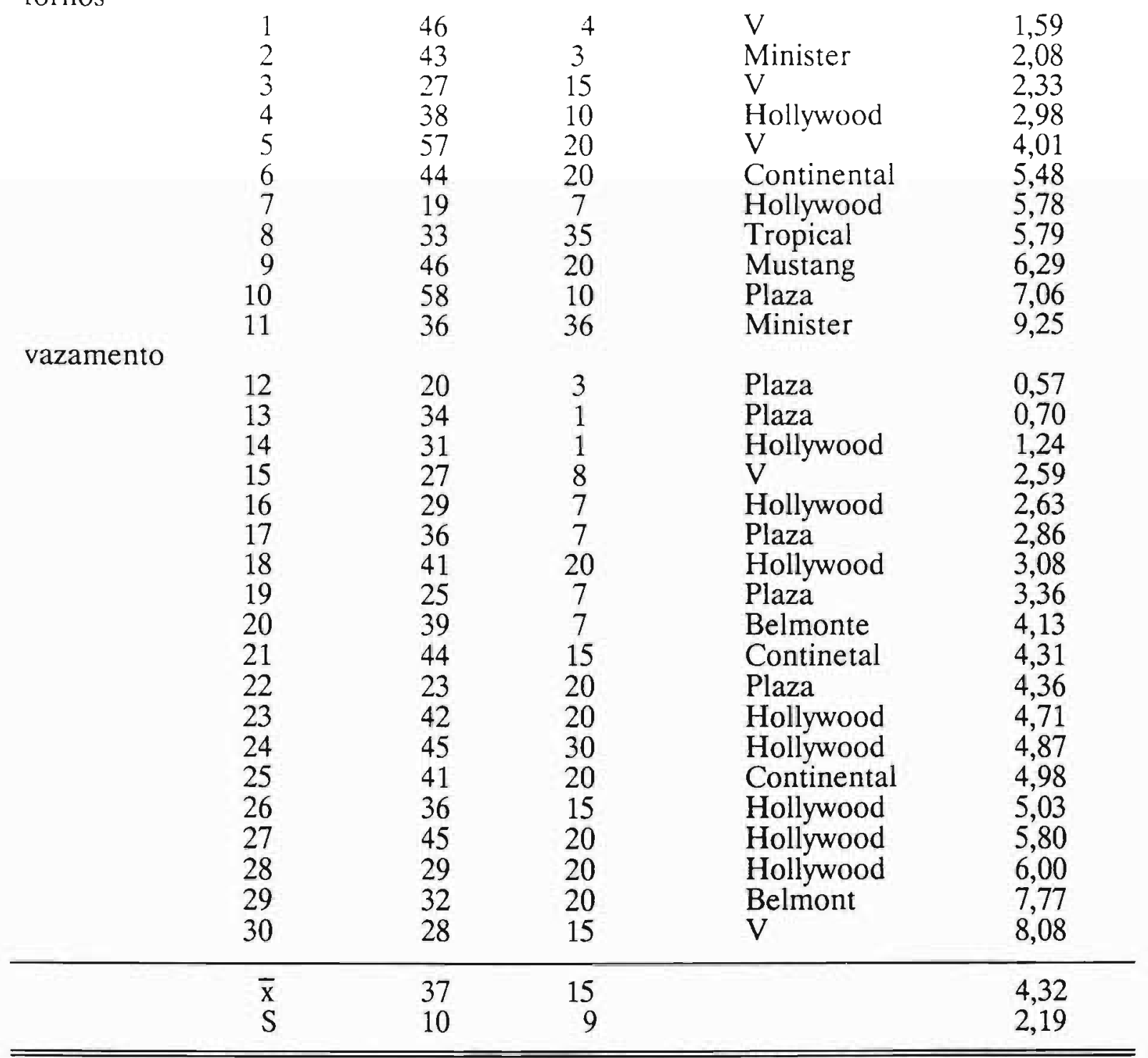


Tabela XXVIII - Concentração de carboxiemoglobina (COHb) em amostras de sangue de trabalhadores do subgrupo Ic, não-fumantes, determinada no final da jornada de trabalho.

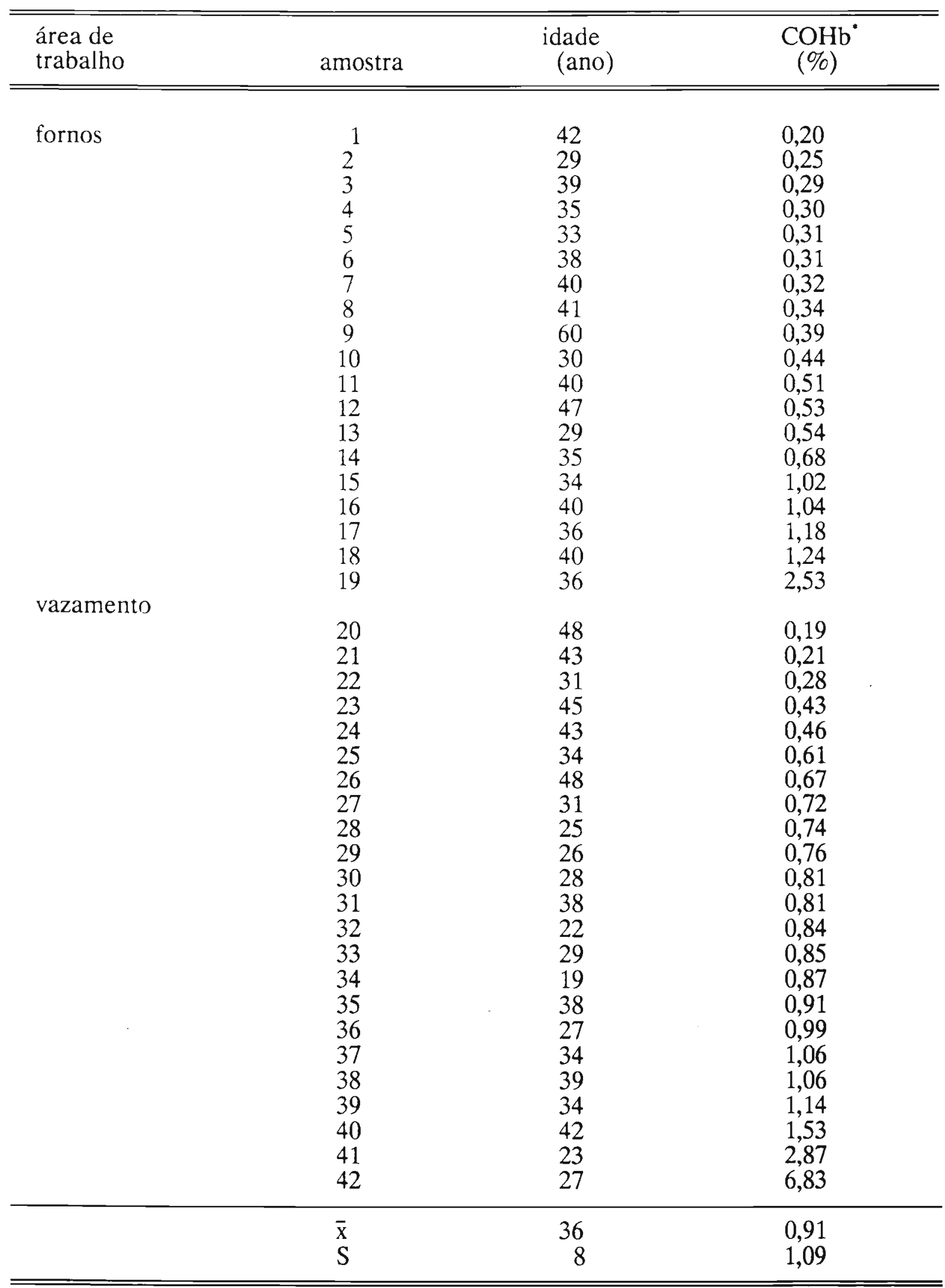

(*) Valor mínimo confiável $0,50 \%$ 
Os resultados obtidos na determinação da carboximeglobinemia em indivíduos que trabalham na regulagem de motores de veículos, do grupo II, são mostrados nas tabelas XXIX e XXXX, respectivamente, para indivíduos fumantes e não-fumantes.

Tabela XXIX - Concentração de carboxiemoglobina (COHb) em amostras de sangue de trabalhadores do grupo II, fumantes, determinada no final da jornada de trabalho.

\begin{tabular}{|c|c|c|c|c|c|}
\hline \multirow{3}{*}{ amostra } & \multirow{3}{*}{$\begin{array}{l}\text { idade } \\
\text { (ano) }\end{array}$} & \multicolumn{3}{|c|}{ cigarro } & \multirow{3}{*}{$\begin{array}{c}\mathrm{COHb} \\
(\%)\end{array}$} \\
\hline & & \multicolumn{2}{|l|}{ consumo } & \multirow[t]{2}{*}{ marca } & \\
\hline & & no dia & por dia & & \\
\hline 1 & 33 & 1 & 2 & Shelton & 2,17 \\
\hline 2 & 19 & 2 & 5 & Marlboro & 2,86 \\
\hline 3 & 25 & 5 & 18 & Marlboro & 4,85 \\
\hline 4 & 26 & 18 & 40 & Shelton & 5,07 \\
\hline 5 & 29 & 4 & 6 & Carlton & 5,12 \\
\hline 6 & 36 & 6 & 10 & Marlboro & 5,22 \\
\hline 7 & 43 & 1 & 2 & Shelton & 5,77 \\
\hline 8 & 34 & 8 & 20 & Winston & 6,09 \\
\hline 9 & 41 & 4 & 10 & Ritz & 6,25 \\
\hline 10 & 26 & 9 & 17 & Ritz & 6,80 \\
\hline 11 & 56 & 14 & 15 & Leuxer & 7,15 \\
\hline 12 & 28 & 10 & 20 & Belmont & 7,45 \\
\hline 13 & 20 & 8 & 15 & Marlboro & 7,53 \\
\hline 14 & 29 & 7 & 10 & Plaza & 7,82 \\
\hline 15 & 27 & 12 & 10 & Galax & 7,84 \\
\hline 16 & 35 & 12 & 15 & Shelton & 7,91 \\
\hline 17 & 23 & 20 & 20 & Free & 7,96 \\
\hline 18 & 37 & 6 & 10 & Free & 8,43 \\
\hline 19 & 24 & 10 & 20 & Plaza & 8,43 \\
\hline 20 & 25 & 8 & 10 & Marlboro & 8,54 \\
\hline 21 & 42 & 10 & 20 & Hollywood & 8,68 \\
\hline 22 & 19 & 6 & 8 & Hollywood & 8,83 \\
\hline 23 & 30 & 5 & 10 & Minister & 8,93 \\
\hline 24 & 22 & 8 & 15 & Mariboro & 9,18 \\
\hline 25 & 42 & 10 & 15 & Plaza & 9,44 \\
\hline 26 & 33 & 10 & 20 & Hollywood & 9,62 \\
\hline 27 & 34 & 8 & 25 & Hilton & 9,88 \\
\hline 28 & 18 & 9 & 13 & Marlboro & 10,95 \\
\hline 29 & 41 & 10 & 20 & Free & 11,99 \\
\hline$\overline{\mathrm{x}}$ & 31 & 8 & 15 & & 7,48 \\
\hline S & 8 & 4 & 8 & & 2,22 \\
\hline
\end{tabular}


Tabela XXX - Concentração de carboxiemoglobina (COHb) em amostras de sangue de trabalhadores do grupo II, não-fumantes, determinada no final da jornada de trabalho.

\begin{tabular}{|c|c|c|}
\hline amostra & $\begin{array}{l}\text { idade } \\
\text { (ano) }\end{array}$ & $\begin{array}{l}\mathrm{COHb} \\
(\%)\end{array}$ \\
\hline 1 & 44 & 1,81 \\
\hline 2 & 32 & 1,97 \\
\hline 3 & 20 & 2,08 \\
\hline 4 & 26 & 2,09 \\
\hline 5 & 33 & 2,18 \\
\hline 6 & 42 & 2,27 \\
\hline 7 & 26 & 2,61 \\
\hline 8 & 35 & 2,70 \\
\hline 9 & 40 & 2,83 \\
\hline 10 & 20 & 3,02 \\
\hline 11 & 21 & 3,03 \\
\hline 12 & 20 & 3,28 \\
\hline 13 & 57 & 3,37 \\
\hline 14 & 42 & 3,69 \\
\hline 15 & 20 & 3,95 \\
\hline 16 & 25 & 4,12 \\
\hline 17 & 32 & 4,46 \\
\hline 18 & 29 & 4,86 \\
\hline 19 & 36 & 4,92 \\
\hline 20 & 21 & 5,65 \\
\hline 21 & 37 & 5,88 \\
\hline 22 & 20 & 6,67 \\
\hline 23 & 49 & 6,83 \\
\hline 24 & 43 & 7,26 \\
\hline 25 & 42 & 7,32 \\
\hline 26 & 25 & 7,45 \\
\hline 27 & 40 & 8,38 \\
\hline 28 & 30 & 8,61 \\
\hline 29 & 39 & 8,95 \\
\hline 30 & 18 & 9,28 \\
\hline$\overline{\mathrm{x}}$ & 32 & 4,72 \\
\hline $\mathrm{S}$ & 10 & 2,38 \\
\hline
\end{tabular}

Os resultados na determinação da concentração de $\mathrm{COHb}$ em indivíduos controle, não-expostos ocupacionalmente ao $\mathrm{CO}$, fumantes e nãofumantes são mostrados nas tabelas XXXI e XXXII respectivamente. 
Tabela XXXI - Concentração de carboxiemoglobina (COHb) em amostras de sangue de indivíduos fumantes do grupo controle.

\begin{tabular}{|c|c|c|c|c|}
\hline \multirow[b]{2}{*}{$\operatorname{amostra}^{*}$} & \multirow[b]{2}{*}{$\begin{array}{l}\text { idade } \\
\text { (ano) }\end{array}$} & \multicolumn{2}{|c|}{ cigarro } & \multirow[b]{2}{*}{$\mathrm{COHb}(\%)$} \\
\hline & & $\begin{array}{l}\text { consumo } \\
\text { diário }\end{array}$ & marca & \\
\hline 1 & 13 & 8 & Free & 2,35 \\
\hline 2 & 26 & 14 & Hollywood & 2,69 \\
\hline 3 & 22 & 15 & Galaxy & 2,78 \\
\hline 4 & 23 & 11 & Hollywood & 2,96 \\
\hline 5 & 22 & 20 & Galaxy & 3,02 \\
\hline 6 & 24 & 20 & Galaxy & 3,64 \\
\hline 7 & 30 & 8 & Carlton & 3,65 \\
\hline 8 & 15 & 15 & Marlboro & 3,73 \\
\hline 9 & 15 & 15 & Marlboro & 4,56 \\
\hline 10 & 29 & 10 & Marlboro & 4,72 \\
\hline 11 & 26 & 15 & Galaxy & 5,15 \\
\hline 12 & 21 & 10 & Marlboro & 5,22 \\
\hline 13 & 26 & 20 & Galaxy & 5,22 \\
\hline 14 & 21 & 12 & Marlboro & 5,30 \\
\hline 15 & 22 & 10 & Hollvwood & 5,75 \\
\hline 16 & 28 & 20 & Hollywood & 5,83 \\
\hline 17 & 25 & 12 & Minister & 6,83 \\
\hline 18 & 21 & 10 & Mariboro & 7,33 \\
\hline 19 & 28 & 30 & Luis XV & 8,32 \\
\hline$\overline{\mathrm{x}}$ & 23 & 15 & & 4,69 \\
\hline S & 5 & 6 & & 1,67 \\
\hline
\end{tabular}

$\left.{ }^{*}\right)$ colhida 6 horas após o início das atividades diárias 
Tabela XXXII - Concentraçāo de carboxiemoglobina (COHb) em amostras de sangue de indivíduos do grupo controle, não-fumantes.

\begin{tabular}{|c|c|c|c|c|c|}
\hline amostra ${ }^{*}$ & $\begin{array}{l}\text { idade } \\
\text { (ano) }\end{array}$ & $\begin{array}{l}\mathrm{COHb}^{* *} \\
(\%)\end{array}$ & amostra & $\begin{array}{l}\text { idade } \\
\text { (ano) }\end{array}$ & $\mathrm{COHb}$ \\
\hline 1 & 28 & 0,10 & 43 & 20 & 0,74 \\
\hline 2 & 42 & 0,14 & 44 & 14 & 0,75 \\
\hline 3 & 29 & 0,20 & 45 & 25 & 0,76 \\
\hline 4 & 29 & 0,20 & 46 & 50 & 0,78 \\
\hline 5 & 18 & 0,25 & 47 & 43 & 0,81 \\
\hline 6 & 34 & 0,25 & 48 & 23 & 0,83 \\
\hline 7 & 21 & 0,29 & 49 & 68 & 0,84 \\
\hline 8 & 25 & 0,30 & 50 & 50 & 0,85 \\
\hline 9 & 23 & 0,31 & 51 & 50 & 0,85 \\
\hline 10 & 33 & 0,32 & 52 & 21 & 0,87 \\
\hline 11 & 37 & 0,34 & 53 & 42 & 0,89 \\
\hline 12 & 49 & 0,34 & 54 & 23 & 0,94 \\
\hline 13 & 22 & 0,35 & 55 & 20 & 0,94 \\
\hline 14 & 20 & 0,37 & 56 & 67 & 0,95 \\
\hline 15 & 58 & 0,38 & 57 & 33 & 0,96 \\
\hline 16 & 12 & 0,40 & 58 & 22 & 1,02 \\
\hline 17 & 24 & 0,42 & 59 & 32 & 1,04 \\
\hline 18 & 36 & 0,45 & 60 & 28 & 1,04 \\
\hline 19 & 19 & 0,47 & 61 & 21 & 1,04 \\
\hline 20 & 32 & 0,49 & 62 & 64 & 1,06 \\
\hline 21 & 30 & 0,49 & 63 & 31 & 1,27 \\
\hline 22 & 33 & 0,51 & 64 & 41 & 1,38 \\
\hline 23 & 53 & 0,52 & 65 & 24 & 1,40 \\
\hline 24 & 20 & 0,53 & 66 & 38 & 1,50 \\
\hline 25 & 24 & 0,53 & 67 & 13 & 1,52 \\
\hline 26 & 24 & 0,53 & 68 & 63 & 1,68 \\
\hline 27 & 42 & 0,54 & 69 & 15 & 1,69 \\
\hline 28 & 26 & 0,55 & 70 & 20 & 1,69 \\
\hline 29 & 59 & 0,56 & 71 & 20 & 1,71 \\
\hline 30 & 22 & 0,59 & 72 & 20 & 1,72 \\
\hline 31 & 21 & 0,61 & 73 & 67 & 1,73 \\
\hline 32 & 25 & 0,62 & 74 & 23 & 1,73 \\
\hline 33 & 64 & 0,63 & 75 & 43 & 1,73 \\
\hline 34 & 60 & 0,64 & 76 & 55 & 1,77 \\
\hline 35 & 13 & 0,65 & 77 & 34 & 1,92 \\
\hline 36 & 30 & 0,65 & 78 & 70 & 2,04 \\
\hline 37 & 26 & 0,65 & 79 & 27 & 2,28 \\
\hline 38 & 70 & 0,65 & 80 & 21 & 2,80 \\
\hline 39 & 38 & 0,65 & & & \\
\hline 40 & 29 & 0,65 & & & \\
\hline 41 & 53 & 0,70 & $\bar{x}$ & 34 & 0,86 \\
\hline 42 & 30 & 0,72 & S & 16 & 0,56 \\
\hline
\end{tabular}

(*) colhida em horário variável

**) Valor mínimo confiável $0,50 \%$

A figura 20 mostra a distribuição percentual da concentração de carboxiemoglobina em trabalhadores dos grupos: controle, Ia, Ic e II, fumantes e nāo-fumantes. 

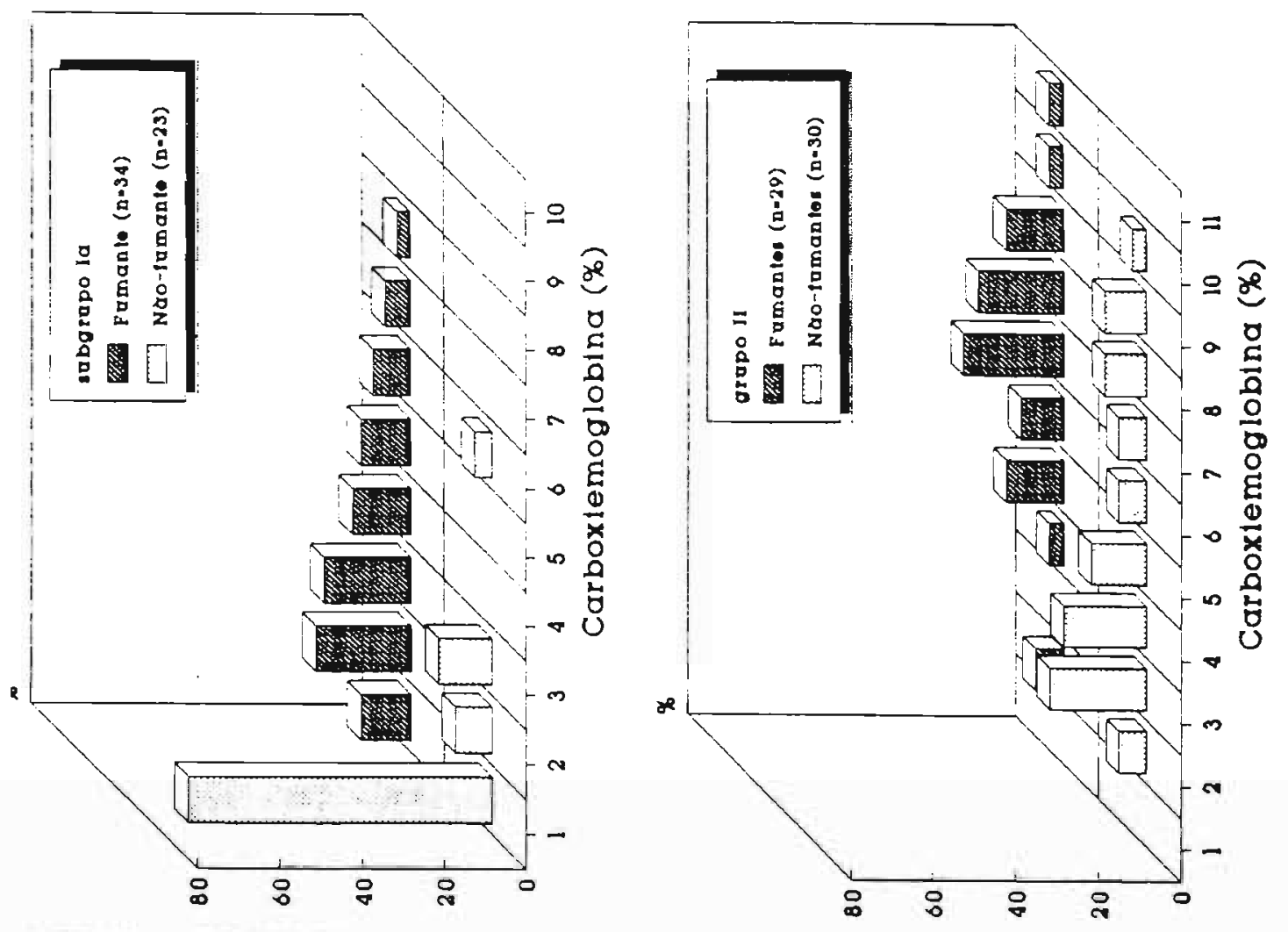

实雭

몽

:

음의

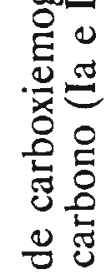

용묘

횽요

늘 홍

造:

웅윰

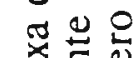

魚焉

흥

.

过

ํํㄹำ
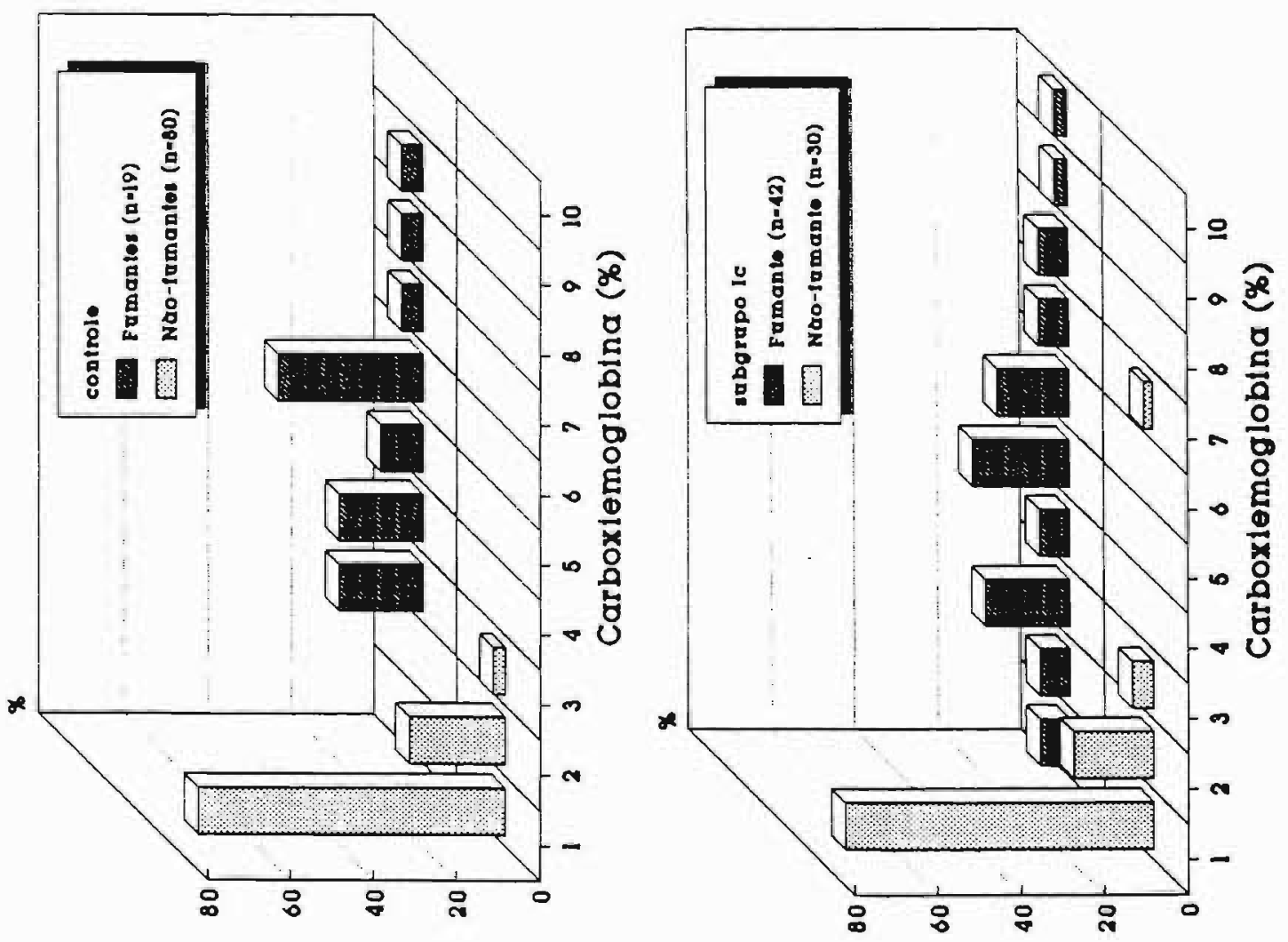

ò.

'ฐ

i

:

뜰

至

ธैं

홍

를일

픔응

으

증

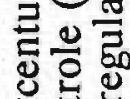

嗼

영유

苛总

总皆

ชิ

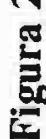




\section{DISCUSSÃO}

- A otimização de um procedimento analítico com vistas à determinação de carboxiemoglobina em indivíduos expostos ocupacionalmente ao CO constitui o objetivo precípuo deste trabalho.

Para tanto, na revisão bibliográfica do assunto, foram selecionadas técnicas analíticas compatíveis que apresentassem sensibilidade, precisão e exatidão, além de simplicidade e aplicabilidade a grande número de amostras.

A determinação direta da carboxiemoglobinemia por espectrofotometria ${ }^{20,29.43 .53 .140,142,158}$ apresenta vantagens sobre as indiretas $38,41,49,92,133$ (quantificaçāo por cromatografia gasosa do monóxido de carbono liberado da $\mathrm{COHb}$ ) quanto ao aspecto de custo e complexidade dos equipamentos requeridos.

Os métodos espectrofotométricos que utilizam a região Soret do espectro visível (390 a $440 \mathrm{~nm})^{20.29 .140 .142 .158 .177}$ apresentam maior sensibilidade que os preconizados por alguns autores com leituras na faixa de 480 a $580 \mathrm{~nm}^{4353.56 .99 .150}$. A figura 21 reproduz o espectro de dois pigmentos hemoglobínicos mostrando a maior absorção na região Soret.
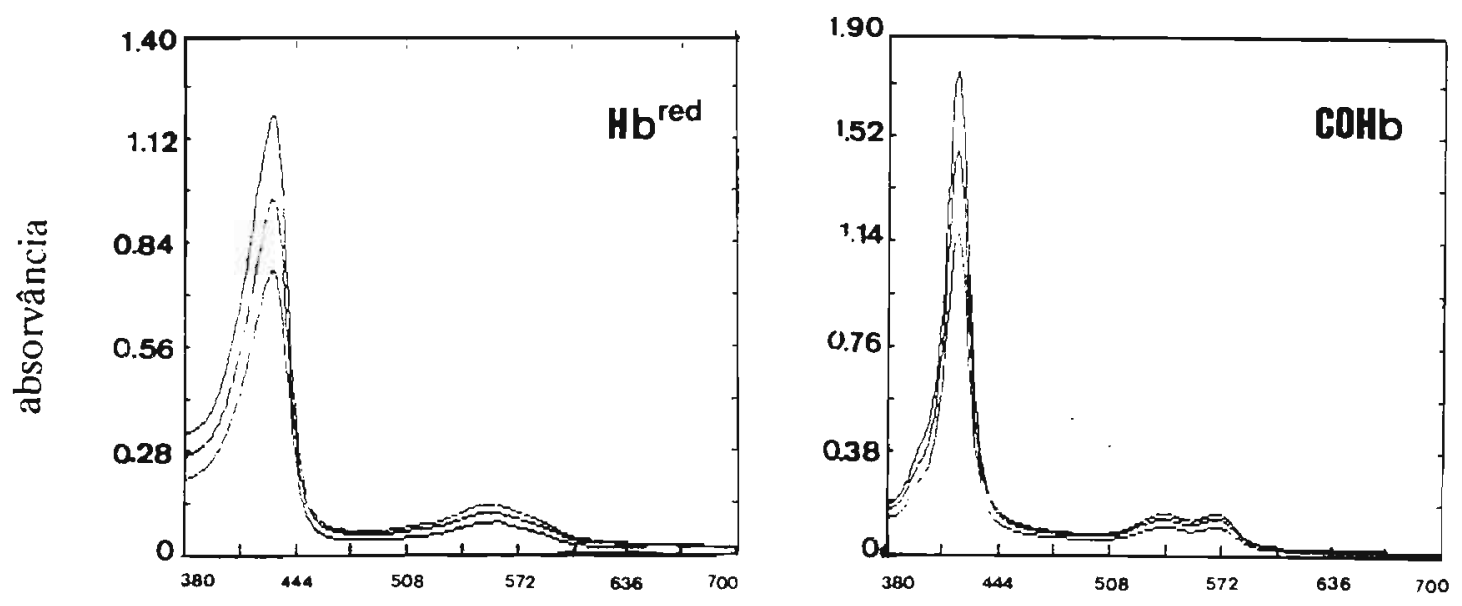

comprimento de onda (nm)

Figura 21 - Espectro de absorção de 3 soluçōes com concentraçōes diferentes de carboxiemoglobina ( $\mathrm{COHb}) \quad \mathrm{e}$ hemoglobina reduzida $\left(\mathrm{Hb}^{\text {red }}\right)$. 
Dentre os métodos que utilizam esta região do espectro, foi selecionado para este estudo o de BEUTLER \& WEST $^{20}$ por não requerer a saturaçāo de cada amostra de sangue com oxigênio e com monóxido de carbono e pela particularidade de usar fatores de calibração do espectrofotômetro.

Neste método, a seqüência analítica é simples, podendo ser entendida como duas diluiçōes subseqüentes. A concentração de carboxiemoglobina é calculada pela razāo das absorvâncias da amostra diluída em 420 e $432 \mathrm{~nm}$, e pelos fatores que correlacionam as absorvâncias molares da hemoglobina reduzida e da carboxiemoglobina nos dois comprimentos de onda.

No método de BEUTLER \& WEST ${ }^{20}$, fundamentado no de RODKEY et al. ${ }^{158}$, foi introduzido no procedimento analítico o tamponamento do meio $(\mathrm{pH}=6,85)$, o que torna desnecessário o resguardo das amostras do contato com o ar e estabiliza a relação das absorvâncias (AR) por até uma hora.

Neste trabalho, a exposição da amostra de sangue ao ar ambiente foi evitada apenas no período compreendido entre a colheita e a análise. Tanto na obtençāo como na conservação das amostras foi utilizado um tubo para colheita a vácuo contendo heparina sódica como anticoagulante, conforme preconiza a maioria dos autores 6.20.29.36.41,43.53.56.67.96,99.136.140.150.186.215. O sal dissódico do ácido etilenodiaminotetracético (EDTA- $\left.\mathrm{Na}_{2}\right)$ também tem sido recomendado como anticoagulante ${ }^{4.33,100.168}$. A amostra deve ser mantida sob refrigeração entre 4 e $8^{\circ} \mathrm{C}$.

Na otimização do método, dois aspectos merecem ser destacados: a avaliação do desempenho do aparelho e a qualidade do reagente redutor, o ditionito.

A exatidão do comprimento de onda é importante na obtenção de resultados confiáveis, especialmente em análises que não utilizam padrōes do cromóforo, como ocorre na quantificação da carboxiemoglobina.

Um dos métodos de avaliação da exatidāo do comprimento de onda, ou seja, a verificação da concordância entre o valor do comprimento de onda assinalado na escala seletora e o da energia radiante proporcionada pelo seletor da faixa espectral, é a determinaçāo do ponto isosbéstico. Este representa o comprimento de onda no qual as duas substâncias convertíveis entre si têm a mesma absorvância ${ }^{95}$. 
Os pontos isosbésticos devem ser próximos aos comprimentos de onda requeridos pelo método em questão. Assim, este foi determinado em $445 \mathrm{~nm}$ usando soluções de dicromato em meio ácido e básico. O valor obtido atestou bom desempenho nos aparelhos usados. GÜNTER ${ }^{95}$ sugere o uso de derivados hemoglobínicos para este fim podendo ser usado o par oxiemoglobina e carboxiemoglobina, com pontos isosbésticos em 421 e $449 \mathrm{~nm}$.

Como a resolução do espectro de absorção pode ser influenciada pela largura da fenda e pela velocidade de varredura da faixa de comprimento de onda ${ }^{77.140}$, estes parâmetros foram fixados para cada espectrofotômetro.

A velocidade de varredura automática usada no aparelho da marca Beckman, modelo DU-70, com sistema de leitura da absorvância monofeixe, foi de $1200 \mathrm{~nm} / \mathrm{min}$ e a largura da fenda do monocromador de $2 \mathrm{~nm}$. Para o espectrofotômetro da marca Intralab, modelo DMS-80, duplo feixe, e sem acessório para varredura automática, a largura da fenda usada também foi de $2 \mathrm{~nm}$. As leituras obtidas foram mais estáveis por ser de duplo feixe.

Por este motivo, as determinaçōes de $\mathrm{COHb}$ necessárias à otimização e à aplicação do método forma feitas no espectroftômetro de duplo feixe.

Outro aspecto a ser considerado é a qualidade do agente redutor ditionito - que requer condiçōes de armazenamento especiais. Em contato com o ar e, mais rapidamente quando em soluçāo, o ditionito oxida-se a bissulfito e bissulfato perdendo a sua capacidade redutora:

$$
\begin{aligned}
& \mathrm{Na}_{2} \mathrm{~S}_{2} \mathrm{O}_{4}+\mathrm{H}_{2} \mathrm{O} \longrightarrow \mathrm{NaHSO}_{2}+\mathrm{NaHSO}_{3} \\
& \mathrm{NaHSO}_{2}+2 \mathrm{H}_{2} \mathrm{O} \longrightarrow \mathrm{NaHSO}_{4}+4 \mathrm{H}^{+}
\end{aligned}
$$

$\mathrm{O}$ bissulfito de sódio, $\mathrm{NaHSO}_{4}$ é ineficaz como agente redutor e pode ser rapidamente formado se o ditionito em pó (seco) for exposto ao ar úmido:

$$
\mathrm{Na}_{2} \mathrm{~S}_{2} \mathrm{O}_{4}+\mathrm{H}_{2} \mathrm{O}+2 / 3 \mathrm{O}_{2} \rightarrow 2 \mathrm{NaHSO}_{4}
$$

A concentração e a qualidade do ditionito têm, assim, papel crítico na análise das amostras de sangue $e^{50,51,107,142}$. Por isso, foi adotada a seguinte conduta: 
- manter o ditionito em recipiente fechado e em dessecador;

- durante o preparo da solução redutora o sal deve ser exposto o menor tempo possível ao ar ambiente;

- pesar exatamente o sal e dissolvê-lo imediatamente, no momento do seu uso;

- diminuir ao máximo o volume de ar no recipiente contendo a solução redutora (capacidade do recipiente igual ao volume de solução).

A qualidade do ditionito pode ser testada pela adição de $25 \mathrm{mg}$ de o-dinitrobenzeno a $10 \mathrm{~mL}$ de solução de hidróxido de potássio $5 \%$ em metanol; a esta mistura adicionar $25 \mathrm{mg}$ de ditionito. A soluçāo deve apresentar imediatamente forte coloraçāo violeta. Se o $\mathrm{Na}_{2} \mathrm{~S}_{2} \mathrm{O}_{4}$ năo for de boa qualidade, a reação não se verifica ou a coloração formada é fraca ${ }^{142}$.

Na otimização do método, o procedimento analítico proposto por BEUTLER \& WEST $^{20}$, foi mantido sem alteraçōes. Entretanto, na determinação dos fatores de calibração dos espectrofotômetros foram introduzidas modificações que permitiram obtenção de resultados satisfatórios.

A determinação dos fatores requer soluções com $100 \%$ de $\mathrm{COHb}$ e $100 \%$ de $\mathrm{Hb}^{\text {red }}$. Na preparação destas, encontram-se na literatura, basicamente, a técnica de borbulhamento dos gases em soluçōes de hemoglobina ${ }^{20,43,95,142}$ e a da saturação pelo contato dos gases com a solução de $\mathrm{Hb}$, usando tonômetro, seringa ou outros recipientes ${ }^{41.56 .140,186}$.

A opçāo, neste trabalho, pelo uso da primeira técnica deu-se, pela intenção de se estabelecer um método adequado às condições da maioria dos laboratórios em nosso país e pela dificuldade de se medir volumes de gases.

A amostra de sangue usada na preparaçāo das duas soluções saturadas deve ser escolhida com determinados critérios: ser de indivíduo nāo fumante, facilitando assim a preparação da solução $100 \% \mathrm{O}_{2} \mathrm{Hb}$ e não apresentar metaemoglobinemia maior que $1 \%$ ou outros derivados da $\mathrm{Hb}$, que não se ligam ao $\mathrm{CO}$, cuja presença impede a formação de $\mathrm{COHb}{ }^{4,92}$. Foi tido o cuidado de determinar a metaemoglobina nas amostras utilizadas com tal finalidade pelo método de HEGESH et al.$^{90}$, obtendo-se o valor médio de $0,51 \%$.

A preparação das soluçōes de $100 \%$ de $\mathrm{Hb}^{\text {red }}$ ou de $100 \%$ de $\mathrm{COHb}$ é 
feita de maneira similar, diferindo apenas nos tempos de borbulhamento dos gases, monóxido de carbono ou oxigênio, que foram definidos pela estabilidade das concentraçōes obtidas em tempos crescentes de borbulhamento.

Para se estabelecer o tempo mínimo de borbulhamento do gás, que permita preparar com certa confiança a solução de hemoglobina saturada, é importante lembrar que ele varia com as condições disponíveis, tais como, o tipo de aparelhagem usado no borbulhamento, o fluxo, a natureza e a pureza do gás e a quantidade de hemoglobina a ser saturada.

O tempo de 15 min, estabelecido para a preparação da soluçāo $100 \%$ de $\mathrm{O}_{2} \mathrm{Hb}$, é válido para o uso de oxigênio medicinal, proveniente de cilindro de gás comprimido, e de um borbulhador que permita fluxo aproximado de $50 \mathrm{~mL} / \mathrm{min}$ (tabela VIII). O tempo de 3 minutos de $\mathrm{CO}$ proveniente de cilindro de gás comprimido foi estabelecido nas mesmas condições (tabela VII).

BEUTLER \& WEST ${ }^{20}$ recomendam os tempos de 30 minutos de CO na preparação de $100 \%$ de $\mathrm{COHb}$, sem definir a procedência do gás, e de 2 horas de ar para a obtenção da solução $100 \% \mathrm{O}_{2} \mathrm{Hb}$, usando $2,0 \mathrm{~mL}$ de hemolisado contidos em balōes volumétricos de $25,0 \mathrm{~mL}$. A substituição desta técnica pelo borbulhamento em maior volume num tubo de ensaio permitiu maior exatidão na preparação das soluções saturadas.

A necessidade da calibraçāo dos balōes volumétricos de $25,0 \mathrm{~mL}$, usados nesta etapa, foi constatada pela variação nos volumes reais encontrados, de 23,0 a $26,0 \mathrm{~mL}$.

As soluçōes, cujas absorvâncias são usadas na determinação dos fatores (descrita em 4.1.2.2.) devem apresentar o mesmo conteúdo hemoglobínico, pois nos cálculos usa-se a relação de absorvâncias e não de absortividades. Isoladamente, o cálculo do F1 não é afetado por relacionar as absorvâncias da mesma soluçāo em dois comprimentos de onda, o que não ocorre no cálculo de F2 e F3.

A preparação das soluçōes com $100 \% \mathrm{COHb}$ e $100 \% \mathrm{Hb}^{\text {red }}$ e a leitura das suas absorvâncias podem ser consideradas as etapas de maior influência na exatidāo do método.

Conhecendo-se o custo elevado do cilindro de CO (grau de pureza 
$99,99 \%$ ) e a dificuldade em obtê-lo, foi estudada a possibilidade do uso do CO produzido por reação química.

A determinação do tempo de borbulhamento adequado foi conduzida de maneira similar à usada para o gás proveniente de cilindro, com variações decorrentes da dificuldade de se controlar o seu fluxo, devido à inconstância na suá geração e a incerteza da sua pureza. A liberação do gás em menor fluxo, comparativamente ao do cilindro, não permitiu o uso do borbulhador.

Para se estabelecer o tempo de borbulhamento adequado do gás gerado foram estudadas várias séries com diferentes tempos de borbulhamento como mostra a tabela IX. Pelos resultados obtidos na primeira série pode-se concluir que, se houve diminuição da produção de monóxido de carbono no final da reação, esta foi compensada pelo aumento do tempo de borbulhamento e que os 5 minutos iniciais não foram suficientes para a saturação da solução.

Na segunda série o tempo total da reação foi menor, permitindo apenas o uso de 3 alíquotas de hemolisado; os primeiros 10 minutos foram suficientes para a saturação da $\mathrm{Hb}$ assim como os tempos subseqüentes. Nas séries seguintes, procurou-se manter os tempos de borbulhamento seqüenciais iguais, para avaliar se a produção de CO seria constante até o final da reação e em quantidade suficiente para saturar a solução de hemoglobina.

Analisando-se os resultados obtidos nas cinco séries, pode-se estabelecer que, excluindo-se os 5 minutos iniciais de produçāo de $\mathrm{CO}$, cada um dos 15 minutos seguintes é suficiente para a obtenção da solução saturada de $\mathrm{COHb}$. Os primeiros cinco minutos foram excluídos pela inconstância da coloração do hemolisado, pelos baixos teores de COHb encontrados, e pelo fato do borbulhamento inicial não ser apenas do CO gerado mas também do ar contido no kitassato.

$\mathrm{Na}$ repetição das reações, observou-se que quando o gotejamento inicial do ácido era lento a primeira alíquota da seqüência apresentava coloraçāo esperada (vermelho-cereja). Se a quantidade de ácido adicionada fosse maior, ocorria borbulhamento intenso e o hemolisado tornava-se enegrecido. Esta alíquota, submetida a maior tempo de borbulhamento, nāo atingia o teor de $100 \%$ de $\mathrm{COHb}$. Possivelmente deve ter ocorrido a formação de sulfaemoglobina, composto de coloração verde que se combina com o $\mathrm{CO}$ formando a carboxisulfaemoglobina ( $\mathrm{COSHb})^{21,57,139}$. 
O rendimento da reação de geração de CO pode ser aumentado pela adição de esferas de vidro ao formiato de sódio que dificultam a formaçāo da crosta de sulfato de sódio e facilitam a homogeneização por agitação manual do kitassato.

$\mathrm{Na}$ preparação das soluções saturadas de $\mathrm{COHb}$ e de $\mathrm{Hb}^{\text {red }}$ ocorre também a dissolução dos gases no líquido. A fração dissolvida deve ser removida por impossibilitar a preparação de concentrações variáveis de $\mathrm{COHb}$ e para evitar a contribuição da absortividade molar do gás na medida das absorvâncias.

A ação redutora do ditionito sobre $\mathrm{o} \mathrm{O}_{2}$ dissolvido e a redução da $\mathrm{O}_{2} \mathrm{Hb}$ a $\mathrm{Hb}^{\text {red }}$ eliminam esta interferência na solução com $100 \%$ de $\mathrm{O}_{2} \mathrm{Hb}$. Entretanto, o $\mathrm{CO}$ permanece dissolvido na solução $100 \%$ de $\mathrm{COHb}$.

Assim sendo, foi borbulhado o nitrogênio para remover os gases dissolvidos nas soluçōes saturadas. O tempo de borbulhamento foi determinado pela comparação entre as \% de $\mathrm{COHb}$ encontradas e a concentração esperada de $50 \%$. O tempo adequado foi de 2,5 minutos (tabela $\mathrm{X}$ ); que foi adotado, também, para a solução $100 \%$ de $\mathrm{O}_{2} \mathrm{Hb}$.

Os tempos de borbulhamento de $\mathrm{CO}, \mathrm{O}_{2}$ e $\mathrm{N}_{2}$ devem ser determinados se forem usadas outras condiçōes laboratoriais devido à influência de uma série de fatores, mencionados anteriormente .

Após a diluição da solução de $\mathrm{O}_{2} \mathrm{Hb}$ com a solução redutora deve-se respeitar o tempo de 10 minutos para que ocorra a reduçāo total, uma vez que os espectros de absorção da $\mathrm{O}_{2} \mathrm{Hb}$ e da $\mathrm{COHb}$ são parcialmente coincidentes. A não observância desta conduta leva a uma superestimaçāo do valor de COHb.

O cálculo dos fatores de calibração do espectrofotômetro pode ser feito, indiferentemente, pelas razōes das médias ou pela média das razōes das absorvâncias. Embora não seja usado o valor de AR das soluções saturadas para este cálculo, é importante conhecê-lo e relacioná-lo à saturaçāo de carboxiemoglobina.

É importante salientar que uma solução de $\mathrm{COHb}$ com maior $\propto$ absorvância em $420 \mathrm{~nm}$, não apresenta, necessariamente, maior teor de $\mathrm{COHb}$ podendo estar refletindo, somente, o maior conteúdo hemoglobínico. 
A figura 22 denota que os espectros das soluções com 50 e $60 \%$ de COHb nāo apresentam correlação direta entre a \% de COHb e absorvância.

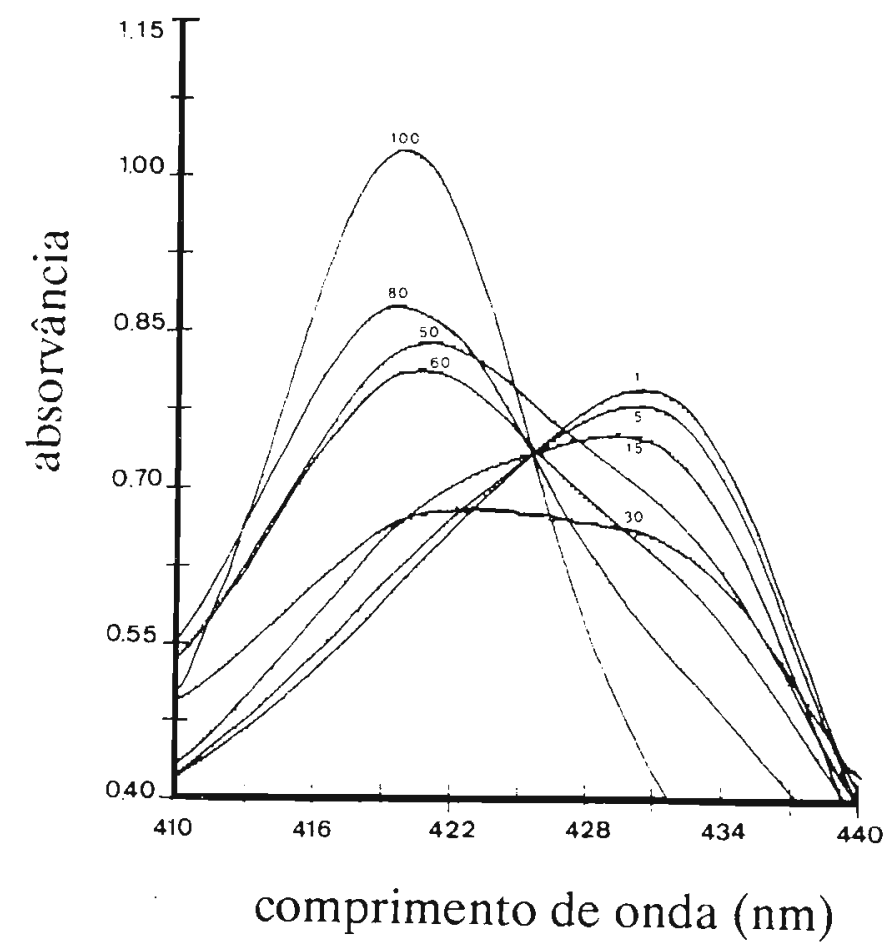

Figura 22 - Espectro de absorção de soluções com diferentes concentrações de carboxiemoglobina $(1,5,15,30,50,60,80 \mathrm{e}$ $100 \%$ de $\mathrm{COHb}$ )

A determinação dos fatores de calibração não precisa ser realizada simultaneamente à análise das amostras de sangue. Entretanto, de acordo com nossa experiência, deverá ser repetida após uma revisão técnica ou sempre que o aparelho for demovido.

Resumidamente, nas etapas que envolvem a determinação dos fatores de calibração é importante ressaltar :

- a interferência dos diferentes pigmentos hemoglobínicos presentes na amostra na preparação das soluções $100 \%$ de $\mathrm{COHb}$ e $100 \%$ de $\mathrm{Hb}^{\text {red }}$;

- a presença de CO dissolvido na solução 100\% de COHb;

- a diminuição da exatidão causada pela diferença de conteúdo hemoglobínico entre as soluçōes $100 \%$ de $\mathrm{COHb}$ e $100 \% \mathrm{Hb}^{\text {red; }}$ 
- a possível alteração da coloração do hemolisado quando se usa o CO gerado por reação química para a preparação da solução $100 \%$ de $\mathrm{COHb}$.

O estudo da exatidão deste método espectrofotométrico foi limitado pela indisponibilidade de soluçōes-padrão de referência de $\mathrm{COHb}$ e de $\mathrm{O}_{2} \mathrm{Hb}$. Para contornar a limitação, os teores de carboxiemoglobina, obtidos nas soluçōes saturadas, foram calculados com os fatores de calibraçāo do espectrofotômetro por nós determinados e cotejados aos calculados com os fatores teóricos indicados na literatura, determinados pelas absortividades molares dos pigmentos ${ }^{158}$ (tabelas VII e VIII). A concordância entre eles permite estabelecer a exatidāo do método como adequada.

Para se estudar a linearidade de um método espectrofotométrico, com leitura da absorvância em apenas um comprimento de onda, determina-se a curva de calibração relacionando a concentração da substância e as absorvâncias respectivas.

Seguindo este raciocínio, a linearidade no presente método seria obtida pela correlação entre as concentrações de $\mathrm{COHb}$ e as razões das absorvâncias. A figura 17-B mostra que esta nāo é linear, pois se comporta de maneira diferente para baixas e altas concentrações. Pequena variação num valor baixo de $\mathbf{A R}$ (baixas concentrações de $\mathrm{COHb}$ ), causa uma variação relativamente maior no resultado da \% de $\mathrm{COHb}$ do que a ocasionada por variações similares em valor elevado de $\mathbf{A R}$ (altas concentração de $\mathrm{COHb}$ ).

Por outro lado, observa-se correlação linear entre os valores esperados e os encontrados na faixa de 0 a $100 \%$ de $\mathrm{COHb}$ (figura $17-\mathrm{A}$ ). $\mathrm{Na}$ preparação das diferentes concentraçōes de $\mathrm{COHb}$, a supressão da etapa de borbulhamento de $\mathrm{N}_{2}$ compromete acentuadamente esta correlação nas soluções com baixos teores de $\mathrm{COHb}$, como ilustra a figura 23. Neste estudo as leituras de absorvância das soluções, inclusive a com $100 \%$ de $\mathrm{COHb}$, foram realizadas 10 minutos após a adição do agente redutor, de modo similar à técnica aplicada às amostras autênticas.

A precisão do método mostra comportamento variável em função da concentração apresentando coeficientes de variação (CV) inversamente proporcionais às concentrações de $\mathrm{COHb}$. Os desvios-padrão obtidos neste estudo mostram que a dispersāo dos resultados é independente da concentração de $\mathrm{COHb}$ (tabela XIV). 


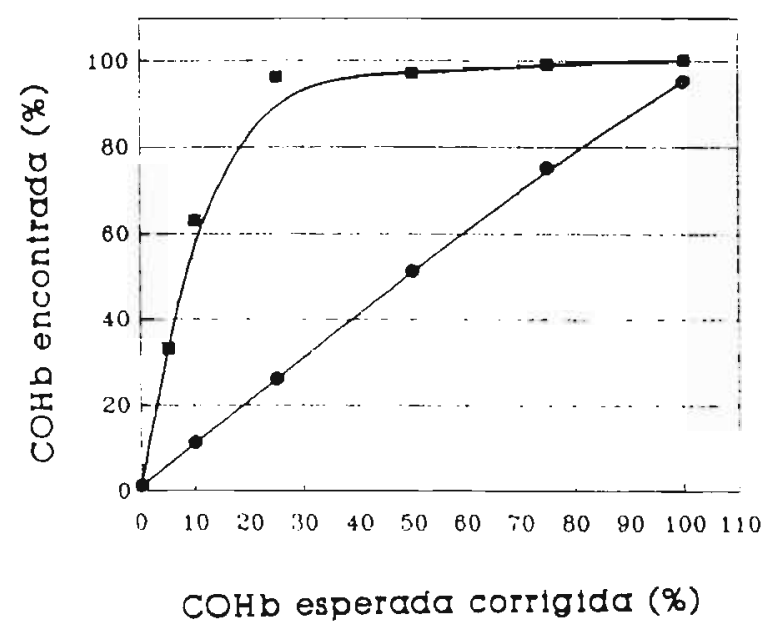
Figura 23 - Correlação entre as $\%$ de carboxiemoglobina $(\mathrm{COHb})$ obtidas experimentalmente, $\operatorname{com}(\bullet)$ e sem $(\bullet)$ o deslocamento do $\mathrm{CO}$ dissolvido na solução saturada de COHb.

Estes dados permitem fixar o valor mínimo confiável do método em $0,50 \%$ de COHb. Dos 349 resultados de carboxiemoglobinemia obtidos, em 155 amostras de fumantes apenas $4(2,6 \%)$ foram inferiores à concentração mínima confiável; nas 189 amostras de não-fumantes este valor foi de $39(20,6 \%)$ sendo 20 pertencentes ao grupo controle e 15 ao subgrupo Ic, que foi o único grupo que não apresentou diferença estatisticamente significativa quando comparada ao grupo controle.

O estudo da influência de cada uma das etapas de diluição (hemólise e redução) na precisão do método mostrou que a variação do resultado é quase que exclusivamente determinada pela primeira diluição (tabela XV). Isto se deve, provavelmente, à variação na pipetagem de pequeno volume de sangue.

$\mathrm{Na}$ tentativa de diminuir o tempo dispendido na análise de cada amostra, foi avaliada a substituição do uso de pipetas comuns por automáticas e repipetadores. A utilizaçāo da pipetagem automática aumentou a desenvoltura da técnica sem prejudicar a precisão do método, como demonstram os coeficientes de variação observados na tabela XVI.

Nos métodos espectrofotométricos é importante investigar a estabilidade do cromógeno na solução final de leitura para que a exatidāo e a 
precisão do método não sejam comprometidas.

O presente estudo mostrou que as soluçōes são estáveis durante o período de uma hora, após a sua preparação, concordando com o reportado por BEUTLER \& WEST, como se pode ver na figura 18.

A possibilidade da perda de $\mathrm{CO}$ durante o período de conservação da amostra após a colheita, motivou o estudo da estabilidade da carboxiemoglobina na mesma, para se conhecer a necessidade da urgência no prosseguimento do processo analítico e, portanto, da sua viabilidade prática.

A estabilidade foi avaliada comparando-se os resultados da análise de 3 amostras, obtidas pelo sistema de colheita múltipla, a vácuo (mesma punção venosa). A colheita das 3 amostras permite contornar a influência do contato da amostra com o ar que ocorre inevitavelmente quando a mesma é analisada diariamente.

Para a análise dos valores obtidos neste estudo (tabela XVIII) foi aplicado o TESTE $F^{175}$ em dois grupos de resultados: (i) os obtidos nas amostras mantidas em vácuo; (ii) a todos os resultados de todas as amostras. A análise de variância das médias diárias permite concluir, ao nível de significância de $99 \%$, que os grupos não são estatisticamente diferentes . Desta forma a amostra pode ser considerada estável por até 8 dias.

Dada a possibilidade dos constituintes da matriz biológica atuarem como interferentes na determinação espectrofotométrica ${ }^{21}$, foram realizados ensaios para avaliar a influência de alguns deles.

O estudo da influência do conteúdo hemoglobínico foi conduzido em em dois ensaios. No primeiro, pela determinação da carboxiemoglobina em alíquotas de uma amostra, variando-se a sua hemoglobinemia numa faixa que extrapola os valores considerados normais, que é de 12 a 17\%. O coeficiente de variação dos resultados obtidos (tabela XIX) foi de 5,12\% para um valor médio de $1,14 \%$ de $\mathrm{COHb}$, o que é similar ao encontrado para este teor, conforme o estudo da precisão do método (tabela XIV).

O segundo ensaio foi realizado para ampliar este estudo a concentrações maiores de $\mathrm{COHb}$. Os resultados do primeiro estudo permitiram estreitar a faixa de concentração de hemoglobina a ser estudada. A preparação de 
concentrações de hemoglobina mais próximas entre si, requeriu portanto, outro procedimento de diluição. $O$ coeficiente de variação dos resultados obtidos para a concentraçāo próxima a $1 \%$ foi concordante com o estudo anterior, porém, para concentraçōes maiores, os coeficientes de variação apesar de aumentados (tabela $\mathrm{XX}$ ), não comprometem a precisão do método

A comparação dos valores de $\mathrm{COHb}$ obtidos com o valor da amostra, sem a variável concentração de $\mathrm{Hb}$, permite concluir que em ambos os estudos o teor de hemoglobina não interfere na quantificação da carboxiemoglobina.

Outro aspecto considerado foi a possível influência da opalescência das amostras nas leituras das absorvâncias. Este fato, aliado à recomendação de que a amostra seja colhida no final da jornada de trabalho $0^{5}$, assume importância relevante dada a possibilidade da colheita da amostra ser realizada no período pós-prandial, dependendo do turno de trabalho.

Foram colhidas amostras de um mesmo indivíduo, fumante, em jejum e após a refeiçāo. O teor de lipídios nas amostras do período pós-prandial duplicou em relaçāo às colhidas em jejum. Por não ser possível comparar diretamente a carboxiemoglobinemia entre as amostras do mesmo indivíduo, o soro lipêmico foi adicionado à amostra do mesmo indivíduo em jejum, triplicando e até quadruplicando a lipemia.

Os teores iniciais de $\mathrm{COHb}$ não se alteraram na triplicação da quantidade de lipídios e apresentaram um aumento de $6 \%$ quando esta foi quadruplicada (tabela XXII). Tais resultados mostram que a amostra colhida no período pós-prandial nāo influencia significativamente a determinação da $\mathrm{COHb}$.

Após serem criteriosamente estabelecidas as várias etapas do método e dispor-se do procedimento analítico otimizado, foi determinada a carboxiemoglobinemia em indivíduos expostos ocupacionalmente ao monóxido de carbono, subdivididos em grupos e subgrupos de acordo com o tipo e local de trabalho.

A colheita das amostras foi realizada preferencialmente no final da jornada de trabalho, conforme preconiza a AMERICAN CONFERENCE OF GOVERNAMENTAL INDUSTRIAL HYGIENISTS (ACGIH) ${ }^{5}$. Dos indivíduos fumantes dos subgrupos $I_{a}$ e $I_{b}$ foram colhidas, também, amostras no início da jornada. Para auxiliar a interpretação dos resultados, foi incluído o estudo em um grupo controle, constituído de indivíduos não-expostos ocupacionalmente ao $\mathrm{CO}$. 
Os trabalhadores de todos os grupos pertenciam ao turno diurno com jornada de trabalho de 8 horas diárias; executavam as tarefas com esforço físico de leve a moderado e nenhum deles usava equipamento de proteção respiratória.

A influência considerável do hábito de fumar na carboxiemoglobinemia torna necessário subdividir a população estudada em fumantes e não-fumantes.

Os teores médios de $\mathrm{COHb}$ para os grupos estudados, fumantes e não-fumantes, foram muito próximos das respectivas medianas, o que condiz com a distribuição das freqüências dos resultados. A mediana é mais representativa do grupo de resultados quando a distribuição nāo é normal, ou seja, um ou poucos valores discrepantes da média da população podem deslocar significativamente o valor médio ${ }^{153.198}$.

A tabela XXXIII mostra a mediana e os valores médios da $\mathrm{COHb}$ obtidos. A distribuição da freqüência dos indivíduos de cada grupo em função dos teores de $\mathrm{COHb}$ está representada na figura 20. O subgrupo $\mathrm{I}_{\mathrm{b}}$ não foi representado por ser pequeno o número de amostras.

As comparações entre os resultados da carboxiemoglobinemia nos diferentes grupos estudados foram submetidas à análise estatística. Na escolha da prova estatística para a tomada de decisão sobre determinada hipótese, é fundamental que se considere o poder de eficiência da prova e a adequabilidade ao tipo e número de dados obtidos ${ }^{19,153,175,198}$.

Formuladas as hipóteses $\mathrm{H}_{0}$ (de nulidade) e $\mathrm{H}_{1}$ (a alternativa), $\mathrm{o}$ estudo estatístico conduz à aceitação de uma delas, levando à conclusão de igualdade ou não entre os grupos. Por exemplo:

$\begin{array}{lll} & \mathbf{H}_{0} & \begin{array}{l}\text { grupo controle }=\text { grupo exposto } \\ \text { grupo controle } \neq \text { grupo exposto }\end{array} \\ \text { ou } & \mathbf{H}_{1} & \text { grupo fumante }=\text { grupo nāo-fumante } \\ & \mathbf{H}_{1} & \text { grupo fumante } \neq \text { grupo nāo-fumante }\end{array}$


Tabela XXXIII - Medianas e médias $(x)$ dos teores de carboxiemoglobinemia obtidos em fumantes e não-fumantes nos grupos expostos ou não ocupacionalmente ao monóxido de carbono $(\mathrm{CO})$.

\begin{tabular}{|c|c|c|c|c|c|c|}
\hline \multirow[t]{2}{*}{ grupo } & \multicolumn{3}{|r|}{ fumante } & \multicolumn{3}{|c|}{ não-fumante } \\
\hline & n & mediana & $\overline{\mathrm{x}}$ (intervalo) & $\mathrm{n}$ & mediana & $\bar{x}$ (intervalo) \\
\hline controle & 19 & 4,72 & $4,69(2,35 \text { a } 8,32)^{\mathrm{a}}$ & 80 & 0,68 & $0,86(0,10 \text { a } 2,80)^{\mathrm{a}}$ \\
\hline exposto & & & & & & \\
\hline $\mathrm{I}_{\mathrm{a}}$ & $\begin{array}{l}34 \\
34\end{array}$ & $\begin{array}{l}2,57 \\
2,01\end{array}$ & $\begin{array}{l}2,95(0,39 \text { a } 7,10)^{\mathrm{a}} \\
2,15(0,17 \text { a } 520)^{\mathrm{b}}\end{array}$ & 23 & 0,70 & $1,09(0,26 \text { a } 5,99)^{\mathrm{a}}$ \\
\hline$I_{b}$ & $\begin{array}{l}7 \\
7\end{array}$ & $\begin{array}{l}4,67 \\
4,22\end{array}$ & $\begin{array}{l}4,51(1,03 \text { a } 6,70)^{\mathrm{a}} \\
4,01(1,34 \text { a } 5,41)^{b}\end{array}$ & 14 & 1,18 & $1,18(0,86 \text { a } 1,44)^{\mathrm{a}}$ \\
\hline $\mathrm{I}_{\mathrm{c}}$ & 30 & 4.34 & $4,32(0,57 \text { a } 9,25)^{\mathrm{a}}$ & 42 & 0,70 & $0,91(0,19 \text { a } 6,83)^{\mathbf{a}}$ \\
\hline II & 29 & 7,84 & $7,48(2,17 \text { a } 11,99)^{\mathrm{a}}$ & 30 & 4,04 & $4,72(1,81 \text { a } 9,28)^{\mathrm{a}}$ \\
\hline
\end{tabular}

(a) colheita da amostra no final da jornada de trabalho

(b) colheita da amostra no início da jornada de trabalho

$\mathrm{n}$ = número de amostras

Desta forma, quando $\mathrm{H}_{0}$ é rejeitada diz-se que a diferença entre os grupos foi estatisticamente significativa. O poder de eficiência de uma prova estatística é, portanto, a probabilidade de rejeitar $\mathrm{H}_{0}$ quando $\mathrm{H}_{0}$ é realmente falsa $^{19}$.

Os testes não-paramétricos para amostras independentes são os mais adequados ao tipo de resultados por nós obtidos. As afirmações decorrentes das provas não-paramétricas são independentes da forma de distribuição da população da qual se extraiu a amostra aleatória. Além disso, estas provas, permitem a comparação entre grupos com número de amostras diferentes e/ou pequenos. São testes de significância livres do tipo da distribuição ${ }^{126,175}$.

Sendo assim, formuladas as hipóteses de nulidade e a alternativa e escolhida a prova adequada, a etapa seguinte consiste em especificar o nível de significância. Escolheu-se o de 0,05 , valor comumente usado em resultados de análise química que aceita em cada 20 determinaçōes uma com erro analítico ${ }^{19}$. 
Em outras palavras, pode-se decidir se as diferenças encontradas entre os resultados da determinaçāo da $\mathrm{COHb}$ são decorrentes apenas de erros experimentais ou da exposição ao monóxido de carbono.

A comparação da carboxiemoglobinemia entre fumantes e nāo-fumantes de cada grupo, avaliada pelo teste não-paramétrico de KolmogorovSmirnov ao nível de significância de $95 \%(\alpha=0,05)$, apresentou diferença significativa em todos os grupos (tabela XXXIV). Quando o valor do parâmetro estatístico $\mathbf{D}_{\text {encontrado }}$ supera o valor $\mathbf{D}_{\text {limite }}$, a hipótese de nulidade é rejeitada. Nesta comparação foram usados apenas os resultados obtidos no final da jornada de trabalho.

Tabela XXXIV - Parâmetros estatísticos (D) do teste de Kolmogorov-Smirnov obtidos na comparaçāo entre a carboxiemoglobinemia entre fumantes e não-fumantes dos grupos expostos e controle.

\begin{tabular}{ccc}
\hline \hline \multirow{2}{*}{ grupo } & \multicolumn{2}{c}{ parâmetro estatístico $(\mathbf{D})$} \\
\cline { 2 - 3 } & $\mathbf{D}_{\text {limite }}$ & $\mathbf{D}_{\text {encontrado }}$ \\
\hline \hline controle & 0,35 & $0,96^{\circ}$ \\
exposto & & \\
& & \\
$\mathbf{I}_{\mathrm{a}}$ & 0,37 & $0,62^{\circ}$ \\
$\mathbf{I}_{\mathrm{b}}{ }^{-}$ & 0,63 & $0,86^{\circ}$ \\
$\mathbf{I}_{\mathrm{c}}$ & 0,33 & $0,80^{\circ}$ \\
$\mathbf{I I}^{*}$ & 0,35 & $0,53^{\circ}$ \\
\hline \hline
\end{tabular}

$\left({ }^{*}\right)$ diferença significativa $(\alpha=0,05)$

Considerando-se $\mathrm{H}_{0}$ como a igualdade entre a carboxiemoglobinemia, em fumantes e não-fumantes, a sua rejeição significa que os grupos comparados sāo diferentes em funçāo do hábito de fumar.

$\mathrm{Na}$ tentativa de se avaliar apenas a exposição ao $\mathrm{CO}$ do ambiente de trabalho, foi solicitado aos indivíduos do primeiro grupo avaliado (subgrupo $I_{a}$ ) que não fumassem no período de trabalho no dia da amostragem, sendo esta realizada no início (i) e no final (f) da jornada.

Em alguns casos, a diferença entre os resultados obtidos nas amostras ( $\mathrm{f}$ - i) foi negativa, o que provavelmente se deve a que estes indivíduos, estando 
expostos a níveis muito baixos de $\mathrm{CO}$ e não tendo fumado durante a jornada de trabalho, passassem a eliminar o xenobiótico (tabela XXV). Resultados negativos também foram encontrados nos indivíduos do subgrupo $\mathrm{I}_{\mathrm{b}}$ (tabela XXVII).

Para tentar correlacionar o hábito de fumar na carboxiemoglobinemia, foi questionado aos trabalhadores a marca e o número médio de cigarros fumados por dia. Pelos resultados obtidos no grupo controle e nos grupos I e II pode-se concluir que não houve correlação direta entre as \% de $\mathrm{COHb}$ e o número de cigarros consumidos pelos indivíduos (figura 24). Este fato, também confirmado por vários autores 7,32.88,92,173, está relacionado às características próprias de cada indivíduo no ato de fumar, como freqüência, duraçāo e profundidade da tragada, além das diferenças na composição do cigarro entre as marcas.

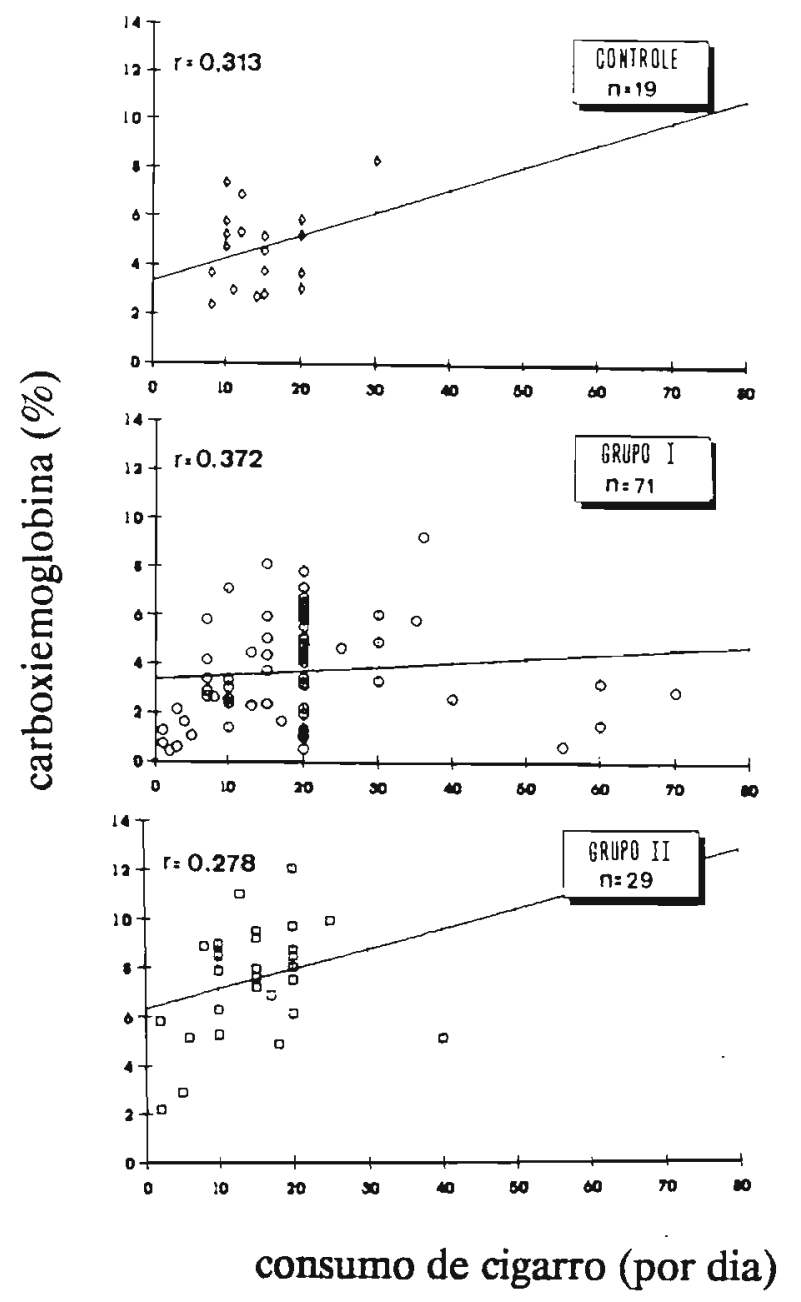

Figura 24 - Correlação entre a carboxiemoglobinemia $(\% \mathrm{COHb})$ e o número médio de cigarros consumidos por dia, em fumantes do grupo controle e expostos ocupacionalmente ao CO (grupos I e II). 
O número de cigarros consumidos por dia, obtido por resposta verbal do indivíduo, é geralmente calculado pela média de cigarros consumidos por semana, apresentando portanto a tendência ao arredondamento para 5, 10, 15 ou 20 cigarros. Na tentativa de se obter informaçōes mais precisas, foi também questionado aos trabalhadores do grupo II quantos cigarros eles tinham fumado naquele dia, até o momento da colheita da amostra de sangue.

Mesmo assim, considerando a resposta mais exata por ser obtida pela memorização do ocorrido no dia, não foi encontrada correlação significativa entre este hábito e a carboxiemoglobinemia (figura 25).

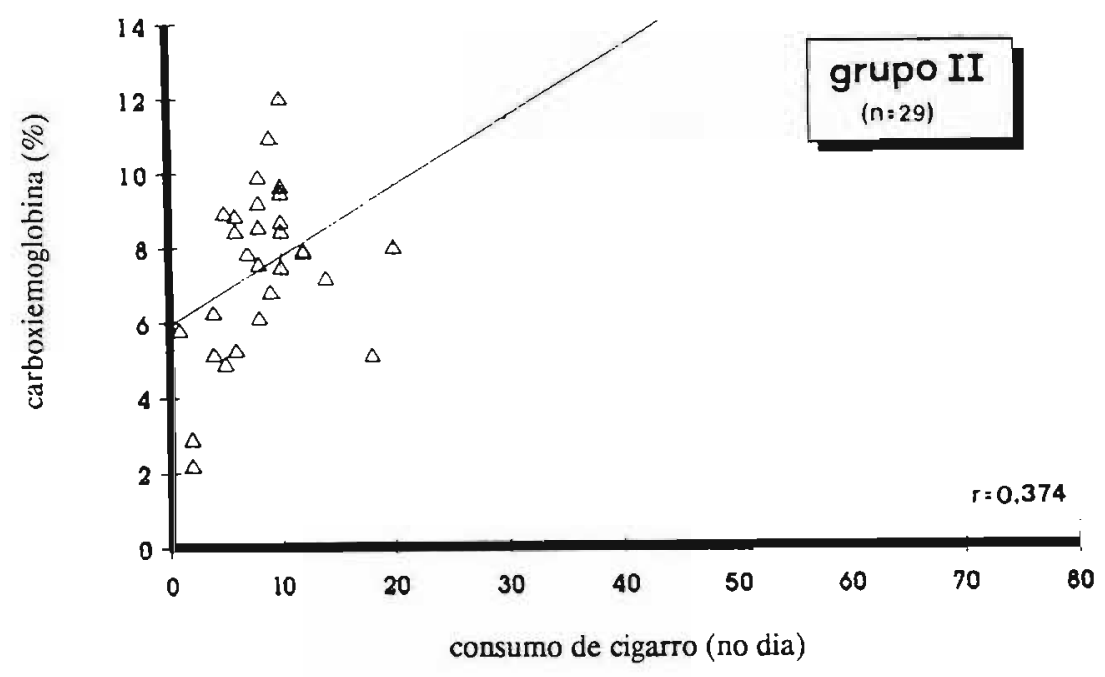
Figura 25 - Correlação entre a carboxiemoglobinemia $(\% \mathrm{COHb})$ e 0 número médio de cigarros consumidos no dia (consumo até o momento da colheita da amostra), em fumantes expostos ocupacionalmente ao monóxido de carbono (grupo II).

$O$ teste não-paramétrico de Kolmogorov-Smirnov foi aplicado também na comparaçāo entre os indivíduos expostos e os do grupo controle, tomando-se inicialmente os grupos como um todo e, em seguida, distinguindo os fumantes de não-fumantes (tabela XXXV). 
Tabela XXXV - Parâmetros estatísticos (D) do teste de Kolmogorov-Smirnov obtidos na comparação entre a carboxiemoglobinemia em indivíduos do grupo controle e dos grupos expostos ( $I_{a, b, c}$ e II)

\begin{tabular}{ccc}
\hline \hline \multirow{2}{*}{ comparação } & \multicolumn{2}{c}{ parâmetro estatí́stico (D) } \\
\cline { 2 - 3 } & $\mathrm{D}_{\text {limite }}$ & $\mathrm{D}_{\text {encontrado }}$ \\
\hline \hline
\end{tabular}

fumantes e não-fumantes

\begin{tabular}{|c|c|c|}
\hline controle $\times I_{2}$ & 0,23 & $0,24^{\circ}$ \\
\hline controle $\times I^{a}$ & 0,33 & $0,53^{\circ}$ \\
\hline controle $\times$ & 0,21 & 0,18 \\
\hline controle $\times$ II & 0,22 & $0,74^{\circ}$ \\
\hline
\end{tabular}

fumantes

$\begin{array}{lllll}\text { controle } & \times & I^{a} & 0,39 & 0,35 \\ \text { controle } & \times & I^{\mathrm{a}} & 0,60 & 0,18 \\ \text { controle } & \times & I^{\mathrm{b}} & 0,40 & 0,14 \\ \text { controle } & \mathrm{x} & \mathrm{II}^{\mathrm{f}} & 0,40 & 0,60^{*}\end{array}$

não-fumantes

\begin{tabular}{|c|c|c|}
\hline controle $\mathrm{x}$ & 0,32 & 0,13 \\
\hline controle $\times \mathrm{I}_{\mathrm{h}}^{d}$ & 0,39 & $0,64^{\circ}$ \\
\hline controle $\mathrm{x} \mathrm{I}_{c}^{\mathrm{O}}$ & 0,26 & 0,03 \\
\hline controle $\times$ II & 0,29 & $0,89^{\circ}$ \\
\hline
\end{tabular}

(*) diferença significativa $(\alpha=0,05)$

Sem a distinção do hábito de fumar, a diferença foi estatisticamente significativa para todos os grupos, exceto no subgrupo Ic, o que se deve, provavelmente, aos baixos teores de $\mathrm{COHb}$ deste subgrupo.

Com a distinção entre fumantes e não-fumantes, observa-se que as diferenças em relação aos respectivos grupos controles foram significativas para os grupos II (fumantes e não-fumantes) e subgrupo $\mathrm{Ib}$ (não-fumantes), indicando que nestes grupos houve exposição ocupacional significativa ao $\mathrm{CO}$.

A comparação entre as diferenças dos parâmetros $D_{\text {encontrado }}-\mathrm{D}_{\text {limite }}$ no grupo II mostra uma diferença maior para os não-fumantes, pelo fato da carboxiemoglobinemia em fumantes já estar em nível superior à dos nāo-fumantes antes da exposiçāo ocupacional.

Desta forma, para o uso da carboxiemoglobinemia como indicador 
biológico de exposição ao $\mathrm{CO}$ há necessidade de se distinguir fumantes de nāo-fumantes, sem o que a interpretaçāo dos níveis encontrados poderá ser errônea.

A legislação vigente no $\mathrm{Brasil}^{27}$ estabelece para a exposição ao $\mathrm{CO}$ o Limite de Tolerância Biológico (LTB) para a carboxiemoglobinemia em 5\% para indivíduos não-fumantes.

Considerando-se os não-fumantes, nenhum do grupo controle $(n=80)$ apresentou teores superiores ao LTB, enquanto que, em todos os grupos expostos, 13 apresentaram valores superiores, o que representa $12 \%$ do total dos indivíduos $(n=109)$ e $37 \%$ dos do grupo II $(n=30)$.

$O$ incremento da carboxiemoglobinemia durante a exposição ocupacional, obtida pela diferença entre os valores das amostras colhidas no final e no início da jornada (subgrupo Ia e Ib) nāo superou o valor de $5 \%$ em nenhum dos trabalhadores $(n=41)$.

Considerando o padrāo de segurança de $5 \%$ de $\mathrm{COHb}$ pode-se inferir aos fumantes maior probabilidade de apresentar efeitos nocivos devido à exposição ocupacional ao $\mathrm{CO}$. Na população estudada de fumantes obteve-se, em $\%$ de resultados superiores a $5 \%$, em cada grupo, o seguinte quadro:

grupo controle

$(n=19)$

grupo exposto
Ia $(\mathrm{n}=34)$
$\mathrm{Ib}(\mathrm{n}=7)$
Ic $(\mathrm{n}=30)$
II $(n=29)$
$18 \%$
$30 \%$
$37 \%$
$93 \%$

$5 \%$

Estes resultados são de importância na avaliação da condição de saúde do trabalhador, que deve ser vista como um todo, independentemente de fonte de exposição ao xenobiótico, e não devem ser negligenciados, mesmo que o valor de até 6,5\% seja tido pela Legislação Brasileira como valor normal para fumantes.

Não sendo possível realizar a monitorização ambiental, o conhecimento dos processos industriais e o detalhamento das operações auxiliaram 
o reconhecimento da exposição dos trabalhadores ao monóxido de carbono.

Teve-se acesso aos resultados de avaliação ambiental (pelo uso de tubos detectores por colorimetria) realizada em período não coincidente ao dia da amostragem do sangue em dois locais. Em um deles (subgrupo Ia) os resultados correspondem à avaliação de 5 dias consecutivos, em 15 locais diferentes, 3 a 4 vezes por dia, fornecendo um valor médio de $4 \mathrm{ppm}(\mathrm{n}=270)$. No outro (grupo II), foram feitas 6 determinaçōes em diferentes locais sendo encontrados níveis entre 20 e $100 \mathrm{ppm}$.

Não foi possível correlacionar diretamente, os teores de $\mathrm{COHb}$ às avaliaçōes ambientais por estas não terem sido concomitantes à monitorização biológica. Mesmo assim, pode-se observar que tanto os baixos níveis de $\mathrm{COHb}$ encontrados nos indivíduos do subgrupo Ia como os níveis mais elevados nos do grupo II são coerentes com os dados da avaliaçāo ambiental.

O estudo do método apresentado foi feito visando sua aplicação à monitorização biológica da exposição ocupacional ao CO. Entretanto, suas características permitem supor que a mesma técnica possa ser utilizada com outras finalidades, como no diagnóstico de intoxicaçōes fatais, em estudos comparativos de carboxiemoglobinemia materna e fetal e na monitorização biológica da exposição ao diclorometano, entre outras. 


\section{CONCLUSÕES}

Os resultados experimentais do presente trabalho permitem concluir que:

- o método espectrofotométrico otimizado para a determinação da carboxiemoglobinemia mostrou-se sensível, preciso, rápido e simples, podendo ser usado na monitorização biológica da exposição ocupacional ao monóxido de carbono;

- o método apresenta precisão dependente da concentração e os coeficientes de variação obtidos permitem estabelecer sua sensibilidade em $0,50 \%$ de carboxiemoglobina;

- a determinação de fatores de correção específicos para o espectrofotômetro é necessária à obtençāo de resultados confiáveis;

- o monóxido de carbono obtido por reação química pode substituir o de cilindro de gás comprimido (puro) na preparação da solução $100 \%$ de carboxiemoglobina;

- o deslocamento do monóxido de carbono dissolvido na soluçāo de $100 \%$ de carboxiemoglobina pelo nitrogênio é imprescindível na preparação de diferentes concentrações de carboxiemoglobina;

- a carboxiemoglobina é estável em amostra de sangue armazenada à temperatura de 4 a $8{ }^{\circ} \mathrm{C}$ por, no mínimo, oito dias (teste $t$ de Student; $\alpha=0,01)$;

- o conteúdo hemoglobínico e a opalescência (lipemia) da amostra de sangue não interferem na quantificação espectrofotométrica da carboxiemoglobina; 
- os trabalhadores dos três grupos de indivíduos expostos ao monóxido de carbono, em fornos de fundição, apresentaram baixos teores de carboxiemoglobina, indicando uma baixa exposição nestes locais de trabalho; um destes grupos não apresentou diferença estatisticamente significativa quando comparado ao grupo controle (teste de Kolmogorov-Smimov; $\alpha=0,05$ );

- o grupo de indivíduos que trabalham na regulagem de motores de combustão interna, apresentaram teores de carboxiemoglobina que indicam exposição acentuada ao monóxido de carbono no local de trabalho ( $37 \%$ dos indivíduos nāo-fumantes com teores superiores a $5 \%$ de carboxiemoglobina); a diferença entre este grupo e o grupo controle foi estatisticamente significativa (teste de Kolmogorov-Smirnov; $\alpha=0,05$ ).

- os fumantes apresentaram diferença estatisticamente significativa nos níveis de carboxiemoglobinemia quando comparados aos năo-fumantes (teste de Kolmogorov-Smimov; $\alpha=0,05$ ); esta diferença é evidenciada em indivíduos do grupo controle e minimizada nos grupos expostos ocupacionalmente ao monóxido de carbono. 


\section{REFERÊNCIAS BIBLIOGRÁFICAS *}

1. ADAIR, G.S. The hemoglobin system. VI. The oxygen dissociation curve of hemoglobin, J. Biol. Chem., Baltimore, 63:529-45, 1925.

2. AITTO, A. \& JARVISALO, J. Collection, processing and storage of specimens for binlogical monitoring of occupational exposure to toxic chemical. Pure Appl. Chem., London, 56(4): 549-66,1984.

3. AMDUR, M.O.; Air pollutants. In; AMDUR, M.D.; DOULL, J.;KLAASSEN, C.D.; eds. Casarett and Doull's toxicology: the basic science of poison. 4 ed. New York, Pergamon Press, 1991. p.868-70.

4. AMERICAN CONFERENCE OF GOVERNMENTAL INDUSTRIAL HYGIENISTS Documentation of the threshold limit values and biological exposure indices. 5. ed. Cincinnati, 1986. BEI vii (88)-BEI xxii(88)

5. AMERICAN CONFERENCE OF GOVERNMENTAL INDUSTRIAL HYGIENISTS - Documentation of the threshold limit values and biological exposure indices. 5 ed., Cincinnati, 1986 p.106-7

6. ANDERSEN, O.S.; PETERSEN, B.N.: REM, J. - Hemoglobin pigments. Spectrophometric determination of oxi-, carboxy-, and sulphemoglobin in capillary blood. Clin. Chim. Acta. Amsterdam, 42: 85-100, 1972.

7. ANGENOT, L. - Composition bhimique de la fumée de tabac. J. Pharm. Belg., Bruxelles, 38 (3): 171-80, 1983.

8. ANTHONY, D.C. \& GRAHAM, D.G. - Toxic responses of the central nervous system - In; AMDUR, M.D.; DOULL, J.;KLAASSEN, C.D.; eds. Casarett and Doull's toxicology: the basic science of poison. 4 ed. New York, Pergamon Press, 1991. p.4070-9.

9. ARIENS, E.J.; LEHMANN, P.A.; SIMONIS, A.M. Introduction a la toxicologia general. México, Diana, 1973.337p.

10. ATHERLEY, G. A critical review of time-weighted average as an index of exposure and dose, and of its key elements. Am. Ind. Hyg. Assoc. J., Akron, 46(9): 481-7, 1985.

11. ATKINS, E.H. \& BAKER, E.L. Exacerbation of coronary artery disease by occupational carbon moxide exposure: A report of two fatalities and a review of the literature. Am. J. Ind. Med., Chicago, 7(1): 73-9, 1985.

12. AYRES, S.M.; GIANNELLI Jr., S.; MUELLER, H. Carboxyhemoglobin and the access to oxygen. Arch. Environ. Health, Chicago, 26(1): 8-15, 1973.

13. BARCROFT, J. In the respiratory function of the blood, Cambridge 1928. Cambridge University Press. Apud: DI CERA, E.; DOYLE, M.L.; CONNELLY, P.R.; GILL S,J,. - Carbon monoxide binding to human hemoglobin $\mathrm{A}_{0}$. Biochemistry, Washington, 26(20): 6494-502, 1987.

\footnotetext{
${ }^{*}$ De acordo com a norma NB 66/78 preconizada pela Associação Brasileira de Normas Técnicas (ABNT). As abreviaturas dos títulos dos periódicos seguem o Chemical Abstracts Service Source Index (CASSI), Columbus, 1990.
} 
14. BARETTA, E.D.: STEWART, R.D.; GRAFF S.A.; DONAHOO, K.K. Methods developed for the mass sampling analysis os $\mathrm{CO}$ and carboxyhemoglobin in man. Am. Ind. Hyg. Assoc. J., Akron, 39(3): 202-9, 1978

15. BARNARD, R.J. \& WEBER, J.S. Carbon monoxide: A hazard to fire fighters. Arch. Environ. Health, Chicago, 34(4): 255-7, 1979.

16. BASELT, R.C. Biological monitoring methods for industrial chemical. Davis, Biomedical Publications, 1980. p.68-71.

17. BASELT, R.C. Analytical procedures for therapeutic drug monitoring and emergency toxicology. Davis, Biomedical Publications, 1980. p.64-7.

18. BERLIN, A.; WOLFF, A.H. ; HASEGAWA, Y., eds. The use of biological specimens for the assessement of human exposure to environmental pollutants. London, Martinus Nijhoff, Publishers ,1979. p.3-7 [Proceedings of the Internacional Workshop at Luxemburg, 18-22 April 1977]

19. BERQUÊ, E.S.; SOUZA, J.M.P.; GOTLIEB, S.L.D. Bioestatística, São Paulo, Pedagógica, 1981. 350p.

20. BEUTLER, E. \& WEST, C. Simplified determination of carboxyhemoglobin. Clin. Chem., Winston-Salem, 30 (6):871-4, 1984.

21. BEUTLER, E. - Metemoglobinemia e sulfemoglobinemia. In: WILLIAMS, W.J.; BEUTLER, E.; ERSLEV, A.J.; RUNDLES, R.W., eds., Hematologia. Rio de Janeiro, Guanabara Koogan, 1976. p.332-4.

22. BISHOP, G.A.\& GILL, S.J. The carbon-oxygen partion coefficient of isolated alpha and beta chains from hemoglobin $A_{o}$, Biopolymers, New York, 25: 1381-4, 1986.

23. BLACKMORE, D.J. The determination of carbon monoxide in blood and tissue. Analyst, London, 95(1130):439-58, 1970.

24. BORLAND, C.; HARMES, K.; CRACKNELL, N.; MACK, D.; HIGENBOTTAM, T. Methemoglobin levels in smoker and nonsmoker. Arch. Environ. Health, Chicago, 40(6): 330-3, 1985.

25. BRASIL, Leis, Decretos, etc. Ministério do Desenvolvimento Urbano e Meio Ambiente. Diário Oficial da União, Brasília, 17 jun. 1986. Seção I, p.8792 [Resolução nº 18, 06 maio 1986].

26. BRASIL. Ministério do Trabalho. Secretaria de Segurança, Higiene e Medicina do TRabalho. NR-7 - Atividades insalubres. In:

Segurança e medicina do trabalho: Lei $\mathrm{n}^{\circ} 6514$, de 22 de dezembro de 1977, normas regulamentadoras (NR) aprovadas pela portaria $\mathrm{n}^{\circ} .3214$, de 8 de junho de 1978. 18.ed. São Paulo, Atlas, 1990. p.69-76 [Manuais de legislação atlas, 16].

27. BRASIL. Ministério do Trabalho. Secretaria de Segurança, Higiene e Medicina do TRabalho. NR-15 - Atividades insalubres. In:

Segurança e medicina do trabalho: Lei $n^{\circ} 6514$, de 22 de dezembro de 1977, normas regulamentadoras (NR) aprovadas pela portaria $\mathrm{n}^{\circ} .3214$, de 8 de junho de 1978. 18.ed. São Paulo, Atlas, 1990. p.94-189 [Manuais de legislação atlas, 16]. 
28. BRUNN, I.O.; CAMPBELL, J.S.; HUIZEL, R.L. Evaluation of occupational exposures: A proposed sampling method. Am. Ind. Hyg. Assoc. J., Akron, 47(4): 229-35, 1986.

29. BUCHWALD, H. A rapid and sensitive method for estimating carbon monoxide in bllod and its application in problem areas. Am. Ind. Hyg. Assoc. J., Akron, 30(1): 564-9, 1969.

30. BURGESS, W.A. Recognition of health hazards in industry: a review of materials and processes. New York, Wiley, 1981. 275p.

31. CASTELLINO, N. \& SANNOLO, N. I legami dell'ossido di carbonio con le emoproteine intra ed extracascolari. Ruolo della $\mathrm{Hb}$ e meccanismi di tossicità del CO. Arch. Sci. Lav.,Roma, 3: 29-58, 1987.

32. CASTELLINO, N. \& SANNOLO, N. Monitoraggio biologico dell'esposizione professionale al CO: proposta di classi di rischio. Med. Lav., Milano, p.119-31.

33. CHACE, D.H.; GOLDBAUM, L.R.; LAPPAS, N.T. Factors affecting the loss of carbon monoxide from stored blood samples. J. Anal. Toxicol., Niles, 10(5): 181-9, 1986

34. CHECKOWAY, H.; DEMENT, J.M.; FOWLER, D.P.; HARRIS, R.L.; LAMM, S.H.; SMITH, T.J. Industrial hygiene involvement in occupational epidemiology. Am. Ind. Hyg. Assoc. J., Akron, 48(6): 51523, 1987.

35. CHERNOFF, A.I. The human hemoglobin in health and disease. N. Engl. J. Med., Boston, 253(8): 322-31, 1955.

36. CHIA, K.S.; JEYARATNAM J.; CHAN, T.B.; LIM, T.K. Airway responsiveness of firefighters after smoke exposure. Br. J. Ind. Med., London, 47( ): 524-527, 1990.

37. CINKOTAI, F.F. \& THOMSON, M.L. Diurnal variation in pulmonary diffusing capacity for carbon monoxide. J. Appl. Physiol., Bethesda, 21(2): 539-42, 1966.

38. COBURN, R.F.; DANIELSON, G.K.; BLAKEMORE, W.S.; FORSTER II, R.E. Carbon monoxide in blood: analytical method and sources of error. J. Appl. Physiol., Bethesda, 19(3): 510-5, 1964.

39. COBURN, R.F.; FORSTER, R.E.; KANE, P.B. Considerations of the physiological variables that determine the blood carboxyhemoglobin concentration in man. J. Clin. Invest., New York, 44(11): 1899-910, 1965.

40. COBURN, R.F.; PLOEGMAKERS, F.; GONDRIE, P.; ABBOUD, R., Myocardial myoglobin oxygen tension, Am. J. Physiol., Bethesda, 224:870-6,1973.

41. COLLISON, H.A.; RODKEY, F.L.: O'NEAL, J. Determination of carbon monoxide in blood by gas chromatography. Clin. Chem., Winston-Salem, 14(2): 162-71, 1968. 
42. COLOMBI, A.; BURATTI, M.; ZOCCHETTI, C; IMBRIANI, M.; GHITTORI, S. Limiti Biologici di Esposizione: evoluzione dei criteri interpretativi e metodologici. Med. Lav., Milano, 80(1): 25-42, 1989

43. COMMINS, B.T. \& LAWTHER, P.J. A sensitive method for the determination of carboxyhemoglobin in a finger prick sample of blood. Br. J. Ind. Med. London, 22:139-43, 1965.

44. COMPANHIA DE TECNOLOGIA DE SANEAMENTO AMBIENTAL Relatório de qualidade do ar na região metropolitana de São Paulo e em Cubatão. São Paulo, 1988. p. 2-59.

45. CONSTANTINO, A.G.; PAR, J.; CAPLAN, Y.H. Carbon monoxide analysis: A comparison of two CO-oximeters and headspace gas chromatography. J. Anal. Toxicol., Niles, 10(5): 190-3, 1986.

46. COOPER, D.Y.; LEVIN, S.; NARASIMHULU, S.; ROSENTHAL, O. Photochemical action spectrum of the termical oxidase of mixed function oxidase systems., Science, Washington, 147:400-2, 1965.

47. CURPHEY, T.J.; HOOD, L.P.L.; PERKINS, N.M. Carboxihemoglobin in relation to air pollution and smoking. Arch. Environ. Health, Chicago, 10:179-85, 1965.

48. DACIE, J.V.; LEWIS, S.M. Hematologia prática, 2.ed. Barcelona, Toray, 1974. p.45.

49. DAHMS, E.T. \& HORVATH, S.M. Rapid, accurate technique for determination of carbon monoxide in blood. Clin. Chem., Winston-Salem, 20(5): 533-7, 1974.

50. DALZIEL, K. \& O'BRIEN, J.R.P. Side reactions in the deoxygenation of dilute oxxhaemoglobin solutions by sodium dithionite. Biochem. J., London, 67:119-23, 1957.

51. DALZIEL, K. \& O'BRIEN, J.R.P. Spectrokinetic studies of the reaction of hydrogen peroxide with haemoglobin in dithionite solutions. Biochem. J., London, 67: 124-36, 1957.

52. DAVIES, D.M.; JOLLY, E.J.; PETHYBRIDGE, R.J.; COLQUHOUN, W.P. The effects of continuous exposure to carbon monoxide on auditory vigilance in man. Int. Arch. Occup. Environ. Health, Berlin, 48(1): 25-34, 1981.

53. DENNIS, R.C. \& VALERI, C.R. Measuring percent oxygen saturation of hemoglobin, percent carboxyhemoglobin and methemoglobin, and concentration of total hemoglobin and oxygen in blcod of man, dog and baboon. Clin. Chem., New York, 26(9): 1304-8, 1980.

54. DI CERA, E.; DOYLE, M.L.; CONNELLY, P.R.; GILL S,J. Carbon monoxide binding to human hemoglobin $A_{0}$. biochemistry, Washington, 26(20): 6494-502, 1987.

55. DI CERA, E.; DOYLE, M.L: MORGAN, M.S.; De CRISTOFARO, R.; LANDOLFI, R.; BIZZI, B; CASTAGNOLA, M.; GILL, S.J. Carbon monoxide and oxygen binding to human hemoglobin $A_{0}$. Biochemistry, Washington, 28(6): 2631-8, 1989. 
56. DIJKHUIZEN, P.; BUURSMA, A.; GERDING, A.M.; VAN KAMPEN, E.J.; ZIJLSTRA, W.G. Carboxyhaemoglobin. Spectrophotometric determination tested and calibrated using a new reference method for measuring carbon monoxide in blood. Clin. Chim. Acta, Amsterdam, 80(1): 95-104, 1977.

57. DIJKHUIZEN, P.; BUURSMA, A.; GERDING, A.M.; ZIJLSTRA, W.G. Sulfhaemoglobin: absorption spectrum, millimolar extinction coefficient at $=620 \mathrm{~nm}$, and interference with the determination of haemiglobin and of haemiglobincyanide. Clin. Chim. Acta, Amsterdam, 78(3): 479-87, 1977.

58. DOMINGUEZ, A.M.; CHRISTENSEN, H.E.; GOLDBAUM, L.R.; STEMBRIDGE, V.A. A sensitive procedure for determining carbon monoxide in blood or tissue utilizing gas-solid chromatography. Toxicol. Appl. Pharmacol., New York, 1(2): 135-43, 1959.

59. DRAGERWERK. AG. Detector tube handbook, 2.ed., LUBECK, 1973. p.4655 [manual].

60. DROZ, P.O. \& GUILLEMIN, M.P. Occupational exposure monitoring using breath analysis. J. Occup. Med. , Chicago, 28(8): 593-601, 1986

61. DUBOWSKI, K.M. Breath analysis as a technique in clinical chemistry. Clin. Chem., Winstom-Salem, 20(8): 966-72, 1974.

62. EDLING, C. \& AXELSON, O. Risk factors coronary heart disease among personnel in a bus company. Int. Arch. Occup. Environ. Health, Berlin, 54(2): 181-3, 1984.

63. ELINDER, C.G. \& VESTERBERG, D. Environmental and biological monitoring. Scand. J. Work Environ. Health, Helsinki, 11 (supl 1): 91$103,1985$.

64. ESTES, E.D. \& HARDISON, D.L. Evaluation of reference methods for measurement of carbon monoxide emissions at refineries. Anal. Chem., Washington, 58(4): 945-50, 1986.

65. FAGGLANO, C. Contaminação pelo monóxido de carbono. Ita Eng., São José dos Campos, 2(5): 34-7, 1971.

66. FENTON, J. Artifact due to races of detergent on laboratory glassware affecting carboxyhaemoglobin measurement. Clin. Chim. Acta, Amsterdam, 39(1): 266-8, 1972

67. FOGH-ANDERSEN, N.; ERIKSEN, P.S.; GRINSTED, J.; SIGGAARDANDDRSEN, O. Gas-chromatographic measurement of carboxyhemoglobin in blood from mothers and newborns. Clin. Chem., Winston-Salem, 34(1): 24-6, 1988.

68. FORBES, W.H. ; SARGENT, F. ; ROUGHTON, F.J.W. - The rate of carbon monoxide uptake by normal men. Am. J. Physiol, Bethesda,143:594-608. 1945. 
69. FORSTER, R.E. Reactions of carbon monoxide with heme proteins p.10-13. In: Effects of chronic exposure to low levels of carbon monoxide on human health behavior and performance. , DUBOIS, A.B. ed., National Academy of Sciences and National Academy of Engineering, Washington, D.C., 1969a. Apud: MINISTER OF NATIONAL HEALTH AND WELFARE - Carbon monoxide, Ottawa, 1983. [83-EHD-85].

70. FRANZINELLI, A.; ROSSI, M.; BARNABÉ, R. Valutazione indiretta della carbossiemoglobinemia. Verifica di una metodica simplice e rapida. Med. Lav., Milano, 74: 57-60, 1983

71. FRINGS, C.S.; FENDLEY, T.W.: DUNN, R.T.; QUEEN C.A. Improved determination of total serum. lipids by the sulfo-phospho-vanillin reaction. Clin. Chem., Winston-Salem, 18(7): 673-4, 1972.

72. GIBSON Q.H. The oxygenation of hemoglobin. In: DOLPHIN,D.,ed. The Porphyrins. New York, Academic Press, 1978. v.5, p.153-63.

73. GILL, S.J.; Di CERA, E.; DOYLE, M.L.; BISHOP, G.A.; ROBERT, C.H. Oxygen binding constants for human hemoglobin tetramers, Biochemistry, Washington, 26:3995-4002, 1987.

74. GODIN, G. \& SHEPHARD, R.J. On the course of carbon monoxide uptake and release. Respiration, Basel, 29:317-29. 1972.

75. GOLDBAUM, L.R.; CHACE, D.H.; LAPPAS, N.T. - Determination of carbon monoxide in blood by gas chromatography using a thermal conductivity detector. J. Forensic Sci., Chicago, 31(1): 133-42, 1986.

76. GOLDSMITH, J.R.; TERZAGHI, J.; HACKNEY, J.D. Evaluation of fluctuating carbon monoxide exposure. Arch. Environ. Health, Chicago, $7: 33-49,1963$

77. GONÇALVES, E. P. Espectrofotometria UV- Visível São Paulo Intralab,s.d. v.2, p.1093-6 (Manual do aparelho DMS - 80).

78. GONÇALVES, M.L.S.S. Métodos instrumentais para análise de soluçles, análise quantitativa. Lisboa, Gulbenkian, 1983. p.13-82.

79. GROTH, R.H.; DOYLE, T.B.; KAHN, M.D. Effect of diluent gas on gas chromatographic analysis of methane using a flame inonization detector. J. Chromatogr. Sci., Niles, 8(6): 359-60, 1970.

80. GUATELLI M. A. Intoxicacion oxicarbonada: estudio bioquímico y metodología analítica. Buenos Aires, Euder, 1971. p.83-9.

81. GUILLERM, R.; BADRÉ, R.; HÉE, J.; MASUREL, G. Composition de la fumée de tabac: analyse des facteurs de nuisance. Rev. Tuberc., Paris, 36(2): 187-208, 1972.

82. HALDANE, J. \& DOUGLAS, C.G. The laws of combination of haemoglobin with carbon monoxide and oxygen, J. Physiol., London, 44: 275-304, 1912

83. HALDANE, J. \& SMITH, J.L. - The absorption of oxygen by the lungs, J. Physiol., London, 22: 231-58, 1897. 
84. HALDANE, J.S. \& PRIESLEY, B.A. The regulation of lung ventilation J. Physiol., London, 32:225-66, 1905. Apud: WILSON, H.K Breath analysis; Physicological basis and sampling techniques. Scand. J. Work Environ. Health, Helsinki, 12: 174-92, 1986.

85. HAMILTON, A. \& HARDY, H.L. Industrial toxicology, 3.ed., Massachusetts, Publishing Sciences Group, 1974.p.239-58.

86. HANIG, J.P. \& HERMAN, E.H. - Toxic responses of the heart and vascular systems In; AMDUR, M.D.; DOULL, J.;KLAASSEN, C.D.; eds. Casarett and Doull's toxicology: the basic science of poison. $4 \mathrm{ed}$. New York, Pergamon Press, 1991. p.430-454.

87. HATCH, T.F. Significant dimensiond of the dose-response relationship. Arch Environ. Health, Chicago, 16: 571-578, 1968.

88. HAWKINS, L.H. Blood carbon monoxide levels as a function of daily cigarette consumption and physical activity. Br. J. Ind. Med., London, 33(2): 123-5, 1976.

89. HECKERLING, P.S.; LEIKIN, J.B.; TERZIAN, C.G.; MATUREN, A. Occult carbon monoxide poisoning in patients with neurologic illness. Clin. Toxicol., New York, 28(1), 29-44, 1990.

90. HEGESH, E.; GRUENER, N.; COHEN, S.; BOCHKOVSKY, R.; SHUVAL, H.I. A senshtive micromethod for the fdetermination of methemoglobin in blood. Clin. Chim. Acta, Amsterdam, 30: 679-82, 1970

91. HEITBRINK, W.A. \& CROUSE, W.E. Application of industrial Hygiene air sampling data to the evaluation of controls for air contaminants. Am. Ind. Hyg. Assoc. J., Akron, 45(11): 773-7, 1984.

92. HESSEL. D.W. \& MODGLIN, F.R. The determination of carbon monoxide in blood by gas-solid chromatography. J. Forensic Sci., Chicago, 12(1): 123-30, 1967.

93. HEYNDRICKI, A.; SCHEIRIS, Ch.; VERCRUYSSE, A.; OKKERSE, E. Gas chromatographic determination of carbon monoxide in blood and the hyperbaric oxygen treatment in carbon monoxide poisoning gases. J. Pharm. Belg., Bruxelles; 25(3): 247ł58, 1970

94. HLASTALA, M.P.; McKENNA, H.P.; FRANADA, R.L. \& DETTER, J.C. The ifluence of carbon monoxide on hemoglobin-oxygenbinding $\mathrm{J}$. Appl. Physiol.,Bethesda, 41(6):893-899, 1976.

95. HOXTER, G. Calibração isosbéstica. São Paulo, 1977. p. 97-100. [Tese de Livre-Docência - Faculdade de Ciências Farmacêuticas da USP].

96. HUSGAFVEL-PURSIAINEN, K.; SORSA, M.; ENGSTROM, K.; WINISTO, P. Passive smoking at work: biochemical and biological measures of exposure to environmental tobacco smoke. Int. Arch. Occup. Environ. Health, Berlin, 59(4): 337-45, 1987.

97. JABARA, J.W.; KEEFE, T.J.; BEAULIEU, H.J. Carbon monoxide: dosimetry in occupational exposures in Denver, Colorado, Arch. Environ. Health, Chicago, 35(4): 198-204, 1980. 
98. KARNIK, A.S. \& COIN, E.J. Carbon monoxide kinetics following simulated cigarette smoking. Arch. Environ. Health, Chicago, 35(3): 146-7, 1980.

99. KATSUMATA, Y.; AOKI, M.; SATO, K.; SUZUHI, O.; OYA, M.; YADA, S. A simple spectrophotometry for determination of carboxihemoglobin in blood. J. Forensic Sci., Chicago, 27(4): 928-34, 1982.

100. KELMAN, G.R. \& DAVIES, T.J. Carboxyhaemoglobin levels in workers in Leicestershire garages. Br. J. Ind. Med., London, 36(3): 238-41, 1979.

101. KIT, S.N.V. - Determinação de teores de carboxihemoglobina pela técnica espectrofotométrica, São Paulo, 1980. [Dissertaçāo de MestradoFaculdade de Ciências Farmacêuticas .USP].

102. KLEINMANN, M.T.; DAVIDSON, D.M.; VANDAGRIFF, R.B; CAIOZZO, V.J.; WHITTENBERGER, J.L Effects of short-Term Exposure to Carbon Monoxide in Subject with Coronary Artery Disease. Arch. Environ. Health, Chicago, 44(6): 361-9, 1989.

103. KLENDSHOJ, N.C.; FELDSTEIN, M.; SPRAGUE, A.L. The spectrophotometric determination of carbon monoxide. J. Biol. Chem., Baltimore, 183(1): 297-303, 1950.

104. KURPPA K.\& RANTANEN, I. Carbon monoxide. In: PARMEGGIANI, L., Encyclopedia of occupational health and safety. 3. ed. Genebra, International Labour Office, 1983. p. 395-9.

105. KURRPA, K.; KIVISTO, H.; VAINIO, H. Dicloromethane and carbon monoxide inhalation: carboxyhemoglobin addition, and drug metabolizing enzymes in rat. Int. Arch. Occup. Environ. Health, Berlin, 49 (1): 83-7, 1981.

106. LAMBERTSEN, C.J. Respiraçāo In: MOUNTCASTLE, V. B. Fisiologia médica, 13.ed., Rio de Janeiro, Guanabara Koogan, 1978. v.2, p.1364-606.

107. LAMBETH, D.O. \& PALMER, G. The kinetics and mechanism of reduction of eletron transfer proteins and other compounds of biological interest by dithionite, J. Biol. Chem., Baltimore, 218(7): 6095 - 103, 1973

108. LAUWERYS, R. \& BERNARD, A. La surveillance biologique de l'exposition aux toxiques industriels: position actuelle et perspectives de développement. Scand. J. Work Environ. Health, Helsinki, 11(3): 15564, 1985 .

109. LAUWERYS, R. - Biological criteria for selected industrial toxic chemicals: a review. Scand. J. Work Environ. Health, Helsinki, 1: 139-72, 1975.

110. LAUWERYS, R. - Individual chemical exposure guidelines for biological monitoring. Paris, Biomedical, 1983. p.1-8.

111. LAUWERYS, R.; - Occupational toxicology. In: AMDUR, M.D.; DOULL, J.;KLAASSEN, C.D.; eds. Casarett and Doull's toxicology: the basic science of poison. 4 ed. New York, Pergamon Press, 1991. p.947-53.

112. LAUWERYS, R.R. Industrial chemical exposure : guidelines for biological monitoring. Davis, Biomedical Publications, 1983. p.112-4, 140-1. 
113. LEHNINGER, A.L. Princípios of biochemistry, New York, Worth, 1982. p.169-206

114. LILIENTHAL, J.L. \& PINE, M.B. The effect of oxygen pressure on the uptake of carbon monoxide by man at sea level and at altitude, Am. J. Physiol., Bethesda, 145:346-50, 1946.

115. LILY, R.E.C.; COLE, P.V.; HAWKINS, L.H. Spectrophotometric measurement of carboxyhaemoglobin. Br. J. Ind. Med., London, 29:4547, 1972.

116. LINCH, A.L. Biological monitoring for industrial chemical exposure control. Cleveland, CRC, 1974. p. 62-72.

117. MAGNIER, M; ROMARY, F.; FONTAINE M.M. Physiologie-rythme circadien de l'action de l'oxide de carbone sur l'émission du gaz carbonique par le Rat en groupe. C.R. Seances Acad. Sci. Sér. D, Paris, 276: $1009-12,1973$.

118. MALENFANT, A.L.; GAMBINO, S.R.; WARAKSA, A.J.; ROE, E.I. Espectrophotometric determination of hemoglobin concentration and percent oxyhemoglobin and carboxyhemoglobin saturation. Clin Chem., Winston-Salen, 14(8): 789, 1968.

119. MALORNY, G., MÜLLER-PLATHE, O; YSTRAUB, M. [alteración del equilibrio acido-básico em la intoxicación aguda por monóxido de carbono y efectos del oxígeno o de las combinaciones de dióxido de carbono y oxígeno]. Naunyn-Schmieddberg's Arch. Exp. Pathol Pharmakol., Berlin, 243:439-58, 1962.

120. MANOLIS, A. The Diagnostic potencial of breath analysis, Clin. Chem., Winston Salem, 29(1):5-15, 1983.

121. MARTIN, A.E. Difference and derivative spectra. Nature, London, 180(4579): 231-3, 1957.

122. McCONNAUGHEY, P.W.; McKEE, E.S.; PRITTS, I.M. Passive colorimetric dosimeter tubes for ammonia, carbon monoxide, carbon dioxide, hydrogen sulfide, nitrogen dioxide and slfur dioxide. Am. Ind. Hyg. Assoc. J., Akron, 46(7): 356-62, 1985.

123. McGILVERY, R.W. Biochemistry : a functional approach. 2 ed. Philadelphia, Saunders, 1979. p. 228-52.

124. MERRICK, M.F. \& PARDUE, H.L. Evaluation of absorption and first-and second-derivative spectra for simultaneous quantification of bilirubin and hemoglobin. Clin Chem., Winston-Salem, 32(4): 598-602, 1986.

125. MIHEVIC, P.M.; GLINER, J.A.; HORVATH, S.M. Carbon monoxide exposure and information precessing during perceptual-motor performance. Int. Arch. Occup. Environ. Health, Berlin, 51(4): 355-63, 1983.

126. MILLER, J.C. \& MILLER,J.N., eds. Statistics for analytical chemistry. 2.ed. Chichester, Ellis Horwood, 1988. 225p.

127. MINISTER OF NATIONAL HEALTH AND WELFARE Carbon monoxide, Ottawa, 1983. [83-EHD-85]. 
128. MOFFAT, K.; DEATHERAGE, J.F.; SEYBERT, D.W. A Structural Model for the Kinetic Behavior of Hemoglobin. Science, Washington, 206(30): 1035-41, 1979.

129. MORAES, E.C.F.; SZNELWAR,R.; FERN CULA, N.A.G.G. Manual de Toxicologia Analítica, São Paulo, Roca, 1990. p.37-41.

130. MUMPOWER, R.C; LEWIS, J.S.; TOVEY, G.P. Determination of carbon monoxide in cigarette smoke by gas chromatography. Tobac Sci., New York, 6:142-145, 1962. Apud: MINISTER OF NATIONAL HEALTH AND WELFARE - Carbon monoxide, Ottawa, 1983. [83-EHD-85].

131. MURAMATSU, T.; WEBER, A.; MURAMATSU, S.; AKERMANN, F. An experimental study on irritation and annouance due to passive smoking. Int. Arch. Occup. Environ. HeaIth, Berlin, 51(4): 305-17, 1983.

132. NATIONAL INSTITUTE FOR OCCUPATIONAL SAFETY AND HEALTH Criteria for a recommended standard ... occupational exposure to carbon monoxide, Washington, 1972.

133. NATIONAL INSTITUTE FOR OCCUPATIONAL SAFETY AND HEALTH Carbon monoxide in blood.: physical and chemical analysis branch analytical p.113:1 - 113:5.

134. OCAK, A.; VALENTOUR, J.C.; BLAKE, R.V. The effects of storage conditions on the stability of carbon monoxide in postmorten blood. J. Anal. Toxicol., Niles, 9(5): 202-6, 1985.

135. OKADA, Y.; TYUMA, I.; UEDA, Y. ; SUGIMOTO,T. , Effect of carbon monoxide equilibrium between oxygen and hemoglobin Am. J. Physiol., Bethesda, 230:471-75, 1976.

136. OKL, H. Os perigos do gás contendo monóxido de carbono, João Momlevade, C.S.B.M. Divisāo Siderurgia IM/SETCCF, 1980. [Semana de Segurança da CST].

137. ORGANIZACION MUNDIAL DE LA SALUD - Monoxido de carbono. México, 1980.[Criterios de Salud Ambiental, n. 13].

138. PACE, N.; CONSOLAZIO, W.V.; WHITE, W.A. ; BEHNKE, A.R. Formulation of the principal factores affecting the rate of uptake of carbon monoxide by man. Am. J. Physiol.,Bethesda, 147, 352-59, 1946.

139. PARK, C.M. \& NAGEL, R.L. Sulfhemoglobinemia clinical and molecular aspects. N. Engl. J. Med., Boston,_310(24): 1581-4, 1984.

140. PARKS, J. \& WORTH, H.G.J. Carboxyhemoglobin determination by secondderivative spectroscopy. Clin. Chem., Winston-Salem, 31(2): 279-81, 1985.

141. PENNEY, D.G. Acute carbon monoxide poisoning: animal models. A review. Toxicology, Shannon, 62:123-60, 1990.

142. PERRIGO, B.J. \& JOYNT, B.P. Evaluation of current derivative spectrophotometric methodology for the determination of percent carboxyhemoglobin saturation in postmortem bloob samples, J. Anal. Toxicol., Niles, 13(1): 37-46, 1989. 
143. PERUTZ, M.F. Stereochemistry of cooperative effects in haemoglobin , Nature, London, 228:726-734,1970.

144. PERUTZ, M.F. The hemoglobin molecule. In: CALVIN, M. \& JOGGENSON, M.J. Bio-organic chemistry. S. Francisco, W.H. Freman, 1968. p. 41-9.

145. PETERSEN, A.R.; SANDERSON, W.L.; LENHARI, S.W. Application of a pilot study to the development of an industrial hygiene sampling strategy. Am. Ind. Hyg. Assoc. J., Akron, 47(10): 655-8, 1986.

146. PETERSON, J.E. \& STEWART, R.D., Absorption and elimination of carbon monoxide by inactive young men. Arch. Environ. Health, Chicago, 21: 165-71, 1970.

147. PETERSON, J.E. Modeling the uptake, metabolism and excretion of dichloromethane by man. Am. Ind. Hyg. Assoc. J., Akron, 39: 41-7, 1978

148. PORTER, K. \& VOLMAN, D.H. Flame ionization detection of carbon monoxide for gas chromatographic analysis. Anal. Chem., Washington, 34(7): 748-9, 1962.

149. PURSER, D.A. \& BERRIL, K.R. Effects of carbon monoxide on behavior in monkeys in relation to human fire hazard. Arch. Environ. Health, Chicago, 38(5): 308-15, 1983.

150. RAMIERI. A.J.; JATLOW, P; SELIGSON, D. New method for rapid determination of carboxyhemoglobin by use of double-wavelenght spectrophotometry. Clin. Chem., Winston-Salem, 20(2): 278-81, 1974.

151. RANNEY, H.M. Funçĺes de transporte dos eritrócitos. In: WILLIAMS, W.J.; BEUTLER, E.: ERSLEV, A.J.; RUNDLES, R.W., eds. Hematologia, Rio de Janeiro, Guanabara Koogan, 1976. p.118-23.

152. RAPPAPORT, S.M.; SELVIN, S.; SPEAR, R.C.; KEIL, C Air sampling in the assessment of continuous exposures to acutely toxic chemicals. Part I. Strategy. Am. Ind. Hyg. Assoc. J., Akron, 42(11): 831-8, 1981.

153. REY, L. Planejar e redigir trabalhos científicos. São Paulo, Edgard Blucher, 1987. 240p.

154. RICHALET, J.P.; RUTGERS, V.; BOUCHET, P.; RIMER, J.C.; KEROMES, A.; DUVAL-ARNOULD, G.; RATHT, C. Diurnal variations of acute moutain sickness, colour vision, and plasma cortisol and ACTH at high altitude. Aviat. Space Environ. Med., Washington, 60:105-11, 1989.

155. ROACH, S.A. A more rational basis for air sampling programs. Am. Ind. Hyg. Assoc. J., Akron, 27(1): 1-12, 1966.

156. RODE, A.; ROSS, R. ; SHEPHARD, R.J., Smoking withdrawal programme: personality and cardiorespiratory fitness, Arch. Environ. Health, Chicago, 24:27-36, 1972.

157. RODKEY, F.L. \& COLLISON, H.A. An artifact in the analysis of oxygenated blood for its low carbon monoxide content. Clin. Chem., Winston-Salem, 16(11): 896-9, 1970. 
158. RODKEY, F.L.; HILL, T.A.; PITTS, L.L.; ROBERTSON, R.F. Spectrophotometric measurement of carboxyhemoglobin and methemoglobin in blood. Clin Chem., Winston-Salem, 25(8): 1388-93, 1979.

159. ROSEMBERG, J. Tabagismo, sério problema de saúde pública. São Paulo, ALMED, 1981.370p.

160. ROSES, O.E. Monoxido de carbono. In: IOVINE, E. \& SELVA, A., eds. - El laboratório en la clínica. 3 ed., Buenos Aires, Panamericana, 1985. p.1312-23.

161. ROUGHTON, F.J.W. The intermediate compound hypotesis in relation to the equilibrio and kinetics of the reactions of haemoglobin with oxygen and carbon monoxide. In : ROUGHTON, F.J.W. \& KENDREW J.K. eds. , Barcroft Memorial Conference Butterworths, London, 1949. p.83. Apud: CASTELLINO, N. \& SANNOLO, N. I legami dell'ossido di carbonio con le emoproteine intra ed extracascolari. Ruolo della $\mathrm{Hb}$ e meccanismi di tossicità del CO. Arch. Sci. Lav., Roma, 3: 29-58, 1987.

162. ROUGHTON, F.J.W. The equilibrium of carbon monoxide with human hemoglobin in whole blood, Ann. N.Y. Acad. Sci., New York, 174:177-88, 1970.

163. ROUGHTON, F.J.W. The equilibrium between carbon monoxide and sheep hemoglobin at very high percentage saturations., J. Physiol. , 126:359-83, 1954 .

164. ROUGHTON, F.J.W.; OTIS, A.B. ; LYSTER, R.L.J. The determination of the individual equilibrium constants of the four intermediate reactions between oxygen and sheep hemoglobin. Proc. R. Soc. London Ser. B 144: 29, 1955. Appud: CASTELLINO, N. \& SANNOLO, N. I legami dell'ossido di carbonio con le emoproteine intra ed extracascolari. Ruolo della $\mathrm{Hb}$ e meccanismi di tossicità del CO. Arch. Sci. Lav.,Roma, 3: 29$58,1987$.

165. ROY, C.; BELLEMARE, G.R.; CHORNET, E. Effect of the sensitivity setting of a katharometer on response factors at low concentrations. J. Chromatogr., Amsterdam, 197(2): 121-7, 1980.

166. RUSSEL, J.B. Química geral. São Paulo, MacGraw Hill, 1981. p. 721-38, 7456.

167. RUSSEV, P.; GIUH, T.A.; WOOLAM, C.J. Detection of inorganic gases using a flame ionisation detector. J. Chromatogr., Amsterdam, 119: 4616, 1976.

168. SANDERSON, J.H.; SOTHERAN, M.F.; STATTERSFIELD, J.P. A new method of carboxyhemoglobin determination. Br. J. Ind. Med., London, 35(1): 67-72, 1978.

169. SANNOLO, N. Gas chromatographic quantitation of breath hydrogen and carbon monoxide for clinical investigation in adults and in children. $J$. Chromatogr., Amsterdam, 276(2): 257-65, 1983. 
170. SANNOLO, N.; BARILLARI, R.; SCOTTO, P.; CASTELLINO, N. Esposizione sperimentale all'ossido di carbonio: comportamento della viscosità, della p50, del 2,3- DPG e del lattato nel ratto. Arch. Sci. Lav., Roma, 1: 211-5, 1985.

171. SCHAEFER, B.A. \& DOUGLAS, D.M. The response of the flame ionisation detector to carbon monoxide and carbon dioxide. J. Chromatogr. Sci., Niles, 9 (10): 612-9, 1971.

172. SCHAUM, D. Física geral, São Paulo, McGraw Hill, 1975. 430p.

173. SCHOENFISCH, W.H.; HOOP, K.A.; STRUELENS, B.S. Carbon monoxide absortion through the oral and nasal mucosae of cynomolgus monkeys. Arch. Environ. Health, Chicago, 35(3): 152-4, 1980.

174. SHARMA P. \& PENNEY D.G. Effects of ethanol in acute carbon monoxide poisoning. Toxicology, Shannon, 62:213-26, 1990.

175. SIEGEL, S. - Estatística não-paramétrica para as ciências do comportamento. São Paulo, McGraw Hill, 1975. 350p.

176. SIPES, I.G. \& GANDOLFI, A.J. - Biotransformation of toxicants. In: AMDUR, M.D.; DOULL, J.;KLAASSEN, C.D.;, eds. Casarett and Doull's toxicology: the basic science of poison. $4 \mathrm{ed}$. New York, Pergamon Press, 1991. p.90-96.

177. SMALL, K.A.; RADORD, E.P.; FRAZIER, J.M. et al. A rapid method for simultaneous measurement of carboxy- and methemoglobin in blood. J. Appl. Physiol., Bethesda, 31:154-60, 1971

178. SMITH, J.R. \& LANDAW, S.A. Smokers polycythemia. N Engl. J. Med., Boston, 298(1): 6-10, 1978.

179. SMITH, R.P. - Toxic responses of the blood. In: AMDUR, M.D.; DOULL, J.;KLAASSEN, C.D.; eds. Casarett and Doull's toxicology: the basic science of poison. 4 ed. New York, Pergamon Press, 1991. p.263-8.

180. STETTER, L.R.; RUTH, D.R.; BLURTON, K.F. Portable gas chromatography and electrochemical detector for carbon monoxide. Anal. Chem., Washington, 48(6): 924-5, 1976.

181. STEWART, R.D. \& FISHER, T.N. Carboxyhemoglobin elevation after exposure to dichloromethane. Science, Washington, 176(4032): 295-6, 1972.

182. STOKER, H.S. \& SEAGER, S.L. Environmental chemistry: air and water pollution., Glenview, Scott Foresman, 1972. p.8-24.

183. STRUMIA, M.M.; SAMPLE, A.B.; HART, E.D. An improved micro hematocrit method. Am. J. Clin. Pathol. Philadelphia, 24:1016-8, 1954.

184. STUPFEL, M. \& BOULEY, G. Physicological and biochemical effects on rats and mice exposed to small concentrations of carbon monoxide for long periods. National Institute of Health and Research, Faris, 342-68. 
185. STUPFEL, M.; VALLERON, A.J.; DEMEESTERE, M.; MASSÉ,H. Hipoxia survival variations in male and female mice as functions of chronological and environmental factors. Aviat. Space Environ. Med., Washington, 49(9): 1092-1092, 1978.

186. SUNDSTROM, G. Blood carboxyhemoglobin: results with conventional standards compared with those with a submicroliter reference of gaseous CO. Clin. Chem., Winston-Salem, 18(3): 188-92, 1972.

187. TAKANO, T.; MIYAZAKI, UY.; SHIMOYAMA, H.; MAEDA, H.; OKEDA, R.; FUNATA, N. Direct effects of carbon monoxide on cadiac finction. Int. Arch. Occup. Environ. Health, Berlin, 49(1): 35-40, 1981.

188. TAULIER, A.; LEVILLAIN, P.; LEMONNIER, A. Determining methemoglobin in blood by zero-crossing-point first-derivative spectrophotometry. Clin. Chem., Winston-Salem, 33(10): 1767-70, 1987.

189. THE INTERNATIONAL TECHNICAL INFORMATION INSTITUTE Toxic and hazardous industrial chemicals safety manual. Tokyo, 1976. p.107-8.

190. THE MERCK index 9 ed. Rahway, 1976. p.231,1115..

191. THOM, S.R. \& KEIM, L.W. Carbon monoxide poisoning: a review epidemiology, pathophysiology, clinical findings, and treatment options including hyperbaric oxygen therapy. Clin. Toxicol., New York, 27(3): 141-56, 1989.

192. TOUITOU, Y.; TOUITOU, C.; BOGDAN A.; REINBERG, ALIN.; AUZEBY, A.; BECK, H.; GUILLET, P. Differences between young and eldely subjects in seasonal and circadian variations of total plasma proteins and blood volume as reflected by hemoglobin, hematocrit, and erythrocyte counts. Clin. Chem., Winston-Salem, 32(5): 801-4, 1986.

193. TRELA, B.A., CARLSON; G.P.; MAYER, P.R. Effect of carbon monoxide on the cytochrome P-450 mediated metabolism of aniline and p-nitroanisole in the isolated perfused rabbit lung., J. Toxicol. Environ. Health, Washington, 27(3):331-40, 1989.

194. TRELA, B.A., CARLSON, G.P.; TUREK, J.; REBAR, A.;MATHEWS, J.M. Effect of carbon monoxide on the cytochrome P-450 mediated activation of 4 -ipomeanol by the isolated perfused rabbit lung. , J. Toxicol. Environ. Health, Washington, 27(3):341-350, 1989.

195. VAINIO, $H$. Is passive smoking increasing cancer risk ?. Scand. J. Work Environ. Health, Helsinki, 13(3): 193-6, 1987.

196. VANDER; A.J.; SHERMAN, J.H.; LUCIANO, D.S. Fisiologia humana, 3.ed. São Paulo, McGraw-Hill, 1981. p.378-423.

a 197. VERHOEFF, A.P.: van der VELDE, H.C.M.; BOLEIJ, J.S.M.; LEBRET, E.: BRUNEKREEF, B. Detecting indoor CO exposure by measuring CO in exhaled breath. Int. Arch. Occup. Environ. Health, Berlin, 53(2): 167$73,1983$.

198. VIEIRA, S. Introdução à bioestatística, Rio de Janeiro, Campus, 1989. 294p. 
199. VREMAN, H.J.; KWONG, L.K.; STEVENSON, D.K. Carbon monoxide in blood: An improved microliter blood-sample collection system, with rapid analysis by gas chromatography. Clin. Chem., Winston-Salem, 30(8): 1382-6, 1984.

200. VREMAN, H.J.; RONQUILLO, R.B.; ARIAGNO, R.L.; SCHWARTZ, H.C.; STEVENSON, D.K. Interference of fetal hemoglobin with the spectrophotometric measurement of carboxyhemoglobin. Clin. Chem., Winston-Salem, 34(5): 975-7, 1988.

201. VREMAN, H.J.; STEVENSON, D.K.; ZWART, A. Analusis for carboxyhemoglobin by gas chromatography and multicomponent spectrophotometry compared. Clin. Chem., Winston-Salem, 33(5): 694-7, 1987.

202. WAGNER, J.A.; HORVATH, S.M.; DAHMS, T.E., Carbon monoxide elimination. Respir. Physiol., Amsterdan, 23:41-7. 1974.

203. WAKAMATSU, C.T.; MENDES, R. ; KITAMURA, S. O uso do laboratório em patologia profissional. Rev. Bras. Saúde Ocup., São Paulo, 3(10): 621, 1975.

204. WEISER, P.C.; MORRILL, C.G.; DICKEY, D.W.; KURT, T.L.; CROPP, G.J.A. Effects of low level carbon monoxide exposure on the adaptation of healthy young men to aerobic work at an altitude of 1,610 meters. In: FOLINSBEE,L.J., ed. Environmental stress, New York, Academic Press, 1978. p.101-11 [Proceedings of Symposiyum, University of California, 1977].

205. WHITE, P. Degradação da hemoglobina. In: WILLIAMS, W.J.; BEUTLER, E.: ERSLEV, A.J.; RUNDLES, R.W., eds. Hematologia, Rio de Janeiro, Guanabara Koogan, 1976. p.156 61.

206. WHITE, P. Carbon monoxide production on heme catabolism. Ann. NY Acad. Sci., New York, 174:23-31, 1970.

207. WIGFIELD, D.C.; HOLLEBONE, B.R.; McKEEN, J.E.; SELWIN, J.C. Assessment of the methods available for the determination of carbon monoxide in blood. J. Anal. Toxicol., Niles, 5(3): 122-5, 1981.

208. WILKS, S.S. Toxic photo-oxidation products in closed environments. Aerosp Med., Washington, 34:838-41, 1963.

209. WILLIAMS, F.W.; WOODS, F.J.; UMSTEAD, M.E. Determination of carbon monoxide in the parts-per-million range with gas chromatography. J. Chromatogr. Sci., Niles, 10(9): 570-2, 1972.

210. WILLIAMS, L.A. Carbon monoxide. Type A procedure. In: SUNSHINE, I., ed. Methodology for analitycal toxicology. Cleveland, CRC Press. 1975. p.64-6.

211. WILSON, H.K Breath analysis; Physicological basis and sampling techniques. Scand. J. Work Environ. Health, Helsinki, 12: 174-92, 1986.

212. WOLFF, D.G. \& BIDLACK, W.R. The formation of carbon monoxide during peroxidation of microsomal lipids. Biochem. Biophys. Res. Commun., New York, 73:850-7, 1976. 
213. ZIELHUIS, R.L. \& HENDERSON, P.Th. Definitions of monitoring activities and their relevance for the practice of occupational health. Int. Arch. Occup. Environ. Health, Berlin, 57: 249-57, 1986.

214. ZWART, A.; BUURSMA, A.; OESEBURG, B.; ZIJLSTRA, W.G. Determination of hemoglobin derivatives with the il 282 CO-oximeter as compared with a manual spectiophotomettric fice-wavelenght method. Clin. Chem., Winston-Salem, 27(11): 1903-7, 1981.

215. ZWART, A.; van KAMPEN, E.J.; ZIJLSTRA, W.G. Results of routine determination of clinically significant heloglobin derivatives by multicomponent analysis. Clin. Chem., Winston-Salem, 32(6): 972-8, 1986. 


\section{ANEXO I}

\section{EQUIVALÊNCIA ENTRE UNIDADES DE CONCENTRAÇÃO}

Os fatores de conversāo das unidades usadas na concentração de CO no ar são ${ }^{127}$ :

a $0^{\circ} \mathrm{C}$ e $760 \mathrm{mmHg}$

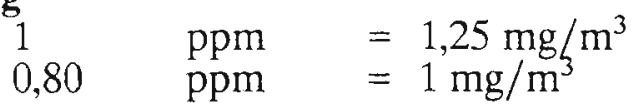

a $25{ }^{\circ} \mathrm{C}$ e $760 \mathrm{mmHg}$

$\begin{array}{lll}1 & \mathrm{ppm} & =1,15 \mathrm{mg} / \mathrm{m}^{3} \\ 0,87 & \mathrm{ppm} & =1 \mathrm{mg} / \mathrm{m}^{3}\end{array}$

a $25^{\circ} \mathrm{C}$ e $700 \mathrm{mmHg}$

$$
\begin{array}{lll}
1 & \mathrm{ppm} & =1,06 \mathrm{mg} / \mathrm{m}^{3} \\
0,95 & \mathrm{ppm} & =1 \mathrm{mg} / \mathrm{m}^{3}
\end{array}
$$

EQUIVALÊNCIA ENTRE UNIDADES DE PRESSÃO

\begin{tabular}{lcccc}
\hline \hline \multicolumn{1}{c}{ pressão } & \multicolumn{3}{c}{ fator de multiplicação para conversão } & \\
\cline { 2 - 5 } unidade (símbolo) & Torr & milibar & Pa & mmHg \\
\hline \hline & 1 & & & \\
torricelli (Torr) & 0,75 & 1 & 133,3 & 1 \\
milibar (milibar) & 0,0075 & 0,01 & 1 & 0,75 \\
pascal* (Pa) & 1 & & & 0,0075 \\
milímetro & & 1,33 & 133,3 & 1 \\
\hline de mercúrio (mmHg) & & & & \\
\hline \hline
\end{tabular}

$\left(^{*}\right)$ Sistema Internacional de Unidades

Adaptado de SCHAUM ${ }^{172}$ 


\title{
ANEXO II
}

\section{RELAÇÕES MATEMÁTICAS ENTRE A CONCENTRAÇĀO ATMOSFÉRICA DE MONÓXIDO DE CARBONO E CARBOXIEMOGLOBINEMIA}

\begin{abstract}
Alguns autores têm proposto equações empíricas que permitem estimar as concentrações de carboxiemoglobina em diferentes condiçōes de exposição. Essas diferem entre si quanto ao número e o tipo de variáveis, o que implica em resultados não necessariamente iguais para a mesma condiçāo de exposição ${ }^{137}$. Destacam-se:
\end{abstract}

1 - FORBES et al.(1945) $)^{68}$ propuseram uma relação entre o aumento da concentração de carboxiemoglobina com a concentração de CO no ar e o tempo de exposição t:

taxa de absorção de $\mathrm{CO}=\mathrm{K} \times \mathrm{P}_{\mathrm{CO}} \mathrm{x} \begin{aligned} & {\left[\mathrm{COHb}_{\mathrm{x}}\right]-\left[\mathrm{COHb}_{\mathrm{t}}\right]} \\ & {\left[\mathrm{COHb}_{\mathrm{x}}\right]-\left[\mathrm{COHb}_{0}\right]}\end{aligned}$

onde $\mathbf{K}=$ constante proporcional à intensidade de atividade física, sendo igual a 3, 5, 8 e 11 para as condições de repouso, trabalho leve, moderado e pesado, respectivamente;

$\mathbf{P}_{\mathbf{C O}}=$ pressão parcial de $\mathrm{CO}$ no ar inspirado;

$[\mathbf{C O H b}]=$ concentração de carboxiemoglobina no início $(0)$, no instante $(\mathrm{t})$ e no momento de equilíbrio $(\mathrm{x})$.

A partir desta, os autores formularam a equação simplificada para o cálculo do aumento da $\mathrm{COHb}$. A variação na \% de $\mathrm{COHb}$ numa determinada exposição, antes da situação de equilíbrio, pode ser calculada por:

\section{$[\Delta \mathrm{COHb} \%]=\mathrm{K} \times[\mathrm{CO}] \times \mathrm{t}$}

onde, $[\mathrm{CO}]=$ concentração de $\mathrm{CO}$ no ar ambiente $(\mathrm{ppm})$;

$\mathbf{t}=$ tempo de exposição (min). 
2 - LILIENTHAL \& PINE (1946) ${ }^{114}$ popuseram uma equação análoga, incluindo um fator relativo à ventilação pulmonar:

$\Delta \mathrm{COHb} \%=0,05 \times \mathrm{V}_{\mathbf{E}} \times\left(\mathrm{P}_{\mathbf{C O}}\right) \times \mathrm{t}$

onde $\mathbf{V}_{\mathbf{E}}=$ volume respiratório $(\mathrm{L} / \mathrm{min})$;

$\mathbf{P}_{\mathbf{C O}}=$ pressão parcial de CO no ar inspirado (Torr);

$\mathbf{t}=$ tempo de exposição $(\min )$.

3 - PACE et al. (1946) ${ }^{138}$ desenvolveram este tipo de equação adicionando um fator de volume sanguíneo(L); o aumento da \% de COHb é obtido por:

$\triangle \mathrm{COHb} \%=$

$$
100 \times \mathrm{V}_{\mathrm{E}} \times[\mathrm{CO}] \times \mathrm{t}
$$

$\mathrm{L}$

onde, $\mathrm{L}=$ volume sanguíneo $(\mathrm{L})$;

$[\mathbf{C O}]=$ concentraçào de $\mathrm{CO}$ no ar inalado $(\%)$;

$\mathbf{t}=$ tempo de exposição $(\mathrm{min})$.

4 - COBURN et al. (1965) ${ }^{39}$ desenvolveram a fórmula mais sofisticada com a introdução das variáveis fisiológicas, relacionando a pressão de $\mathrm{O}_{2}$ nos capilares pulmonares, a constante de afinidade relativa, a saturação de $\mathrm{O}_{2}$, a capacidade de difusão pulmonar, a ventilação alveolar, a produção endógena de CO e a pressão de CO no ar inspirado de acordo com a seguinte equação:

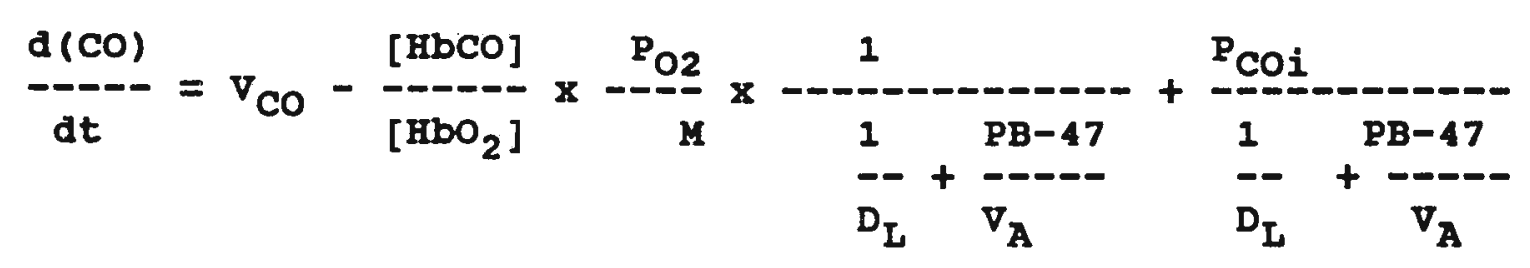

onde, $[\mathrm{HbCO}]=$ concentraçāo de $\mathrm{CO}$ no sangue $(\mathrm{mL}$ de $\mathrm{CO} / \mathrm{mL}$ de sangue;

$\left[\mathrm{HbO}_{2}\right]=$ concentração de $\mathrm{O}_{2}$ no sangue $\left(\mathrm{mL}\right.$ de $\mathrm{O}_{2} / \mathrm{mL}$ de sangue;

$\mathbf{D}_{\mathbf{L}}=$ capacidade de difusão pulmonar $(\mathrm{mL} / \mathrm{min} / \mathrm{mmHg})$;

$\mathbf{V}_{\mathbf{A}}^{\mathbf{L}}=$ índice de ventilação alveolar;

PB = pressão barométrica;

$\mathbf{P}_{\mathbf{C O i}}=$ pressão parcial do $\mathrm{CO}$ inalado;

$\mathbf{P}_{\mathrm{O2}}$ = pressão média do oxigênio capilar pulmonar;

$\mathrm{M}=$ constante de Haldane(220-240 com $\mathrm{pH}=7,4)$;

$\mathbf{V}_{\mathbf{C O}}=$ índice de produção endógena de $\mathrm{CO}(\mathrm{mL} / \mathrm{min})$. 
ANEXO III

LIMITES MÁXIMOS PERMISSÍvEIS DE MONÓXIDO DE CARBONO NO AR

$\left[\mathrm{ppm}\left(\mathrm{mg} / \mathrm{m}^{3}\right)\right]$

\begin{tabular}{|c|c|c|c|c|c|}
\hline \multirow{2}{*}{ referência } & \multirow{2}{*}{ LT } & \multirow{2}{*}{ PEL } & \multicolumn{3}{|c|}{ TLV } \\
\hline & & & TWA & STEL & $\mathrm{C}$ \\
\hline $\begin{array}{l}\text { Legislação } \\
\text { brasileira }^{26}\end{array}$ & $\begin{array}{c}39^{\mathrm{a}} \\
(43)\end{array}$ & --- & --- & $--\cdot$ & $-\cdots$ \\
\hline $\mathrm{OSHA}^{104}$ & --- & $\begin{array}{r}50 \\
(55)\end{array}$ & --- & -- & --- \\
\hline NIOSH$^{132}$ & --- & --- & $\begin{array}{l}35^{b} \\
(39)\end{array}$ & -- & $\begin{array}{r}200 \\
(220)\end{array}$ \\
\hline ACGIH $^{5}$ & --- & --- & $\begin{array}{l}50^{c} \\
(55)\end{array}$ & $\begin{array}{r}400 \\
(440)\end{array}$ & --- \\
\hline
\end{tabular}

OSHA = OCCUPATIONAL SAFETY AND HEALTH ADMINISTRATION

NIOSH = NATIONAL INSTTIUTE FOR OCCUPATIONAL SAFETY AND HEALTH

ACGIH = AMERICAN CONFERENCE OF GOVERNMENTAL INDUSTRLAL HYGIENISTS

TL = LIMITE DE TOLERÂNCLA

TLV = THRESHOLD LIMTT VALLE

TLV.TWA = TIME WEIGHTED AVARAGE

TLV STEL = SHORT TERM EXPOSURE LIMTT

TLV.C = CEILING

TWA-PEL = PERMISSIBLE EXPOSURE LIMTT

$a=$ exposição de 48 horas semanais

$\mathrm{b}=$ exposição de 40 horas semanais

$c=$ estabelecido com base em efeitos no desempenho cardiovascular sob stress físico (1980)

Valores limites recomendados em outros países ${ }^{5}$ :

Austrália, Finlândia, Holanda, Bélgica, Iugoslávia, Suíça e

Alemanha Ocidental

$50 \mathrm{ppm}$

Suécia

$35 \mathrm{ppm}$

Alemanha Oriental

$30 \mathrm{ppm}$

Tchecoslováquia, Hungria,

România, Polonia

$26 \mathrm{ppm}$

Bulgária, Rússia

$17 \mathrm{ppm}$ 


\section{ANEXO IV}

\section{LIMITES BIOLÓGICOS DE EXPOSIÇĀO}

\begin{tabular}{|c|c|c|c|}
\hline \multirow[b]{2}{*}{ referência } & \multicolumn{3}{|c|}{ indicador biológico } \\
\hline & $\begin{array}{c}\mathrm{COHb} \\
\text { [sangue] } \\
(\%)\end{array}$ & $\begin{array}{c}\mathrm{CO} \\
\text { [sangue] } \\
(\mathrm{mL} / 100 \mathrm{~mL})\end{array}$ & $\begin{array}{c}\mathrm{CO} \\
{\left[\begin{array}{c}\text { ar exalado] } \\
(\mathrm{ppm})\end{array}\right.}\end{array}$ \\
\hline
\end{tabular}

Legislação Brasileira ${ }^{27}$

$\begin{array}{ll}\text { limite } & 5(\mathrm{NF}) \\ \text { valor referência } & 2(\mathrm{NF}) \\ & 6,5(\mathrm{~F})\end{array}$

ACGIH $^{5}$

limite $^{\mathrm{a}}$

valor referência

$\quad<8$
0,4 a $0,7(N F)$
5 a $9(\mathrm{~F})$

Lauwerys $^{112}$

limite

$\begin{array}{lcc}5 & 10 & 18 \\ <1(\mathrm{NF}) & <0,15(\mathrm{NF}) & 2(\mathrm{NF})\end{array}$

ACGIH = American Conference of Governamental Industrial Hygienists

$\mathrm{NF}=$ não-fumante

$F=$ fumante

$\mathrm{a}=$ colheita da amostra no final da jornada de trabalho 